\title{
If something is important for me, is it important for Canada? Exploring salience with political events, issues and opinion polls
}

\section{Jeff Blackman}

A thesis submitted to the Faculty of Graduate and Postdoctoral Affairs in partial fulfillment of the requirements for the degree of

Master of Arts

in

Political Science

Carleton University

Ottawa, ON

(C)2012

Jeff Blackman 
Library and Archives

Canada

Published Heritage

Branch

395 Wellington Street

Ottawa ON K1A ON4

Canada
Bibliothèque et

Archives Canada

Direction du

Patrimoine de l'édition

395 , rue Wellington

Ottawa ON K1A ON4

Canada
Your file Votre référence

ISBN: 978-0-494-91562-2

Our file Notre référence

ISBN: $978-0-494-91562-2$
NOTICE:

The author has granted a nonexclusive license allowing Library and Archives Canada to reproduce, publish, archive, preserve, conserve, communicate to the public by telecommunication or on the Internet, loan, distrbute and sell theses worldwide, for commercial or noncommercial purposes, in microform, paper, electronic and/or any other formats.

The author retains copyright ownership and moral rights in this thesis. Neither the thesis nor substantial extracts from it may be printed or otherwise reproduced without the author's permission.
AVIS:

L'auteur a accordé une licence non exclusive permettant à la Bibliothèque et Archives Canada de reproduire, publier, archiver, sauvegarder, conserver, transmettre au public par télécommunication ou par l'Internet, prêter, distribuer et vendre des thèses partout dans le monde, à des fins commerciales ou autres, sur support microforme, papier, électronique et/ou autres formats.

L'auteur conserve la propriété du droit d'auteur et des droits moraux qui protege cette thèse. $\mathrm{Ni}$ la thèse ni des extraits substantiels de celle-ci ne doivent être imprimés ou autrement reproduits sans son autorisation.
In compliance with the Canadian Privacy Act some supporting forms may have been removed from this thesis.

While these forms may be included in the document page count, their removal does not represent any loss of content from the thesis.
Conformément à la loi canadienne sur la protection de la vie privée, quelques formulaires secondaires ont été enlevés de cette thèse.

Bien que ces formulaires aient inclus dans la pagination, il n'y aura aucun contenu manquant. 


\begin{abstract}
This thesis pertains to an experiment in interpreting opinion polls. By asking news-conscious university students to explain changes in public opinions - among other Canadians and in particular demographics - an understanding was gained of how these respondents perceive others' perceptions of political affairs. The experiment was a two stage project: first a survey of personal opinions to determine salient topics for each respondent; then a 'news quiz' that asked respondents to explain shifts in public opinion. In this second stage an experiment group was exposed to political spin from professional partisans. Three chief hypotheses were made. First, respondents would demonstrate false consensus/transference; that personal salience would inform perceived public salience. This was demonstrated both quantitatively, by correlations between stage 1 and stage 2 reply topics, and qualitatively, by literal linkages between, for instance, personal pet issues and chronicles of public opinion shift. Second, respondents would demonstrate cognitive dissonance when opposing a poll trend (e.g. making "excuses" for a popular sentiment they do not share). Qualitative evidence of this was found (for instance references to holidays or the passage of time since a previous scandal) but was undermined by a lack of respondents who "agreed" with the public to balance out dissenters. Third, when exposed to spin, treatment respondents would incorporate spin in a manner in line with the previous two hypotheses (citing reasons that relate to their own personal salience and attitudes towards the poll trend). In addition to a lack of "progovernment" respondents, this hypothesis could not be fully tested as a significant
\end{abstract}


number of control subjects behaved unexpectedly and altered their replies "posttreatment." 


\section{Acknowledgements}

I'd like to thank first and foremost my family: my father for editing my work and passing on his love of statistics; my mother for her support and listening to me explain my research; my sister for listening too; and my wife for, in addition to countless acts of charity and kindness, bringing me dinner when I was camped out at Carleton too late on a weekend, and bringing me home.

I thank my supervisor, Dr. Scott Bennett, for providing me with this opportunity and for the many undergraduate courses he taught in which he gave me chances to investigate unusual hypotheses.

Of other professors, I'd particularly like to thank Prof. Jonathan Malloy for demanding results when I just wanted to read, Prof. Jon Pammett for turning me onto cognitive dissonance, and Prof. William Walters for letting me write about topics I won't mention here. I thank the Political Science Department for giving me a place to be challenged, and in particular Brookes Fee for guiding me through the thesis steeplechase. Of my friends, I thank Pete for teaching me how to survive graduate school; Hij and Brendan for being people I can disagree with and still rely upon; Bardia for saying something that inspired my experiment (I can't remember what); Dave for incessantly wanting to discuss headline news; Justin for teaching me how to be "political;" Owen and Matt for getting pre-tested; the folks at In/Words writers' circle who proof-read my application to graduate studies; and all my other friends who were available all hours online or at Mike's Place to hear my complaints and sleep-deprived insights. 
Additionally, I thank the English Department, my second home; the Research Ethics Board, for their understanding and encouragement; the Department of Journalism and Communication, particularly Prof. Klaus Pohle and Elizabeth Dwivedi, for facilitating this project; and everyone who works at Rooster's Coffee House, in the least, for maintaining their frequent coffee drinkers cards.

Finally I thank the 27 students who participated in my experiment, even those of you who did not make it to stage 2 . Without your willingness to take part in student research, I would have been forced to make lab rats read The National Post. 


\section{Table of Contents}

$\begin{array}{ll}\text { Page Section } & \text { Subtitle } \\ \text { ii } & \text { Thesis abstract } \\ \text { iv } & \text { Acknowledgements } \\ \text { vi } & \text { Table of Contents }\end{array}$

Section 1: Set-up

$\begin{array}{lll}1 & 1.1 & \text { Introduction } \\ 2 & 1.2 & \text { Literature review } \\ 12 & 1.3 & \text { Hypotheses } \\ 16 & 1.4 & \text { Research design and experiment summary } \\ 28 & 1.5 & \text { Statistically capturing events and issues }\end{array}$

Section 2: Stage 1 findings: Summarizing the sample and determining salience

$37 \quad 2.0$

$38 \quad 2.1$

$48 \quad 2.2$

$51 \quad 2.3$

$56 \quad 2.4$
Stage 1 analysis overview

Summary of sample by demographic and opinion variables

Correlations between demographic and opinion variables

Top events and pet issues; common responses and patterns

Top events and pet issues; correlations with demographic and opinion variables, and between issues and events

Section 3: Stage 2 findings: Testing our hypotheses

$61 \quad 3.0 \quad$ Stage 2 analysis overview

$64 \quad 3.1$

$\begin{array}{ll}68 & 3.2\end{array}$

$\begin{array}{ll}75 & 3.3 \\ 7 & 3.4\end{array}$

$\begin{array}{ll}77 & 3.4\end{array}$

$81 \quad 3.5$

$84 \quad 3.6$

$87 \quad 3.7$

$90 \quad 3.8$

$92 \quad 3.9$

$96 \quad 3.10$

$98 \quad 3.11$ optimistic optimistic respondents
Stage 1 variable difference between control and treatment subjects Qualitative analysis of causal chronicles

Quantitative analysis using meta-tag dummies

Quantitative analysis of chronicles re: All Canadians more

Quantitative analysis of chronicles re: University graduates more

Quantitative analysis of chronicles re: People without postsecondary education more optimistic

Quantitative analysis of chronicles re: Women more optimistic

Correlations between stage 1 and stage 2 topic scores

Respondent attitudes towards poll trends and spin

Correlations between treatment and topic score change

Cumulative analysis: comparing the consistency of associations

Section 4: Conclusions
$107 \quad 4.1$
$112 \quad 4.2$
Questionnaire weaknesses
Conclusions

116

Works Cited 
List of Tables

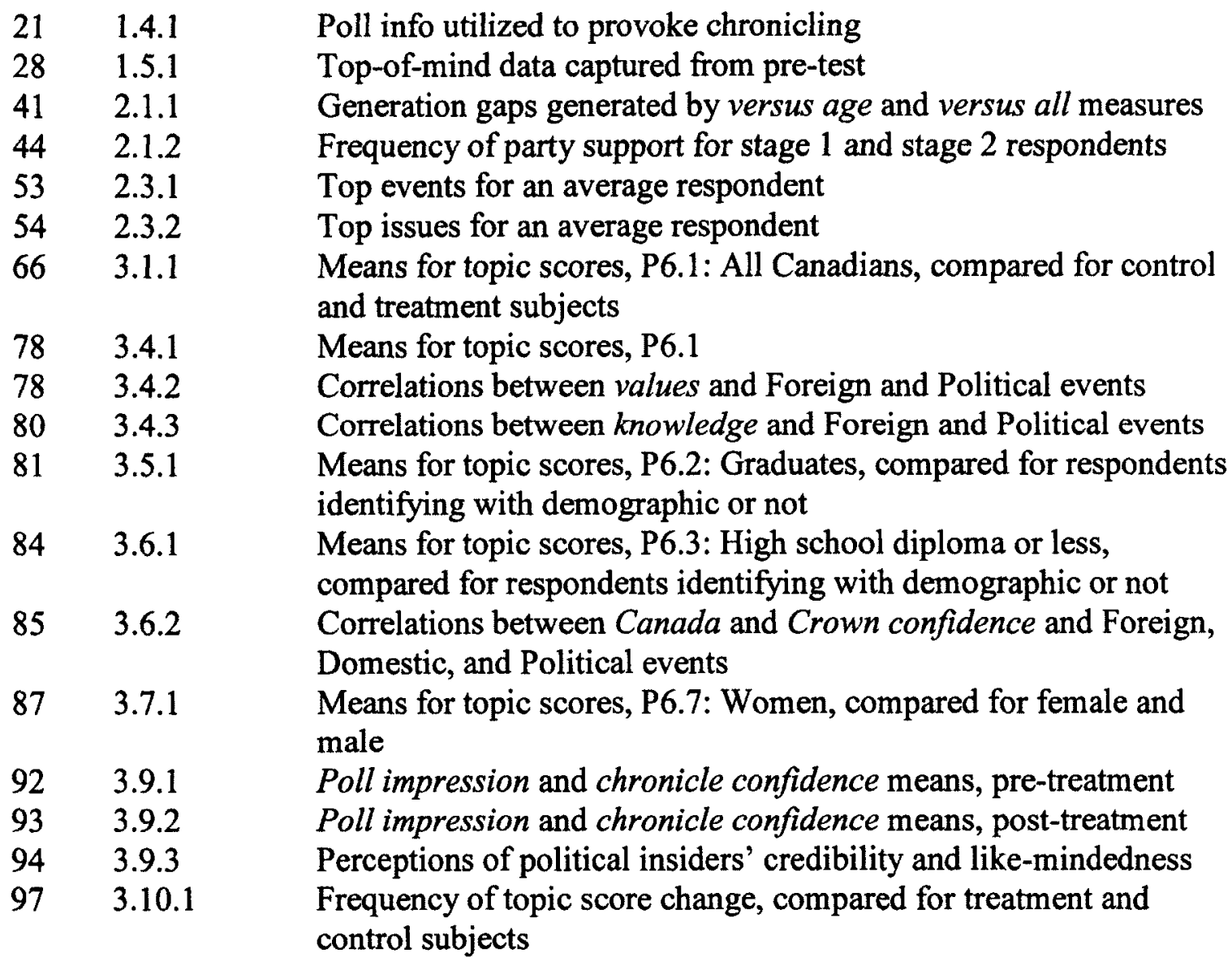

List of Figures

$\begin{array}{ll}12 & 1.3 .1 \\ 16 & 1.4 .1 \\ 30 & 1.5 .1 \\ 34 & 1.5 .2 \\ 36 & 1.5 .3 \\ 51 & 2.3 .1\end{array}$

Independent, interacting and dependent variables Data collection schedule How replies and respondents are given topic scores Examples of narrative construction using the replies dataset Coding case study for respondent 13

Relative frequency of search engine queries (from Canada) for top five events

100 3.11.1 Consistent variable-to-topic associations (Age, gender, values, knowledge)

$101 \quad 3.11 .2 \quad$ Consistent variable-to-topic associations (Liberal, NDP, Crown confidence)

$103 \quad 3.11 .3 \quad$ Consistent topic-to-topic associations 
List of Appendices

$\begin{array}{lll}121 & 1 & \text { Consent form } \\ 124 & 2 & \text { Recruitment poster } \\ 125 & 3 & \text { Recruitment script } \\ 126 & 4 & \text { Stage 1 (time 1) or pre-experiment questionnaire } \\ 133 & 5 & \text { Stage 2 (time 2a) or pre-poll questionnaire } \\ 136 & 6 & \text { Stage 2 (time 2b) or post-poll questionnaire } \\ 152 & 7 & \text { Insiders biographies and spin scripts } \\ 154 & 8 & \text { Insider evaluation questionnaires } \\ 156 & 9 & \text { Stage 2 (time 3) or post-treatment questionnaire } \\ 157 & 10 & \text { Debriefing script } \\ 158 & 11 & \text { Telephone scheduling script } \\ 160 & 12 & \text { Email scheduling Script }\end{array}$




\subsection{Introduction}

This thesis pertains to an experiment in interpreting opinion polls. By asking news-conscious university students to explain changes in public opinions - among other Canadians and in particular demographics - an understanding was gained of how these respondents perceive others' perceptions of political affairs. The experiment was a two stage project: first a survey of personal opinions to determine salient topics for each respondent; then a 'news quiz' that asked respondents to explain shifts in public opinion. In this second stage an experiment group was exposed to political spin from professional partisans. Three chief hypotheses were made. First, respondents would demonstrate false consensus/transference; that personal salience would inform perceived public salience. This was demonstrated both quantitatively, by correlations between stage 1 and stage 2 reply topics, and qualitatively, by literal linkages between, for instance, personal pet issues and chronicles of public opinion shift. Second, respondents would demonstrate cognitive dissonance when opposing a poll trend (e.g. making "excuses" for a popular sentiment they do not share). Qualitative evidence of this was found (for instance references to holidays or the passage of time since a previous scandal) but was undermined by a lack of respondents who "agreed" with the public to balance out dissenters. Third, when exposed to spin, treatment respondents would incorporate spin in a manner in line with the previous two hypotheses (citing reasons that relate to their own personal salience and attitudes towards the poll trend). In addition to a lack of "progovernment" respondents, this hypothesis could not be fully tested as a significant number of control subjects behaved unexpectedly and altered their replies "posttreatment." 


\subsection{Literature review}

Public opinion polls, usually the result of surveying a relatively small sample of the larger population, register opinions in a few discrete options, usually no more nuanced than strong opposition or support for a particular view or moderate opposition or support. Since the rise of professional polling in the interwar period there have been critics who doubt the capacity of polls to truly represent public opinion. In his still oftreferenced text The Phantom Public (1925), Walter Lippman argued that public opinion was not something ever-present but rather the mobilized response to issues shaped by elite actors. Lindsey Rogers, writing after the miscalled 1948 U.S. Presidential election and building from Lippman, argued there was no 'eternal thing' such as public opinion and questioned The Pollsters capacity to even accurately approximate that response:

"About all the polls [do is] tell us the number of persons who answered yes or no or confessed ignorance or indifference when they were asked specific questions. To say that 'public opinion' is being 'measured' is to make skimmed milk masquerade as cream." (9)

More recently, H.J. Rotfeld (2005) has challenged the 'snapshot' conception of public opinion and prefers to see polls as impressionist paintings, coloured by data grabbers and interpreters. A study of miscalled vote totals for the 2004 and 2006 Canadian federal elections suggests polling information be seen as "a mixture of signal and noise" from which, even by averaging and elimination of sample error and bias, true public opinion may not be elicited (Pickup \& Johnston, 2007: 460-1). This in mind, Canadian columnist Dan Gardner (Ottawa Citizen, 2010) disparagingly refers to pollsters as part of the "plausible-hypothesis industry." In one of the few Canada-centric texts on this industry, Peter M. Butler says of our dominant pollsters: "It is clear the quality of interpretations of 
the data and not the data collection itself that sets the good pollster apart from the ordinary" (i.e., the pollster who appears in the news versus the one who does not) (2007: 44). Nevertheless, polls regularly appear in media and shape political commentary. So how then should they be reported?

In Advanced Questionnaire Design (1980) Patrica J. Labaw argues that polls should designed with more open-ended questions (versus closed dichotomous ones), with conclusions drawn aimed at generality over specificity. On coding open-ended responses it is better to summarize answers broadly than tightly:

"I fail to understand why it is necessary to provide fifteen categories of respondent answers when five will provide the information the client really needs, even if this selectivity does result in a 25 percent 'other' category. Certainly the client will find four or five actionable code categories more meaningful than twenty categories that account for every answer but only satisfy idle curiosity about the wide variety of possible respondent answers." (140).

Butler notes that reforms to the Canada Elections Act in 2000 made headway in this regard as it required media reports on electoral opinion polls to note the basic methodological aspects of the poll, including sample size and margin of error, to discourage drawing unfounded conclusions. However doubts persist and pollsters themselves have challenged their colleagues' interpretations. Most recently and prominently, during the 2011 Ontario provincial election the polling firm Ipsos Reid issued a press statement calling out pollsters and journalists for "selling methodological snake oil," drawing particular attention to what they considered untested 'new' techniques for capturing voting intention (Bricker \& Wright, 2011). Moreover, even the answers to 'traditional' questions about vote intention, qualities associated with political 
leaders, and most important issues, can be warped. During the 2011 Federal election in Canada, Nik Nanos, president of Nanos Research, told the media that a weekend dip in support for the Conservative Prime Minister and a bump in support for the Liberal Leader of the Opposition was the result of Liberal attack ads aired that weekend questioning the government's commitment to universal health care. In addition to Nanos not disclosing whether respondents were asked if they had viewed the ads, the poll also observed a decreased percentage of respondents, roughly equal to the bump, who considered health care a major concern. Matheson (in Ruper, 2010), who draws on the philosophy of Roland Barthes (1977), might refer to this error as "fallacy of sequentiality" (41).

For whatever many reasons we receive our news like an unfolding story. Matheson notes that narrative models of understanding the news are so dominant they are "almost a form of academic common sense" (in Ruper, 2010: 37). Jack Lule (2001) argues for a need to distinguish between narrative and chronicle, the former being a true (and rare) account of reality and the latter as mere sequence given false meaning. Ruper and Matheson both argue that these false chronicles are in part the result of journalists working in particular fields or 'beats,' and that when events occur in the same beat they are interpreted to be non-randomly connected. Additionally, Helen Fulton (2005) argues that a tendency to report news in a dramatic fashion, chronologically listing events and with a focus on individuals over systems creates a more accessible product. While this is 'democratizing' in a sense, it contributes to an impression of the news as factual, objective, and driven by powerful actors (like individual politicians), and denies the infinite nuance of reality. Johannes Ehrat (2010) argues that there are no such things as “[p]ure news developments - news understood as one event following another" (18), and 
that all news is published within context. Ehrat explores the phenomena of scandal, an event that "serves ... to delineate a breach in moral and conduct and authority" (22). Fulton (2005) and Lewis (2001) both argue this contextualized reporting serves to support dominant and elite ideology. Taken together, we can see Mr. Nanos' false narrative as an example of the pitfalls of treating political events and public opinion polls as elements of an ever-unfolding story. It is thus not surprising that some critics consider polls as tools for control.

Polls can be seen as such from two angles: by looking at who is doing the polling and by looking at what the polling asks of its respondents. Lewis (1999), noting the links between media outlets and research companies, argues "[t]he technology of polling is ... intertwined with the manufacturing of news" (204). Opinion polling took off, in part, as governments during the Great Depression and Second World War sought "to foster morale ... to be able to assess it and understand it, in order to develop, adjust and evaluate policies towards it" (Osborne \& Rose, 1999: 380). Butler, tracking the history of polling in Canada, notes that famed American pollster George Gallup first came to Canada at Prime Minister King's behest to determine support for conscription during WWII (2007: 40). This need to gauge morale continues today as, Butler observes, "[p]erceptions about prospects for the long term, or confidence in the future of the country are predominant factors in purchase behavior and in the level of public trust in institutions" (32-3).

Researching polling effects requires understanding the fulcrums of opinion or "flashpoints;" collective opinion cleavages to measure and manipulate. Using E.F. Shaw (1977) as a guide, Karen S. Johnson-Cartee distinguishes two such objects media uses to 
build stories: issues and events (2005). Events are "discrete, finite happenings," while issues are an accumulation of events assembled within "a media context that provides a thematic structure, [which] assigns significance and prioritization" (57). Thus, while an event is only a concern by itself, issues are conflicts with adversarial sides. This has a circular effect as new events are given meaning by their issue-context and serve as public opinion flashpoints. Johnson-Cartee notes though that not all issues are adversarial or divisive but are presented as such by individuals and institutions attempting to shape the public agenda. Politicians and others will attempt to 'spin' the news 'in a manner which generates the most favourable reaction to it from [their] standpoint" (Butler 89). This concern is surmised well in a 2009 study on the uses and misuses of polling on Canadians satisfaction with healthcare services (high) and desire for radical reform (also high):

"Putting a given situation regularly into the media spotlight and presenting this situation as problematic will objectify the situation as an object of political intervention, and this focus will, in turn, contribute to legitimizing the idea that this situation is actually problematic." (Contandriopoulos \& Bilodeau, 2009: 111).

How the passive observer interprets issues and events is a function of personal-level and societal-level judgments, the latter particularly dependent on media frames (Sonck \& Loosveldt, 2010).

Subjectivity to media frames, for a particular issue, has been found to correlate negatively with opinion strength and history of an issue (how long it has been in the news). People with no opinion or a weak opinion, particularly on new issues, are more prone to media effects. This occurs due to their need for orientation or 'NFO' (Matthes 2008). Building off McCombs' 2004 model, Matthes constructs a two-stage process with the prominence of issue (i.e., is it topical?) as a prerequisite for NFO. He hypothesized 
that if an issue is treated as salient by the media and if a person is uncertain of their own opinion, they will have a greater NFO, and thus be more susceptible to agenda-setting effects. By analyzing subjects' top sources for political information, Matthes found significant evidence that "NFO does predict that individuals will turn to news media in order to gather information, but it fails to predict which specific issue attributes will be chosen as orienting cues" (emphasis added, Matthes, 2008: 450), suggesting that the media may determine what is important but not, as significantly, what is the proper view.

As a general hypothesis, this project predicted that when shown a poll gauging public satisfaction with government, respondents will animate the yeas and nays with their own personal interests. a.m. koazk (2010) would call this "trip up" a fundamental attribution error; that "knowing yourself [is] a trigger," a preloaded explanation for someone else's situation. In opinion surveying, this is related to selective recall; the tendency to rely on memory rather than truth (Wojcieszak \& Price, 2009). In a wide range of disciplines, this effect is known as false consensus or transference. In a review of the "first decade" of the subject's study, Marks \& Miller (1987) outlined dominant perspectives as to why subjects will explain what other people are thinking with a personal touch. Summarized, the theories suggest false consensus occurs due to, one, selective exposure and cognitive availability, two, issue salience and focus of attention, and, three, logical information processing. For our purposes, the first two may be bundled as the "top-of-mind" phenomenon; that personal experiences and interests are intuitively privileged in an interview setting. The third cause may be explained as the personal belief that independent variables, like events or other stimuli, are experienced by others in the same way as oneself. 
On this intrusion of the personal in polling, there are arguments for and against. Butler, drawing on Zaller (1992), argues interviewees adopt ready-made views drawn from a "selective record of events" and parrot likeminded politicians and media commentary in replying to questions (Butler: 18-9). While not purely personal, this suggests the interviewee will respond in a way that reflects their beliefs. Others argue the style of interviewing, for instance the common use of seven-point scales to capture opinion, determines what opinion may be expressed. Osborne \& Rose (1999) say "we have to acknowledge that the notion of opinion is the product of the particular procedures by which opinion is elicited" (387). Moreover they argue polling methodology is internalized within the public such that people abandon more nuanced opinions in exchange for relative ones, thus undermining the accuracy of polling as respondents will tell not what they think but where they believe they fit (392). This phenomenon, Lewis notes in his review of research on polling, is further shaped by the relevant knowledge a respondent brings to an interview (1999: 201). Pickup \& Johnston argue that the mere asking of vote intention can push an interviewee to more extreme opinions, as such a question "put [respondents] in a mindset more reflective of election day $[. .$.$] in a context$ of disagreement" (464), but that this is not easily remedied as more discourse-oriented and open-ended questioning may lead to recall bias. Wlezien (2005) argues the common open-ended question, "What is the most important problem facing the country today?," is troubled by disparate definitions of important and problem, and further complicated by the context of a political poll that may emphasize problems traditionally considered to be actionable by the state over those outside the purview of public policy (557-8). These qualms in mind, it is not surprising that many critique polling as a mere measure of 
public response to policy disputes between elites (e.g., Brookes, Lewis, \& WahlJorgenson, 2001; Habermas, 1989). What then of breaks with elite opinion?

Cognitive dissonance is the gap between personal desires and actual personal or societal behavior. In order to grapple with this disconnect, individuals will either alter their attitudes to match behavior, or reinterpret behavior in way that falls in line with their attitudes. Eric Anderson investigates this in his 2010 study of infidelity among undergraduate males. He finds that philandering males engaged in cognitive acrobatics as they uphold monogamous relationships as the ideal, despite their infidelity, and are unwilling to attempt to negotiate "open relationships" with their primary partners as "at least with cheating there is an attempt at monogamy" (2010: 864). Studying media habits, particularly the shift from print to television news in the USA during the 1970 s and 80 s, Claussen (2004) argues "much of the American public erroneously convinced itself that television news is as complete, more accurate, more credible, less biased, and so on as newspaper content" (216); that perceptions were altered to support behavior. How the news is digested can also be reinterpreted to match attitudes. A 2006 survey of Americans on the Iraq war and the economy saw optimism and pessimism divide along partisan lines: the war was going well said $60 \%$ of Republicans but only $20 \%$ of Democrats, and the economy was doing well said $70 \%$ of Republicans but only $25 \%$ of Democrats (PEW 2006). A study of the 2000 Presidential election (Kay, Jiminez \& Tost 2002) found the desirability of one candidate winning correlated positively to the perceived likelihood of that candidate winning, suggesting "people tend to elevate an initially unattractive outcome as it becomes more probable" (1306). In Canada, studies of 
"issue ownership" - that a particular policy competence is associated with partisanship have found similar trends (Bélanger and Meguid, 2008).

Recent studies on false consensus and cognitive dissonance in collective opinion estimation still draw on these perspectives and understandings of how a person understands public opinion. In a year-long study preceding the 2000 U.S. Presidential election, Wojcieszak \& Price (2009) found exposure to disagreement mitigated the effect of opinion strength on collective opinion estimation. In a control group, strong supporters of character education and gun control overestimated support for their own pet issues. Treatment groups, however, estimated less public support for these positions when exposed to "heterogeneous discussion networks" (i.e. they had to speak with people they disagreed with). By involving subjects in mediated, online chats with unlike-minded subjects, the tendency to overestimate like-mindedness at large was controlled by treating for selective exposure. Sonck \& Loosveldt's recent study of poll effects (2010) found that while subjects revised their estimations of collective opinion when presented with polling data, they did not revise their own opinions. Noteworthy, while issue-specific opinion strength did influence initial estimations, it did not preclude or otherwise affect revisions. The researchers however troubleshot this willingness to revise perceptions while maintaining personal beliefs as a potential result of subjects' ability to distinguish their own opinion from collective opinion; a phenomenon in line with perspectives that connect ego and self-esteem to personal opinion. Contrary to Sonck \& Loosveldt however, Wolf \& Holian (2006) found exposure to poll results on less (personally) salient issues did influence personal opinion. In 2004, subjects presented with polling suggesting then-President Bush's social security policy (low salience) was generally supported were 
persuaded to "join the majority," but not persuaded to support Bush's Iraq policy (high salience) under similar pressure. Interestingly, only "positive" polling had an effect; polls suggesting majority opposition did not persuade subjects to oppose Bush's policy. Wolf \& Holian did not give their subjects an opportunity to distinguish personal and collective opinions however. Against these studies, Boon and Meurs (1991) found university students regularly considered their peers who studied alongside them to be more rightwing in their political orientation than themselves. This was extrapolated to their city and country, suggesting that individuals may also tend to see themselves as unique in their opinions.

Some researchers have sought quantitative methods to verify issue salience captured by opinion polls, by comparing polls to other statistical trends. Wlezien (2005), looking at Americans polled during the Cold War, sought correlations between the general topic of "most important problem" replies and other statistics. Most significantly, he found a positive correlation between Foreign/Defense topics and negative attitudes towards the Soviet Union. Additionally, he found a positive association between Defense replies and leading economic indicators, suggesting "[w]ith a good economy, we need to look elsewhere for problems" (556). Scharkow and Vogelgesang (2011) sought to verify "important issues" during a German federal election by comparing survey replies to search engine queries using Google Insights for Search (GIFS). While only an initial test, the researchers found searches for a prominent economist to positively correlate with mentions of the economist or his plans in survey responses. 


\subsection{Hypotheses}

Figure 1.3.1: Independent, interacting and dependent variables

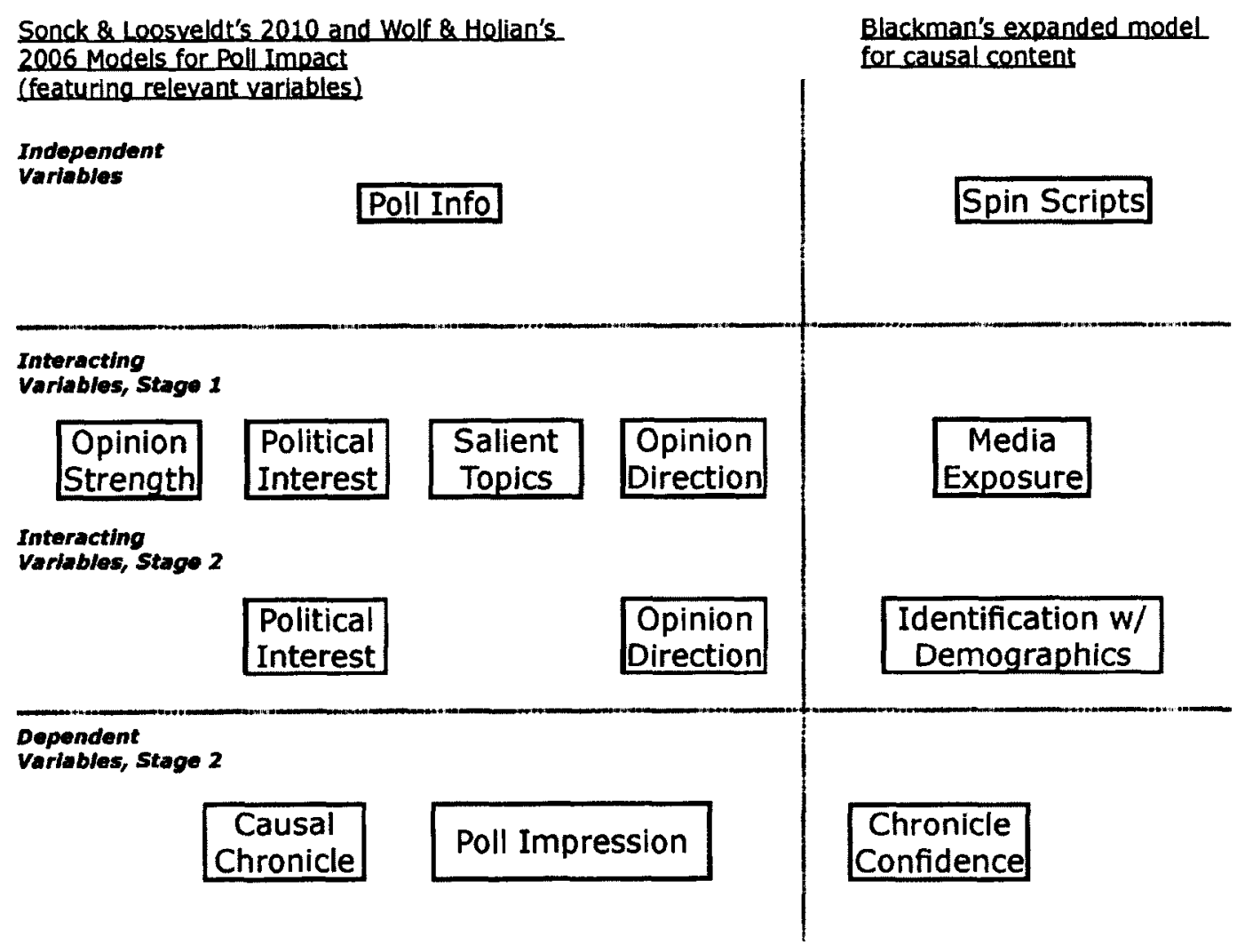

We have ultimately three hypotheses. The first (H1) is that respondents will demonstrate a top-of-mind phenomenon, such that when they are asked to explain a change in public opinion, or "poll trend," they will provide a "causal chronicle" utilizing their own interests and pet issues. H1 is supported if significant correlations are found between top events (P1) and pet issues (P2) (from Data Collection, Stage 1) and causal chronicles (P6s pre-treatment, P9s post-treatment) (from Stage 2). This is done by, one, coding the responses as issue- and event-specific dummy variables, and two, by creating general topic scores which quantify replies' relation to five topic areas (Economic, 
Defense, Foreign, Domestic, and Political). (See 1.5, Statistically capturing events and issues, for how this is done). A supportive example would be if a respondent's pet issues and causal chronicles both related chiefly to foreign affairs. The null hypothesis is that the same topic correlations are no more significant or common as different topic correlations, or correlations between topic scores and other variables. As a sort of $\mathrm{H} 1 \mathrm{~b}$, subjects were particularly expected to rely on personal salience for chronicling poll trends for demographics they identify with (e.g. female subjects will have strong correlations for topic scores when asked why women as a group are more optimistic or pessimistic). Additionally as a sort of $\mathrm{H1c}$, it is hypothesized that expressed confidence in explaining poll trends (measured by the variable chronicle confidence) will increase when respondents draw on personal salience.

The second hypothesis $(\mathrm{H} 2)$ is that respondents will demonstrate cognitive dissonance should poll trends presented contradict their own beliefs (i.e. if an increasing number of Canadians are confident in the government's direction while the respondent is pessimistic). A special poll impression variable is captured to measure this. This would be demonstrated if causal chronicles tend to rely on issues and events which are not related to the federal government, but rather to other political actors or events and issues of a non-political nature (e.g. the weather). The null assumes this trend is as common with respondents whose beliefs are in line with the poll trend.

In order to test the strength of the first two hypotheses, our treatment group was exposed to "spin" in the form of partisan chronicles to explain the poll trend, and thus a third hypothesis is made: respondents who find spin credible and in-line with their own beliefs will incorporate spin into their causal chronicles. H3 would be supported if we see 
chronicles change as such; the null hypothesis presumes no such pattern emerges. As a sort of $\mathrm{H} 3 \mathrm{~b}$, it is anticipated that $\mathrm{H} 3$ will also be influenced by the expectations of $\mathrm{H} 1$ : that respondents will incorporate particular spin when it relates to their pet issues (i.e. a respondent most interested in economic issues will be more likely to incorporate spin which deals with the economy than with defense issues). Additionally we should not expect significant change in causal chronicles among our control subjects (that is, their responses should not change when asked for them a second time).

For the most part these hypotheses are tested using a respondents-as-cases dataset. Each respondent has a 0 or 1 dummy score for our four top-of-mind captures (e.g. did the respondent mention the Governor General in P1, P2, any P6, or any P9). Each respondent also has a topic score for each particular question (P1, P2, and each P6 and P9 question). Due to the small sample size these trends are also investigated qualitatively by looking for literal connections between Stage 1 and Stage 2 replies.

In addition to the respondents dataset, a replies-as-cases dataset was created to double-check findings and discover possible thematic associations between replies. In this replies dataset individual replies for $\mathrm{P} 6 \mathrm{~s}$ and $\mathrm{P} 9 \mathrm{~s}$ are made individual cases and coded with all the same variable values as the respondents who gave them (i.e. each reply has a gender, a voting intention, etc.). Themes or "dominant narratives" were created by looking at all chronicle replies and for repeated sentiments, such as Canada is relatively better, whether compared to the U.S. economically or the Mid-East stability-wise, and creating associated dummy variables (More examples of these themes are also available in the section 1.5). While subjectively selected from causal chronicles, these narratives 
will be used to discuss findings and see the sort of collective judgments our subjects made of particular demographic groups. 


\subsection{Research design and experiment summary}

Figure 1.4.1: Data collection schedule

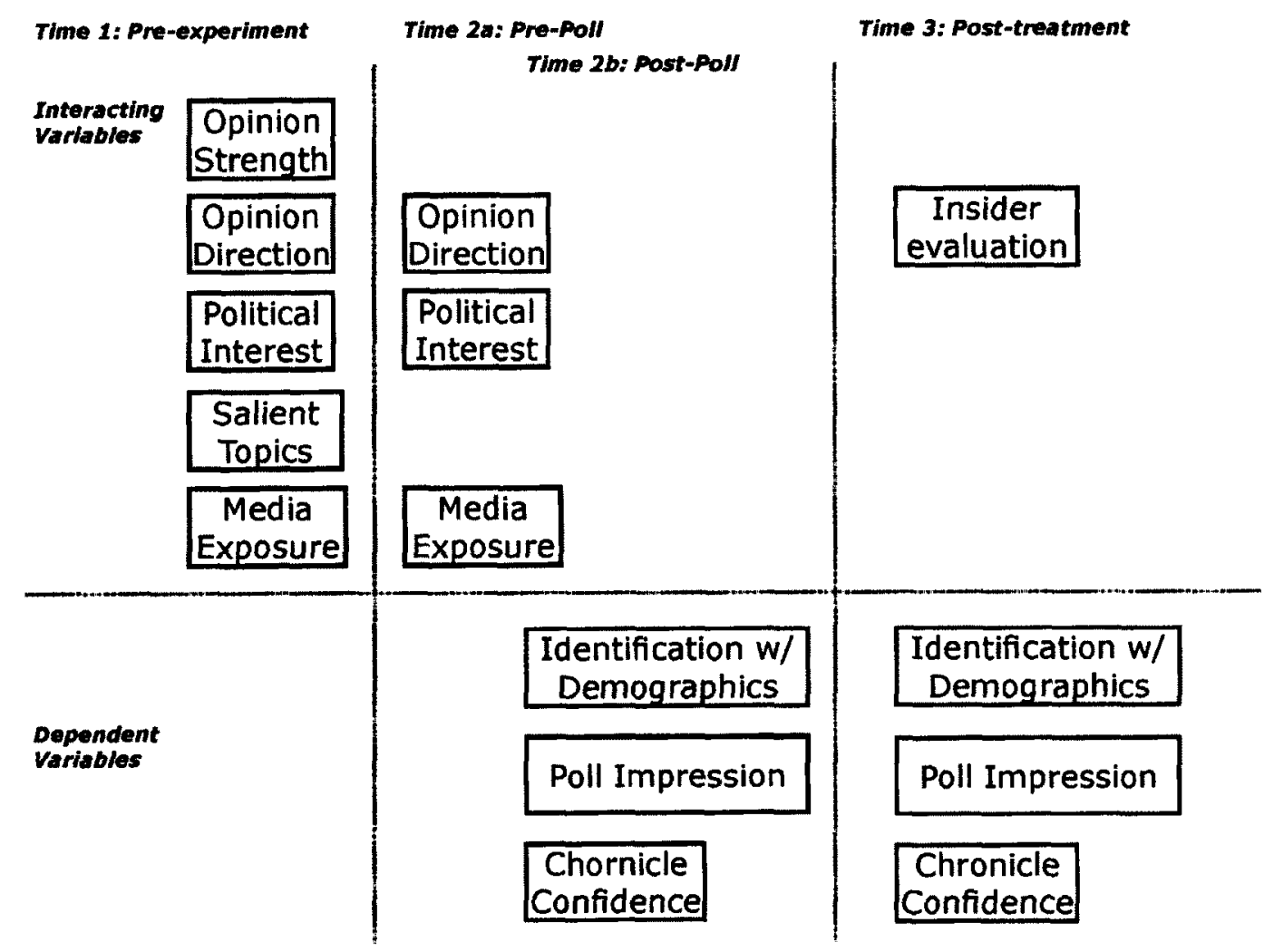

Note: All questionnaires will be completed on paper. We refer to top-of-mind fields throughout this report by the question number they were assigned (e.g. P1=top events; P6.2=chronicle for university graduates, pre-treatment; P9.7=chronicle for women, posttreatment). 
Step 1: Recruitment \& the "stage 1" questionnaire ("Time 1," 10/01/2010 to 31/01/2010)

Students were recruited between January 10 and January 31 and were directed to complete a 'pre-experiment' questionnaire (see Appendix 4). Primarily it asked them what they believed were the top five Canadian political events of 2010 and the top five issues the federal government should focus on in 2011. These issues and events were interpreted as what they consider important, Canadian politics-wise, and served as a topof-mind and salience capture. Further questions were asked regarding attention to Canadian politics, preferred sources of political news, political persuasion and participation, and whether they felt the federal government was headed in the right direction (which related directly to the poll data used in the stage 2 questionnaire).

The questionnaire was packed in an envelope with two copies of a consent form (see Appendix 1) and all documents coded with an identification number used to identify respondents anonymously in the analysis of results. One copy of the consent form and the completed questionnaire was returned to the student researcher via the journalism office. Working with the journalism office assured subjects their responses were treated professionally and kept in strict confidence. This was vital as subjects had to provide their name and a preferred method of contact, either their Carleton email address or phone number, to participate in stage 2 .

One participant contacted the student researcher and asked to be withdrawn from the project. This respondent's completed stage 1 questionnaire was destroyed and thus the number of total stage 1 participants for study was 26 .

It was presumed that journalism and communication students are among Carleton's most 'news-conscious' students and populated the study sample. (Klaus Pohle, 
professor responsible for journalism undergraduates, was consulted to help develop this project.) A series of questionnaires or 'news quizzes' - a term employed by journalism professors - were used to capture subjects' perspectives and chronicles.

It was hoped that upwards of 60 students would be recruited with, ideally, equal numbers of students with second, third, and fourth year standing, and all enrolled in Carleton's nationally-renowned journalism program. Alas only 27 students were initially recruited and completed stage 1 and only 10 of those attended the stage 2 experiment. This low response rate contributed to the decision to allow non-journalism students, and graduate students to participate, despite the more exclusive targets at the project's outset. This also altered proposed plans to have one control group and three treatment groups, with each of these 'spun' groups receiving information from one, two, or three insiders (a Liberal volunteer known to the student researcher was approached). Control and experiment groups each had five members, and group assignment was assigned randomly barring some adjustments for participant availability.

To maintain a sample of university students who are particularly news conscious, only students with a second year undergraduate standing or higher and enrolled in courses in Carleton's Department of Journalism and Communication were targeted for participation. The 'standing' requirement is in place as typically half of first year journalism students do not qualify for second year. Second year students and their seniors may be expected to be more 'into the news,' as they have proven themselves by making the cut in a competitive program and because it is not until second year that journalism students enrol in a dedicated reporting course. Based on experience within the program himself, the student researcher is aware that many communication students are in fact 
those who did not make the cut but still wanted to study communication and media. While this sample of 'news junkies' cannot be said to be indicative of their age demographic, a well-informed set of respondents was deemed necessary to ensure a high response rate to the open-ended top-of-mind questions central to the hypotheses.

The student researcher spoke to journalism and communication students at the start of their classes. A standardized script was employed to recruit participants (see Appendix 3). In total, eight classes were visited including a media law course required for all journalism undergraduates (second year), four reporting homerooms for journalism undergraduates (third year), a course on covering politics for journalism and communication undergraduates (fourth year), and a homeroom for journalism and communication graduates. On two occasions during January 2010 a table was set up in the department's foyer and students were recruited personally (with a condensed 'pitch' to participate). Additionally posters (see Appendix 2) were put up throughout the department and all journalism and communication students were emailed, with these two methods directing students to pick up a stage 1 questionnaire package at the departmental office. Unfortunately the use of the table and poster approaches resulted in the recruitment of two students from the department's parent school of Public Affairs and Policy Management, though neither of these students participated in stage 2. Our final stage 2 group contained eight journalism majors and two communication majors, and by chance, neatly divided into our control and treatment groups.

Step 2: Scheduling (between 01/02/2011 and 08/02/2011) 
Students who completed the questionnaire were scheduled to attend the stage 2 experiment (see Step 5). It was at this point that respondents were given identification numbers of no chronological significance. Group assignment was determined by placing ID numbers in a hat and alternately assigning participants to the treatment or control group as numbers were drawn. Participants were given an opportunity to choose a particular date if they had schedule restraints but were not informed whether they would be in a treatment or control group. See Appendices 11 and 12 for telephone and email scripts.

\section{Stage 3: Poll capture (between 10/01/2011 and 09/02/2011)}

A series of opinion polls, asking the same question, act as interval measures. For instance, regular polls of 'like samples,' say 1000 Canadians proportionately representative of major demographic and regional population segments, provide a running score on the federal government's overall performance. The fluctuations between intervals may be assigned meaning; e.g. policy decision $\mathrm{X}$ and event $\mathrm{Y}$ caused the government to gain five percentage points in public confidence between two intervals. The period between intervals is referred to as "poll periods." It is hypothesized the issues and events used to explain trends are dependent on an individual's perspectives.

This project took place in real life ("IRL"), rather than through simulation.

Subjects responded to real poll numbers published by Ekos Research Associates between August 2010 and late January 2011 in response to the question, "All things considered, do you think that the federal government of Canada is headed in the right direction?" (Possible replies: right direction, wrong direction, unsure/don't know) (Ekos Research 
Associates, 2010a through 2010j, 2011a and 2011b). Ekos conducts such polls every two or three weeks and they are typically published soon after a week-long polling period of approximately 1500-2000 adult Canadians. The publication includes breakdowns for particular demographic groups. The difference between polls formed the change that respondents were asked to 'chronicle' (though this term was not employed in the questionnaire). The last poll incorporated covered an unusually longer span of time (January 13-26) and an unusually larger number of respondents (nearly 4000) as Ekos was trying its first interactive voice response or "robo" poll. A poll taken February 5-9 was not made public until the evening before stage 2 and thus, unavoidably, questions referred to trends truncated by two weeks.

Table 1.4.1: Poll info utilized to provoke chronicling

\begin{tabular}{|l|l|l|l|l|l|}
\hline & & \multicolumn{2}{|l|}{ Poll Period } & \multicolumn{2}{l|}{$\begin{array}{l}\text { Confidence in direction of } \\
\text { the federal government }\end{array}$} \\
\hline Questions & Demographic & First Poll & Last Poll & First Poll & Last Poll \\
\hline $6.1 / 9.1$ & All adult Canadians & Oct 20-26 & Jan 13-26 & $36.1 \%$ & $43.6 \%$ \\
\hline $6.2 / 9.2$ & University graduates & Dec 1-7 & Jan 13-26 & $32.8 \%$ & $43.8 \%$ \\
\hline $6.3 / 9.3$ & High school diploma / less & Nov 3-9 & Jan 13-26 & $35.2 \%$ & $43.3 \%$ \\
\hline $6.4 / 9.4$ & All men & Nov 3-9 & Dec 9-15 & $46.4 \%$ & $40.9 \%$ \\
\hline & All 25-44 year olds & Nov 3-9 & Dec 9-15 & $41.2 \%$ & $32.8 \%$ \\
\hline $6.6 / 9.6$ & All men & Dec 9-15 & Jan 13-26 & $40.9 \%$ & $47.2 \%$ \\
\hline & All 25-44 year olds & Dec 9-15 & Jan 13-26 & $32.8 \%$ & $42.7 \%$ \\
\hline $6.7 / 9.7$ & All women & Nov 3-9 & Jan 13-26 & $30.9 \%$ & $41.4 \%$ \\
\hline $6.8 / 9.8$ & Quebec & Nov 3-9 & Jan 13-26 & $31.4 \%$ & $31.3 \%$ \\
\hline
\end{tabular}

The above table summarizes the polling data presented to stage 2 participants. For P6.1/P9.1, subjects were asked for up to five issues or events contributing to the rise or "uptick" in the polls. For the subsequent demographic-specific questions, a maximum of three replies were requested. This data was chosen for questions as it represented significant trends in the polls (i.e. sustained direction of change for multiple polls of a 
magnitude outside the margin of error for each bracket). Line graphs were presented with questions to illustrate the trends visually. Please see the actual stage 2 questionnaire in Appendix 6 for particular phrasing and presentation of the polling information, in particular for questions P6.4/P9.4 and P6.6/P9.6 that ultimately proved troublesome (see 4.1, Questionnaire weaknesses, for further discussion).

Doing this project 'IRL,' a chief concern was that polling numbers would stagnate in the weeks leading up to the experiment. While the May 2011 Federal election saw great shifts in party fortunes, during the poll period there was a sense of electoral stagnancy regularly reported in the media. Carleton University's Jonathan Malloy, midway through the April campaign, penned an editorial for the Ottawa Citizen entitled "No one's vote will change." However the inclusion of real opinions was central to this project. If no significant changes were observed in the months running up to stage 2 , it was planned to either contrive polling data and present it as real (with the Carleton Research Ethic Board's approval) or delay the experiment entirely. As we presume poll trends represent genuine shifts in public opinion (e.g. that one in twenty Canadians changed their mind between one interval and the next), we expected employing genuine trends over contrived ones would improve the quality of causal chronicles. This would be so because respondents' replies would be intuitive as they would relate to true public opinion rather than reach against reality and thus more likely satisfy our hypotheses. The converse was possible as well however. If poll trends were contrived, respondents would be able to draw on impersonal frames (e.g. their own news sources, reliable spin from insiders) to sufficiently inform their replies. With a disconnect between reality and the numbers, respondents may have been likelier to draw upon their own salient topics, also 
satisfying our hypotheses. However enough change was observed such that contriving trends was not necessary.

To ensure that poll trends were sufficient fodder for provoking responses, a pretest was conducted using real trends. In November 2010 two friends of the researcher were given questions suggesting that confidence in the federal government was up among Canadians, particularly in Quebec and among university graduates. They replied as expected, citing a variety of government policies (e.g. "effects of the Economic Action Plan"), political events (e.g. "Recent Governor General appointment favourably viewed") and assumptions about the public or particular demographics (e.g. "Christmas is approaching," "Quebecois are a fickle people"). See section 1.5 for how this pretest contributed to initial coding schemes.

\section{Step 4: Spin prep (between 01/02/2011 and 11/02/2011)}

The two political insiders, though not technically part of the research team, were then-active employees and supporters of two major federal political parties, one (Hijal De Sarkar) with the New Democratic Party, the other (Brendan Mulvihill) with the Conservative Party of Canada, and are friends of the student researcher. While both were trusted to act and did act in a professional manner, they were expected to be biased and present a personal spin narrative. They had no role in developing any aspect of this research project other than their spin script and did not have access to stage 1 data. Insiders were sent a summary of the poll changes and asked to provide their own explanations of the trends. These 'spin scripts' were opinionated but respectful in tone and content (or at least no more pointed than typical editorial fare), each no longer than 
500 words, and to be read aloud to the treatment participants. (See Appendix 7 for the actual scripts.)

Step 5: The Experiment or 'stage 2' (Times 2a, 2b, and 3; 12/02/2011 to 13/02/2011)

Focus groups were held on February $12^{\text {th }}$ and $13^{\text {th }}$ in a classroom in the journalism department. The author administered the experiment and, unless otherwise indicated, directed and instructed respondents. Respondents were given a folder containing questionnaires with their identification on the front. Due to the low number of respondents, the student researcher was able to track respondents who questioned the insiders. Here is what occurred in each group session:

Control Group (Approx. 45 min. on 12/02/2011 at 1:00 PM): Subjects were welcomed and seated. They were instructed not to communicate with other subjects during the session. They completed a 'pre-poll' questionnaire (Time 2a, see Appendix 5) similar in content to the stage 1 questionnaire, minus the top events and issues questions. They were then given a 'post-poll' questionnaire (Time 2b, see Appendix 6) that asked for causal chronicles. They were told not to worry greatly about the specific dates of events as some questions referred to poll periods three months prior. Once all subjects were finished, they were asked to complete it again (Time 3, see Appendix 9). Subjects were told they could either copy their 'pre-treatment' replies completely or change them however they pleased. Once complete, subjects were debriefed (see Appendix 10) and directed to a refreshment buffet, administered by the researcher's spouse, Kate Maxfield, as nutritious, non-monetary compensation for their participation. 
Treatment Group (Approx. $65 \mathrm{~min}$. on 13/02/2011 at 1:00 pm): Same as the control group but after the post-poll questionnaire was first administered (Time 2b), our political insiders presented their spin scripts to the subjects one at a time (they were not in the room together). The pro-government insider, Mr. Mulvihill, presented first because it seemed intuitive to let the "government speak" before the opposition. Subjects were permitted to take notes using scrap paper provided. Both insiders took questions from the treatment group. After each insider left subjects completed an 'insider evaluation' (see Appendix 8) to briefly capture their opinions of the insider (whether they trusted their story and/or consider them politically likeminded). While the spin scripts are available in Appendix 7, they did make some on-the-spot additions in reply to questions. A brief account of what occurred:

First the pro-government insider, Mr. Mulvihill, presented his script. He focussed on three key themes: stronger than expected job growth, positive economic news coming from the American media and a poor job by the Official Opposition (Liberal) to provide an alternative narrative. On this last theme Mr. Mulvihill explained that the Opposition was either focussed on 'esoteric' issues or issues affiliated with the Conservative brand. One respondent asked how these themes may impact particular demographic groups. Mr. Mulvihill responded that women and university graduates in particular accepted the "dominant narrative" that the government was responsible for job gains. Another respodnent asked for more explanation regarding 'salience issues' associated with the Conservative brand. Mr. Mulvihill responded that when the Liberals speak about war and taxes, and headlines reflect this, the typical public response is still to associate these 
matters with Conservatives; that the Conservatives 'own' these issues and thus any mention inherently favours their fortunes.

The anti-government, or poll-doubting, insider Mr. De Sarkar presented his script. He presented four points: the media was too focussed on the electoral horserace rather than substantive policy issues, competition between the opposition parties, a sense of national stability relative to the then-nascent Arab Spring, and a 'Holiday boost' as most poll periods spanned December. One respondent asked two questions. First, regarding Mr. De Sarkar's first point, how did the 'confidence in government' question not capture policy performance, Mr. De Sarkar responded by simply suggesting error on the part of the pollsters. The respondent then asked, regarding the third point, have not things "been bad for a while" elsewhere? Mr. De Sarkar responded that the media focus on the Conservatives' fifth anniversary as governing party contributed to a general retrospection by Canadians as to whether the "past five years [had been] better or worse" for Canada; that the polls were not reflecting recent events but recent years.

After evaluations were completed for both insiders, subjects completed the 'postspin' questionnaire (Time 3, Appendix 9) that asked the same questions as the prior postpoll questionnaire. As noted, the subjects were told they could copy their answers verbatim or change their replies however they chose, incorporating the spin as they saw fit. Once this was finished, they were debriefed and directed to the refreshment buffet. 
Step 6: Response Review + Withdrawal Period (between 14/02/2011 and 05/03/2011)

This period was the 'withdrawal window' for subjects to request that their responses be removed from total data collected and destroyed (articulated in briefing). No subjects withdrew or expressed any concerns post-experiment.

Step 7: Post-human interaction data review and thesis development (between 06/03/2011 and 30/11/2011)

After all interaction with subjects was complete, responses were analyzed for hypothesized trends and incorporated into the student researcher's graduate thesis. Documentation linking subject names and contact information to respondent identification numbers was destroyed. Respondents are identifiable solely by ID numbers. 


\subsection{Statistically capturing events and issues}

Table 1.5.1 Top-of-mind data captured from pre-test

\begin{tabular}{|l|l|l|}
\hline Issue or Event & Angle & Fild \\
\hline Gordon Campbell's ousting as Premier RE: taxes & Finance & Leadership \\
\hline $\begin{array}{l}\text { CRTC's decision RE: Net Neutrality and common } \\
\text { carriage }\end{array}$ & Industry & Policy \\
\hline Ignatieff's poor leadership & Politics & Leadership \\
\hline Extension of Afghan military commitment & Defense & Conflict \\
\hline $\begin{array}{l}\text { Use military power to ensure sovereignty instead } \\
\text { of foreign missions }\end{array}$ & Defense & Safety \\
\hline
\end{tabular}

Content tagging of Pretest replies to "In your opinion, what were the biggest Canadian political events in 2010?" and "What issues do you think the federal government should focus on in 2011?"

It was initially proposed that open-ended responses to top-of-mind fields (top events, pet issues, causal chronicles) would be given two narrative tags, one relating to topic field and one to the nature or 'news angle' of the reply. Field was defined whenever possible as a public policy area. If possible, policy areas were linked to a federal department as the poll information pertained to the federal government's performance. Issues or events that did not fit a policy area would be labeled as Politics (i.e. not involving 'hard' topics), or if not political as Culture (e.g. "Christmas is approaching - no one likes politics around the holidays"). Otherwise unclassified fields would be treated as missing values. Angle was defined as the newsworthy or controversial aspect of the issue or event. The total number of field and angle tags was to be kept low, no more than twenty of the former and ten of the latter. It was hoped that by limiting all issues and events to two tags, it would be possible to construct index and dummy variables, to be used to measure trends in interest and opinion projection. However this proved an inappropriate approach. 
Using this approach the pretest data did show evidence seeming to support $\mathrm{H} 1$ as fields did seem to carryover from top events and pet issues to causal chronicles. However once there were a greater number of cases to code this method demonstrated itself to be vague and subjective considering the sort of issues and events. As an example, the most common top event cited was the G8 and G20 summits held in Hunstville and Toronto, Ontario, respectively (in some instances referring to both, or one). While most responses were basic (often as concise as "G20") six respondents made mention of the violence at the summits and three noted the summits' costs. How should one code the summit? It could be considered a foreign affairs matter due to the attendance of foreign dignitaries, or a law \& order matter due to the violence, or an example of government misspending due to the highly-criticized costs (e.g. the 'Fake Lake' scandal that preceded the summits). Similarly hard to code was the 2010 Winter Olympic Games in Vancouver; a 'foreign' event in one sense, but a mere sporting event in another. Moreover mentions were made of the effect the games had on the city and the province, with references to the "post-games economy" and anti-Olympic protests by Aboriginal and activist groups. 


\section{Figure 1.5.1: How replies and respondents are given topic scores}

Step 1: Each reply is given a positive value (1) for each topic it identifies with or 'hits;' otherwise it is coded 0. For the replies as cases dataset, no further steps are taken. For the respondents as cases dataset, further steps are taken to create topic summary variables.

\begin{tabular}{|l|c|c|c|c|c|}
\hline & Economic & De f e n s e & Fo re i g n & Domestic & Politic al \\
\hline Prorogation & 0 & 0 & 0 & 0 & 1 \\
\hline Long Form Census & 0 & 0 & 0 & 1 & 0 \\
\hline G-20 Spending & 1 & 0 & 1 & 1 & 0 \\
\hline Losing the base in UAE & 0 & 1 & 1 & 0 & 0 \\
\hline Helena Guergis Debacle & 0 & 0 & 0 & 0 & 1 \\
\hline
\end{tabular}

Sten 2: For each particular reply, each topic hit is divided by the number of total topic hits. For instance, "G-20 Spending" hits Foreign and Domestic (as all G8/G20 mentions), as well as Economic. Thus the number of total topic hits is 3 , and this event is revised to have values of $1 / 3$ for Economic, Foreign and Domestic.

\begin{tabular}{|l|c|c|c|c|c|}
\hline & Economic & De fe n s e & Fore i g n & Domestic & Politic al \\
\hline Prorogation & 0 & 0 & 0 & 0 & 1 \\
\hline Long Form Census & 0 & 0 & 0 & 1 & 0 \\
\hline G-20 Spending & 0.3333 & 0 & 0.3333 & 0.3333 & 0 \\
\hline Losing the base in UAE & 0 & 0.5 & 0.5 & 0 & 0 \\
\hline Helena Guergis Debacle & 0 & 0 & 0 & 0 & 1 \\
\hline
\end{tabular}

Step 3: Column values are added to create total topic hits for an entire set of replies, which when added will equal five. These numbers are raw however and give added weight for respondents who give the maximum number of replies (i.e., a respondent who only provides four top events will have lower values).

\begin{tabular}{|l|c|c|c|c|c|}
\hline & Economic & De fe ns e & Fore ig n & Domestic & Political \\
\hline All top events & 0.3333 & 0.5 & 0.8333 & 1.3333 & 2 \\
\hline
\end{tabular}

Sten 4: Each topic hit score is divided by the total number of replies given. This creates a set of standardized scores, with each individual score ranging from 0 to 1 , and the total of all scores always equalling 1 (unless no replies were given in which it is left as zero). These scores are used for topic testing.

\begin{tabular}{|l|c|c|c|c|c|}
\hline & Economic & De fe ns e & Fore ig n & Domestic & Political \\
\hline All top events & 0.0667 & 0.1 & 0.1667 & 0.2667 & 0.4 \\
\hline
\end{tabular}


With these examples and others in mind, a few key problems had to be addressed. One, statistical measures of events and issues had to be made more general. Thus a system that coded replies by a few distinct topics was created. This system gave respondents 'topic scores' for each set of top-of-mind questions, summarizing say their entire set of pet issues (P1), or their causal chronicle for increasingly optimistic graduates (P6.3/9.3). Second, topic overlap had to be allowed for. Thus the coding system allowed for one issue or event to relate to multiple topics. As Figure 1.5.1 explains, topic scores were nuanced to allow for a particular event to be classified as more than one topic without giving that topic extra weight in statistical analyses. Thirdly, a particularly common issue or event reply could disproportionately skew topic trends. Therefore dummy tag system had to be maintained to track specific correlations, and thus a system of meta-tag dummy variables was used in addition to the topic scores. A meta-tag is a dummy variable that measures positive association with a keyword or concept. This is used commonly for online articles. Using database software, articles may be associated with or "hit" particular tag variables (e.g. "Elections" or "Fraud").

The score system was inspired by Christopher Wlezien's 2005 study of salience issues. He coded open-ended replies to 'most important problem' polls into four topic areas: Economic, Defense, Foreign, and Other. The topics were mutually exclusive. Our system breaks the other category into two defined topics, Domestic and Political. Domestic was added to distinctly capture what was largely captured by Wleziens' Other; matters like social policy, crime, and the environment. Political was added as while Wlezien studied important problems, our interest was in political events, problematic or 
not, and necessitated demarcating responses outside of policy areas, such as elections and resignations. As well, Political captures issues relating to Parliament (e.g. "getting more women in federal politics," "cooperating with other parties") and "non-events' / passageof-time replies that were somewhat common in causal chronicles (e.g. "scandals fading from public memory," "Parliament was on a break"). As discussed above, requiring replies to "hit" only one topic was problematic. By allowing topic sharing, subjectivity in coding was reduced. Nevertheless, we concede what Wlezien concludes about his own methodology, that "[i]n effect, we are doing science backwards, making do with instruments without knowing or being clear about what they represent" (575). Should our respondents have been asked to rank the topic areas the federal government should focus on, such direct questioning may have produced trends different from what we have deduced.

Building on this weakness, it was possible that some issue and event replies were miscoded as they overtly linked to one topic but in the news served as proxies for another. For example, the Afghan detainees file and the Omar Khadr trial scored exclusively for Defense but in the news and in Parliament, opposition focus more often was about general government transparency. Another example was the federal government's maternal health initiative, classified as Foreign (and the dummy, foreign aid) but in the news became a proxy for the abortion debate, or at least an attempt by some to paint the Prime Minister as anti-abortion. These examples all feed into a larger narrative of "Stephen Harper as secretive," which has been present at least since he was accused of a "hidden agenda" during the 2004 federal election. Ultimately it was deemed 
imprudent to force topic associations where they were not explicitly made, even if our largely anti-Conservative sample may have been doing so implicitly.

As mentioned, to detail our scoring system we have maintained a meta-tagging system. Initially over 150 dummy variables were created to capture various issues, event, and themes. These were distilled to 44 tags. By merging similar tags and eliminating tags that only appeared in stage 1 or stage 2 top-of-mind fields. Four sets of these 44 tags were created, capturing tag hits for all P1, P2, P6 and P9 replies. These were improper dummy variables as, first, each particular reply can hit more than one tag (e.g. "Losing the base in the UAE" is tagged Foreign Affairs - Mid-East and National Defense), and second, the tags correspond to up to 23 distinct replies (e.g. all P6 chronicle replies). To control for the latter, all tags are coded 0 or 1 ; no such hits for this question or at least one hit. While most tags were topic-oriented some were more abstract. Most notable was Proper_drop that counted instances of mentioning proper names (mostly politicians, and some other notables).

As mentioned in our hypotheses, a set of narrative dummies were also coded for causal chronicles in the replies dataset. The minimum for a narrative was that it draw together at least one reply from two respondents for the same question. Figure 1.5.2 (next page) shows examples of narratives comprised of causal chronicles from question P6.1. Each reply case was assigned a dummy value to designate which demographic group the chronicle referred to (e.g. P6.1 replies are tagged "All Canadians," P6.2 replies are tagged "University graduates"). Using these demographic dummies it could then be tested whether respondents collectively imposed particular narratives upon particular segments of the population. 


\section{Figure 1.5.2: Examples of narrative construction using the replies dataset}

\begin{tabular}{|c|c|c|}
\hline Narrative nickname & Resp. & Contributing causal chronicle (P6.1) \\
\hline \multirow{4}{*}{ anada relatively better } & 11 & [Congressowman] Giffords shooting [in USA] increased confidence in laws + policies \\
\hline & 16 & One of the best post-recession economies in the G-8 \\
\hline & 22 & Canada wasn't that impacted by WikiLeaks \\
\hline & 25 & international chaos \\
\hline \multirow[t]{2}{*}{ Scandals fading } & 1 & The shock of the HST has passed/HST cheques \\
\hline & 23 & scandals fading from public memory (ex. prorogation) \\
\hline \multirow[t]{4}{*}{ Eyes elsewhere } & 11 & Political news shifted to provincial level - premiers resigning, elections in Fall 2011 \\
\hline & 11 & Shift in focus to international issues such as Egypt + Tunisia \\
\hline & 16 & Resignation of unpopular premiers; Gordon Campbell, Ed Stelmach \\
\hline & 25 & Winter break - therefor, no news \\
\hline \multirow[t]{4}{*}{ Big Blue Machine } & 1 & 5th year anniversary of the Conservative Party in power, ads promoting the party appear of \\
\hline & 22 & Harper is making efforts to become more personable (piano playing, interview, etc.) \\
\hline & 25 & successful by-elections [ for Conservatives] $>>$ lots of campaigning \\
\hline & 27 & Harper's increased public profile (played in a band-setting at Conservative gathering) \\
\hline
\end{tabular}


Taken as a whole, we have three systems for coding top-of-mind fields. Figure 1.5.3 (next page) shows how a sample of issues and events provided by respondent 13 are coded. The meta-tag and narrative variables included are limited to those which this respondent "hit." 
Figure 1.5.3: Coding case study for Respondent 13 (control subjet, Liberal, male)

\begin{tabular}{|c|c|c|c|c|c|c|c|c|c|c|c|c|c|c|c|c|c|c|c|c|c|c|c|}
\hline \multirow[b]{2}{*}{ Question/Replies } & \multicolumn{5}{|c|}{ Relative Topic Score } & \multicolumn{14}{|c|}{ Meta-tag Dummy Hits } & \multicolumn{4}{|c|}{$\begin{array}{c}\text { Narrative } \\
\text { Dummy Hits }\end{array}$} \\
\hline & $\begin{array}{r}.0 \\
\text { : } \\
\vdots \\
0 \\
\end{array}$ & 岂 & $\begin{array}{r}5 \\
.00 \\
5 \\
0 \\
\end{array}$ & 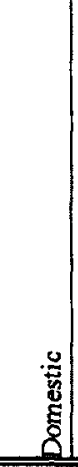 & |: & 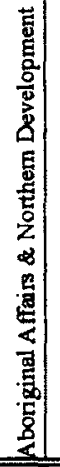 & 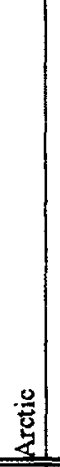 & 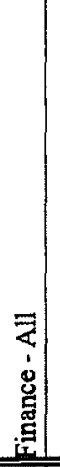 & 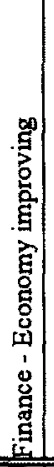 & 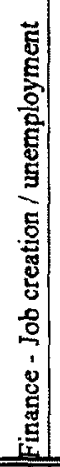 & 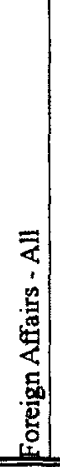 & 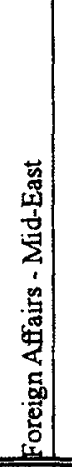 & $\begin{array}{l}\text { 号 } \\
\text { 空 } \\
0 \\
0 \\
0 \\
0 \\
0\end{array}$ & 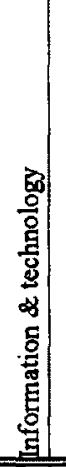 & 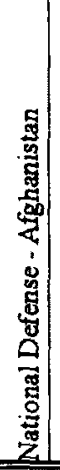 & 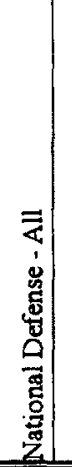 & 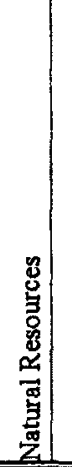 & 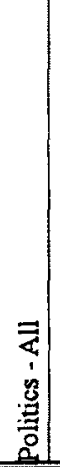 & 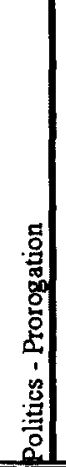 & 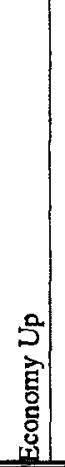 & $\begin{array}{l} \\
5 \\
0 \\
0 \\
0 \\
0 \\
0\end{array}$ & 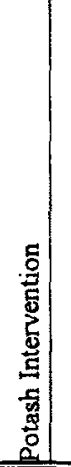 & 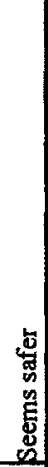 \\
\hline \multicolumn{24}{|l|}{ Pt: Top events 2010 Canadian Polltics } \\
\hline Prorogation & & $\overline{0}$ & $-\frac{1}{0}$ & $-\infty$ & -7 & 0 & 0 & 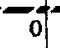 & of & of & 0 & 0 & 0 & 0 & of & 0 & 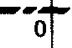 & 1 & 1 & & & & \\
\hline Long Form Census & 0 & 0 & 0 & 1 & 0 & 0 & 0 & 0 & 0 & 0 & 0 & 0 & 0 & 1 & 0 & 0 & 0 & 0 & 0 & & & & \\
\hline G-20 Spending & 0.33 & 0 & 0.33 & 0.33 & 0 & 0 & 0 & 0 & 0 & 0 & 0 & 0 & 1 & 0 & 0 & 0 & 0) & 0) & 0 & & & & \\
\hline Losing the base in UAE & 0 & 0.50 & 0.50 & 0 & 0 & 0 & 0 & 0 & 0 & o) & 1 & 1 & 0 & 0 & 0 & 1 & 0 & of & 0 & & & & \\
\hline Hel ena Guergis debacle & 0 & 0 & 0 & 0 & 1 & 0 & 0 & 0 & 0 & 0 & 0 & 0 & 0 & 0 & 0 & 0 & 0 & 1 & 0 & & & & \\
\hline P2: Issues for 2011 federal govt focus & 0.40 & 0.10 & 0.20 & 0.10 & 0.20 & 1 & 1 & 1 & 1 & 1 & 0 & 0) & 0 & 0 & a] & 1 & 1 & 1 & 0 & & & & \\
\hline Deficit & -1 & $-\frac{\pi}{0}$ & $-\frac{-1}{0}$ & -0 & $-\frac{1}{0}$ & 0 & 0 & it & of & of & 0 & 0 & 0 & 0 & 0 & 0 & 0 & 0 & 0 & & & & \\
\hline Economic Growth / unemployment & 1 & 0 & 0 & 0 & 0 & 0 & 0 & 1) & 1 & 1 & 0 & 0 & 0 & 0 & 0 & 0 & 0 & 0 & 0 & & & & \\
\hline House of Commons seat redistribution & 0 & 0 & 0 & 0 & 1 & 0 & 0 & 0 & 0 & 0 & 0 & 0 & 0 & 0 & 0 & 0 & 0 & 1 & 0 & & & & \\
\hline Arctic Defense / sovereignty & 0 & 0.5 & 0.5 & 0 & 0 & 1 & 1 & 0 & 0 & 0 & 0 & 0 & 0 & 0 & 0 & 1 & 0 & 0 & 0 & & & & \\
\hline Keeping control of Canadians natural resources & 0 & 0 & 0.5 & 0.5 & 0 & 0 & 0 & 0 & of & 0 & 0 & of & 0 & 0 & 0 & 0 & 1 & 0 & 0 & & & & \\
\hline P9.1: Causal Chronicle for 'All optimistic' & 0.63 & 0.25 & 0.13 & 0.00 & 0.00 & - & 0 & 1 & 1 & 1 & $\mathbf{0}$ & (0) & (0) & 0 & - & 1 & 1 & (1) & 0 & 1 & 1 & 1 & 1 \\
\hline Job numbers improving & i & 0 & -0 & -0 & 0 & of & 0 & 1 & of & if & 0 & $\overrightarrow{0}$ & 0 & 0 & of & if & 0 & 0 & 0 & 0 & 1) & of & 8 \\
\hline Economic growth rebounding & 1 & 0 & 0 & 0 & 0 & 0 & 0 & 1 & 1 & 0 & 0 & 0 & 0 & 0 & 0 & 0 & 0 & 0 & 0 & 1 & of & of & 0 \\
\hline Denial of sale of Potash Corp & 0.5 & 0 & 0.5 & 0 & 0 & 0 & 0 & 0 & 0 & 0 & 0 & 0 & 0 & 0 & 0 & 0 & 1 & 0 & 0 & 0 & 0 & 1 & 0 \\
\hline Calm in Afghanistan & 0 & 1 & 0 & 0 & 0 & 0 & 0 & 0 & 0 & 0 & 0 & 0 & 0 & 0 & 0 & 1 & 0 & 0 & 0 & 0 & 0 & 0 & 1 \\
\hline
\end{tabular}




\subsection{Stage 1 analysis overview}

In subsequent sections we present our stage 1 demographic and political opinion variables, summarize our samples by them and use top-of-mind fields to determine topic saliency for respondents.

First (2.1), we present our stage 1 participants in terms of demographic and opinion variables. Using measures of central tendency we identify basic patterns in variables in order to set the guidelines for stage 2 analyses (e.g. In order to test $\mathrm{H} 2$, regarding cognitive dissonance, we need to know if do government-party voters indeed express greater confidence in the federal government than opposition-party voters).

Second (2.2), we check these patterns by looking for correlations between demographic and opinion variables. The associations found here are cited in stage 2 analysis and help to explain variable-to-topic correlations (particularly sections 3.4 through 3.7).

Third (2.3), we report on the most commonly cited top events (P1) and top issues (P2), and translate all P1 and P2 replies into topic scores. Using the meta-tag system, topic scores are dissected in order to demonstrate how nuanced issues create associations between topics.

Fourth (2.4), we look for correlations between the variables discussed in section 2.1 and topic scores. This leads to identification of particular topic saliencies with particular demographics and opinions. 


\subsection{Summary of sample by demographic and opinion variables}

The precise wording and presentation of the questions which generated these variables is available in Appendix 4.

The total sample was disproportionately female ( 17 women to 9 men), but representative considering the population from which we drew ${ }^{1}$. Age ranged from 19 to 24. The median and mode ages were 20 and the mean age was 20.62 .22 of 26 respondents were undergraduate students $\left(2^{\text {nd }}\right.$ year standing or higher: seven in $2^{\text {nd }}$ year, nine in $3^{\text {rd }}$ year, and six in $4^{\text {th }}$ year), while only three were at the graduate level. One respondent did not provide their academic standing.

\section{Knowledge}

Overall, this group considered itself above-average regarding knowledge of Canadian politics. Political knowledge was measured using two seven-point scales; versus people 'your age' (know v. age) and versus all adult Canadians (know v. all). 1, 4, and 7 were defined as "I know a lot less", "I know about the same", and "I know a lot more," respectively. For both measures at least $75 \%$ of respondents considered them as, if not more, knowledgeable than everyone else. For know v. age, the mean was 5.15 and the median and mode were both 6 . For know v. all, the mean reduced slightly to 4.69 , the median and mode to 5, and, compared to $v$. age, the replies were more varied. As all the respondents were in a tight age bracket, they either considered themselves more

\footnotetext{
${ }^{1}$ For the 2010/2011 school year, there were 234 females and 91 males enrolled in the School of Journalism and Communication in either second, third, or fourth year undergraduate, or graduate studies (Department figures).
} 
knowledgeable than each other (echoing Boon and Meurs), or perhaps as journalism and communications students, or as post-secondary students in general, more in-tune than their peers or generation. It is also possible that with knowledge comes interest and thus the experiment merely attracted such respondents from a more 'average' population.

\section{$\underline{\text { Values }}$}

In place of a left-right self-positioning scale, respondents were asked whether they felt that their values were more traditional or progressive relative to people their age and all adult Canadians. This seven-point scale defined its poles, 1 and 7, as "a lot more traditional" and "a lot more progressive," respectively. The mid-point 4 was defined "I consider my values average." In hind-sight this was an insufficient substitution.

Values were not defined. Are we asking for religious or cultural values, or political values; for a position on rights for transgendered persons, or on a living wage? While within the context of a Canadian politics survey respondents may expect to bring in all the typical considerations of a survey (e.g. more or less government; tax cuts or social services) and auto-associate traditional and progressive with right and left we cannot assume this question was interpreted uniformly. While left-wing is usually equated with being progressive and 'pro-change,' it may be argued that, especially in regards to entitlement programs, left-wingers are conservative relative to right-wingers as left-wingers wish to maintain welfare programs as is, only changing how much revenue they receive (more), while right-wingers are more receptive to reform and change. 


\section{Problems with using relative measures}

While most questionnaire weaknesses are assessed in a concluding section (4.1), it is necessary to address issues with our relative measures for knowledge and values here as they are routinely cited and new variables were computed using their values. To better test against Boon and Meurs findings, knowledge or values 'relative to people your age' may have been replaced with 'relative to other students.' This would create a more intimate relativity measure, while the 'all adults' measure captures relative knowledge more generally. Moreover, this entire style of measure has a problem. By asking for relative knowledge, participants may be influenced by their ego, considering themselves either above- or below-average. A different measure, such as that used in the stage 2 prepoll questionnaires (e.g. "how attentively do you follow Canadian politics"), may have been better at capturing a 'truer' level of knowledge. However even this may blur the distinction between interest and knowledge.

Why not combine knowledge and value variables to create two 14-point measures? One objection is redundancy, as all adult Canadians include people your age (although considering our sample is entirely under 24 years old, respondents may have excluded themselves from adults). On the other hand it may be these variables measure discrete concepts (relation to one's peers versus all Canadians). 14-point variables were created and tested, and generally correlated with other variables as did their respective 7point components. The most particular fault of the combined scale, and why it is not employed routinely in this report, is that component $v$. age and $v$. all variables are not consistently relative. A high variance for the difference between $v$. age and $v$. all measures (for the same aspect) would suggest a variance in how respondents consider 
Canadians, their generation, and themselves relative to one another. For example,

Respondent 6 considered their knowledge above-average for their age (6) but on par with all adults (4), while Respondents 5 and 26 both considered their knowledge slightly below-average for their age (3) and also on par with all adults (4). This demonstrates a gulf in perceptions of the generational difference.

Table 2.1.1: Generation gaps generated by $v$. age and $v$. all measures

\begin{tabular}{|c|c|c|c|c|c|}
\hline $\begin{array}{l}\text { Perceived } \\
\text { generational } \\
\text { knowledge gap }\end{array}$ & $\begin{array}{l}\text { know v. all - } \\
\text { know v. age } \\
(\mathrm{N}=26)\end{array}$ & $\begin{array}{l}\text { Only Stage 2 } \\
\text { Participants } \\
(\mathrm{N}=10) \\
\end{array}$ & \begin{tabular}{|l|} 
Perceived \\
generational \\
values gap \\
\end{tabular} & $\begin{array}{l}\text { values } v . \text { all } \\
\text { - values v. } \\
\text { age }(\mathrm{N}=26)\end{array}$ & $\begin{array}{l}\text { Only Stage } 2 \\
\text { Participants } \\
(\mathrm{N}=10)\end{array}$ \\
\hline $\begin{array}{l}-2 \text { versus all } \\
\text { adults }\end{array}$ & 2 & 1 & & & \\
\hline $\begin{array}{l}-1 \text { versus all } \\
\text { adults }\end{array}$ & 10 & 5 & & & \\
\hline $\begin{array}{l}\text { Generation \& } \\
\text { all on par }\end{array}$ & 12 & $\overline{4}$ & $\begin{array}{l}\text { Generation \& } \\
\text { all on par }\end{array}$ & 11 & 4 \\
\hline $\begin{array}{l}+1 \text { versus all } \\
\text { adults }\end{array}$ & 2 & 0 & $\begin{array}{l}+1 \text { versus all } \\
\text { adults }\end{array}$ & 15 & 6 \\
\hline
\end{tabular}

To explore this issue, 'generation gap' variables were computed for both knowledge (know gap) and values (value gap) by subtracting v. age measures from their respective $v$. all measures. Overall, differences like the cases above are rare. Looking at Table 2.1.1, we see 12 respondents did not differentiate their knowledge relative to their age versus adults, however just as many respondents gave replies suggesting all adults (presumably a group dominated by people over 25) generally know more about Canadian politics than their own generation. Only two respondents, the aforementioned Respondents 5 and 26, invert generational perceptions. For values variables the situation is simpler. A majority of respondents' replies suggest a belief their generation is more progressive than all adults while the remainder do not distinguish their generations so. The generation gap variables do not significantly associate $(P=.321$, sig $=.110)$, so this 
suggests only weakly the sample may be divided by those perceiving and not perceiving a generational gap in both political knowledge and values. However, when we compare this for only our 10 stage 2 participants, the correlation becomes significant at the .1 level and inverts direction $(P=-.574, \mathrm{sig}=.083)$. Moreover, of the six who considered themselves less knowledgeable $v$. all, five considered themselves more progressive $v$. all, and of the remaining four who considered themselves as knowledgeable $v$. all, only one considered herself more progressive $v$. all. Thus for the replies dataset, which is employed only to explore stage 2 respondents' replies, combined scales are utilized for simplicity's sake. The combined scale is also referred to in some respondents dataset analysis, but only to casually refer to a subgroup of the sample (e.g. the three most traditional respondents). Know gap had a weak positive correlation $(.351, .078)$ with know v. all, and values gap has a similarly weak positive correlation $(.366, .066)$ with values $v$. all. This suggests that more knowledgeable respondents distinguish themselves less from all adult Canadians (regarding knowledge), and that more progressive respondents consider their generation as a whole more progressive. Neither gap variable had a significant association with respondent age dispelling notions there may be a generation gap within the sample itself. While a twenty-four year old graduate student might commonly think themselves older than a nineteen year-old undergraduate, considering a lack of correlation between gaps and age, it will be assumed in this investigation that these two persons would consider each other "people your age." 


\section{Confidence in country \& crown}

Respondents were asked, all things considered, if they felt Canada and the federal government were headed in the right direction. These were measured using seven-point scales from 1 , strongly disagree, to 7 , strongly agree, with a midpoint 4 defined as neutral. As is often captured in polls, confidence in the country usually ranks higher than confidence in government.

Confidence in country (Canada confidence) stuck largely around a neutral median of four, with a median of 3.96 and an inter-quartile range between 3 and 5 . Confidence in government (Crown confidence) was about a point lower, with a median/mode of 3 , a mean of 3.04 , and an inter-quartile range between 2 and 4 . On the whole this sample was not especially optimistic, though variance for confidence in government did have a variance just above 2 .

\section{Party choice}

Participants were asked "If a federal election were held tomorrow, what party would you vote for?" All major parties with seats in the House of Commons, as well as the Green Party of Canada, were listed, and options were given for other choices (including a space to write the party of choice), as well as a combined 'Don't Know/Refuse to Answer' ${ }^{2}$ option and a 'Would not vote' option. The results appear in the table below. While no participant stage 2 participants changed their vote choice from their stage 1 reply, the sample ultimately slanted Liberal, with 'dropping out' most common among likely Conservative voters and those who were unsure or refused to provide an answer.

\footnotetext{
${ }^{2}$ See the Questionnaire weaknesses section for problematizing of this combined option.
} 
Table 2.1.2: Frequency of party support for stage 1 and stage 2 respondents

\begin{tabular}{|l|c|c|}
\hline Likely vote & Stage 1 frequency & Stage 2 frequency \\
\hline Conservative Party of Canada & 6 & 1 \\
\hline Liberal Party of Canada & 8 & 5 \\
\hline New Democratic Party & 5 & 2 \\
\hline Green Party of Canada & 1 & 1 \\
\hline Pirate Party & 1 & 1 \\
\hline Don't Know/ Refuse to Answer & 5 & 0 \\
\hline
\end{tabular}

Party choice \& confidence in 'Canada' and 'Crown'

It was hypothesized as intuitive that, the Conservatives forming government at the time of the research, that likely Conservative voters (from here on we drop the word 'likely') would express higher Canada and Crown confidence, while those supporting the major opposition or 'coalition' parties would express the opposite. However our findings did not support such assumptions.

Comparing Conservative voters ( $\mathrm{n}=6$ ) and 'Coalition' voters (Liberal, NDP, or Green) ( $n=14)$, the opposition parties were slightly more optimistic about Canada's direction. The Tory-voters had a 'neutral' mean, median, and mode of 4 , while the Coalition voters had a mean of 4.14 , a split median of 4.5 , and a mode of 5 . Notably the former group was not as neutral as it appears as replies ranged from 1 to 7. For Crown confidence, vote choice was more intuitive: Tory voters averaged 4.17 , and their median was 4 and mode 3; Coalition voters averaged 2.93, and their median 3 and mode 1. For values, Conservatives had a v. age mean of 3.5 and a $v$. all mean of 4 , while the 'more left' party supporters had a $v$. age mean of 4.64 and a $v$. all mean of 5.21. Thus while the values and crown confidence measures did work as expected, the results for Canada confidence were against the grain suggesting a belief among Conservative participants that the country is going the wrong way and the government is a doing a good job to 
reverse this. The values variances were much higher for Conservatives with 1.900 and $2.400 v$. age and all respectively, while for the 14 Coalition supporters the variances were only .555 and .951 .

\section{Electoral participation}

As a measure of political participation, and as there had been a municipal election in Ottawa the autumn preceding this experiment (as well as elections in other major cities), respondents were asked if they voted municipally in the fall. As all Carleton students are (presumably) living in Ottawa for at least the duration of the school year, all respondents may have voted in the 2010 Ottawa municipal election. By combining Ottawa votes and 'elsewhere' votes, a dummy variable measuring participation was constructed. 10 voted in Ottawa, three voted elsewhere, and 13 did not vote, resulting in a ' $50 \%$ turnout rate' among all participants. Given the following options, two non-voters cited "extenuating circumstances," none cited ineligibility due to age or citizenship, and the remaining 11 cited "other reasons."

\section{$\underline{\text { Poll's worth }}$}

Respondents were asked how important they considered opinion polls as a tool to keep government behaving democratically. The seven-point scale ranged from 'not at all vital' to 'extremely vital,' with the mid-point defined as 'relatively vital.' The median and mode were 4 and the mean was 4.54 . . This poll's worth measure was included with the presumption higher values would positively correlate with chronicle confidence. 


\section{$\underline{\text { Sources }}$}

Respondents were asked to cite their top three sources for Canadian political news and specify the medium where appropriate. Participants' most cited sources for political news were online with 21/26 citing at least one specific website. (One website source was just 'CBC News.' This was coded 'online' for two reasons: the most common mention of $\mathrm{CBC}$ was its online iteration and the $\mathrm{CBC}$ 's news homepage is cbc.ca/news.). Five respondents mentioned aggregators, some sort of computer application which provides them with multiple online sources (this includes one person who cited "Internet in general"), and with this $22 / 26$ rely on the web overall. The next common sources were print with 15/26 mentioning at least one print source (including 2 mentions of a traditional print source (e.g. The Globe \& Mail) without specifying its medium (online or print)). 11 respondents cited at least one personal source, mainly being friends, family, or professors (one respondent actually cited Members of Parliament they interview for assignments). Finishing the pack were 10 who cited radio and 10 who cited TV.

To measure sources as statistics, six source variables were created: personal, print, website, aggregator, radio, and TV. The lowest possible value for any of these variables was zero (no such citation). Ideally the highest possible value for any one of these variables should be 3 , which would indicate a heavy reliance on one medium and zero reliance on other media. However seven respondents 'broke the rules' by mentioning multiple sources in the same line (e.g. Respondent 23 cited " $\mathrm{CBC}$ (website and TV)" as "one" of their top three). Thus it is possible for a respondent to have values of 2 for, say, both print and online. The most extreme case was Respondent 15 who ultimately cited one print source, two websites, two radio stations, and two television 
stations. As the question asked respondents to list their top three sources in no particular order it would be unwise to truncate responses to only the first three in sequence. Thus statistical findings regarding sources should be considered somewhat loose in their parameters unlike the issue and event variables which stick between 0 and 5 or 0 and 3 replies depending on the question.

To address this, a test variable, rulebreaker, was given the value of the number of total sources above 3. Because this respondent error primarily involved multiple formats of a proper news source (e.g. Respondent 15 cited "BBC (online/radio/tv)), this variable's positive correlations with website, radio, and $T V\left(.492^{*}, .624^{* *}\right.$, and .381 , respectively) are not surprising. Rulebreaker did not have a consistent and significant association with other variables or topic score. Thus it is not discussed in further analysis. 


\subsection{Correlations between demographic and opinion variables}

For ease of reporting, this section is organized first by basic demographic variables, and all their significant associations, then by knowledge, then party choice and values, then Canada and Crown confidence, then by sources. Reported figures are Pearson's correlations, and unless otherwise noted, are all significant at the 0.1 alpha level. Single asterisks denote significance at the 0.05 level and double asterisks denote significance at the 0.01 level.

\section{Basic demographics}

As expected, age and academic standing had a strong association $\left(.800^{* *}\right.$, sig $=.000$ ) which suggests these two may be used largely interchangeably. Age will be referenced by default and academic standing only discussed when distinct from age. Thus, both had very similar modest positive correlation with values (e.g. .443*v. age for age, $.498 * v$. age for academic standing). The two were however distinct in regard to sources, with older respondents eschewing print $(-.363$, sig $=.068)$ and preferring aggregators $(.333, \mathrm{sig}=.097)$, and higher academic standing associating with radio $\left(.417^{*}, \mathrm{sig}=.038\right)$.

Gender (or being female) had a modest positive association with Canada confidence $\left(.418^{*}\right.$, sig $\left.=.033\right)$ but no significant relation with Crown confidence. Females were also somewhat more likely to prefer the NDP $(.355$, sig $=.075)$ but no more likely to not vote for another party. 


\section{Checking related measures}

Relative $v$. age and $v$. all measures correlated positively and strongly, for both knowledge $\left(.873^{* *}\right.$, sig $\left.=.000\right)$ and values $\left(.925^{* *}\right.$, sig $\left.=.000\right)$, as was anticipated. So did Canada confidence correlate with Crown confidence, but to a lesser extent (.685**, sig $=.000$ ).

\section{Knowledge}

Knowledge correlated positively with voting Liberal (e.g. v. age $.394^{*}$, sig=.047) and negatively with voting NDP (e.g. v. age, $-.461^{*}$, sig=.018), but did not correlate in a significant way with voting Conservative. While this occurred, knowledge did not associate with values. Know $v$. age, and not $v$. all, had a weak association with providing a DK/refuse to answer reply for vote choice (.356, sig=.074). Higher knowledge weakly repelled personal sources (e.g. $v$. age -.369 , sig=.063) but was not significantly related to other sources.

\section{Values}

The inverse of knowledge perhaps, values did not correlate with either 'progressive' party but did correlate negatively, and with modest-to-strong strength, with voting Conservative (e.g. -.504** v. age,.$- .467^{* *} v$. all, both at the .009 significance level). More progressive respondents were somewhat more likely to reply $\mathrm{DK} /$ refuse to answer for vote choice but only for $v$, all $(.378, \mathrm{sig}=.074)$. Related, more traditional values lined up with support for the direction of the federal government, though rather 
weakly $(-.331 v$. age, $-.342 v$. all). Otherwise, the only association for values was a weak preference for $T V$ (v. age .331 , sig $=.098$ ).

\section{Other Party Associations}

The only other Party associations were both 'turn-offs:' Liberals were less likely to rely on personal sources $\left(-.393^{*}\right.$, sig=.047), and Dippers were less likely to rely on websites $(-.348$, sig=.081).

\section{Other Sources Associations}

Sources were largely unassociated with one another, but some repelling was observed. Phrased one way, subjects reliant on personal sources for political news were much less likely to rely on websites $\left(-.591^{* *}\right.$, sig=.001) and a little less likely to rely on radio $(-.366, \mathrm{sig}=.066)$. Personal also had a modest positive association with values gap $\left(.420^{*}, \mathrm{sig}=.033\right)$. This is interesting considering the mix of elders (e.g. "my grandmother," "father," "my professor") and contemporaries (e.g. "friends", "other journalism students") among persons cited. 


\subsection{Top events and pet issues; common responses and patterns}

The response rate for our two stage 1 top-of-mind captures was quite good. For top events (P1) the mean was 3.38 but was largely the result of one respondent providing no replies and another providing only one (The mode for top events was five). For pet issues (P2) the mean was 4.38. Comparing stage 1 only and stage 2 participants, there does not appear to be great difference in the number of top-of-mind field replies provided. Stage 1 only participants provided on average 4.56 top events and 4.13 pet issues, while stage 2 participants provided on 4.5 and 4.8 replies respectively.

Figure 2.3.1: Relative frequency of search engine queries (from Canada) for top five events

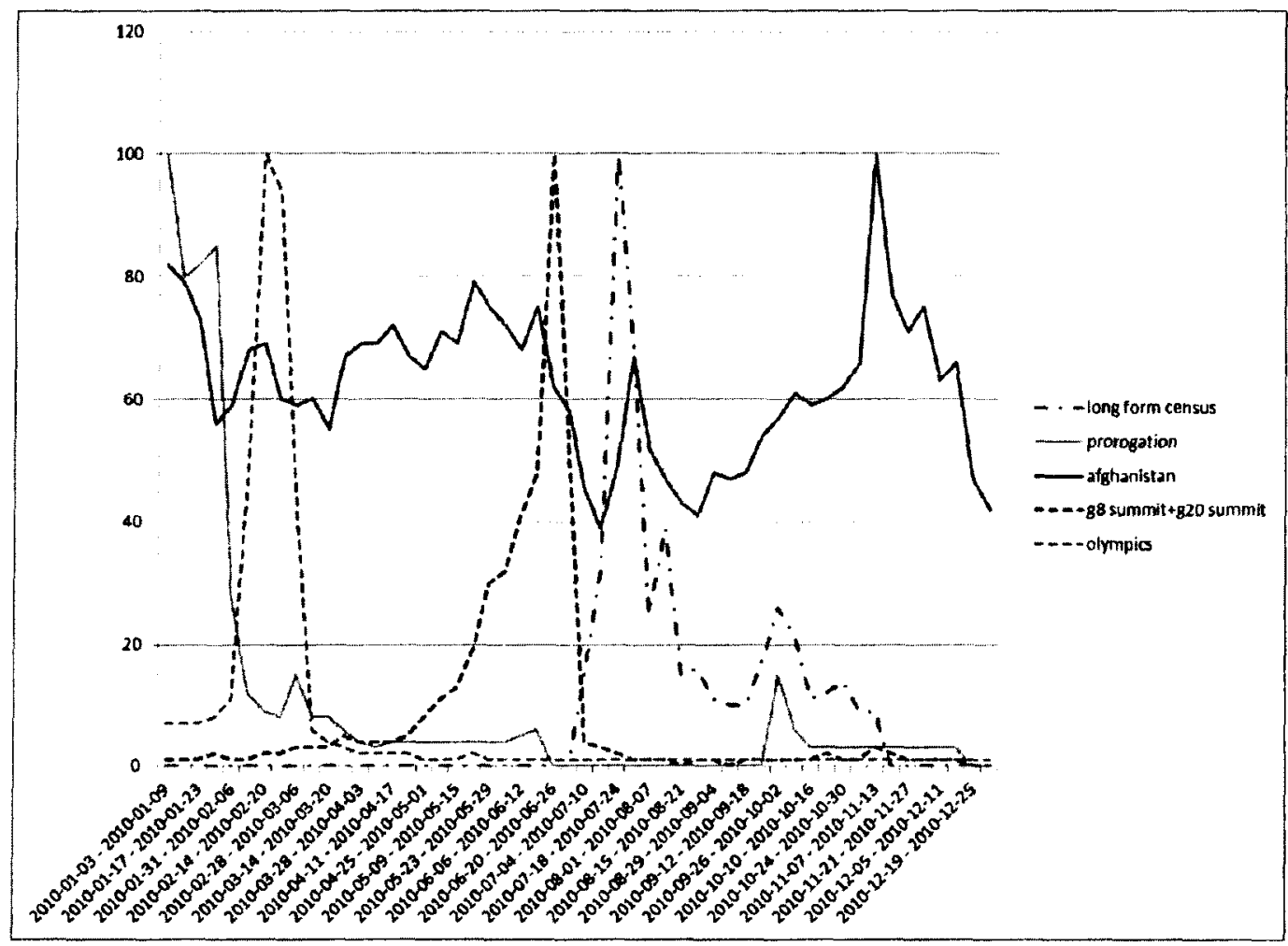


The five most common P1 replies were the G8 and/or G20 summits (15/26 respondents), the Prorogation of Parliament (13/26), the 2010 Winter Olympics in Vancouver (10/26), the extension of Canada's mission in Afghanistan (9/26), and the federal government's decision to make the Long Form Census voluntary (8/26). A special top five events variable was created to see how respondents' replies compared and related to variables such as voting intention and other opinion variables. The mean for top five events was 2.11 and this variable will be later discussed in relation to other variables where significant. Figure 2.3.1 is in the spirit of Scharkow and Vogelgesang's (2011) use of search engine queries to determine the relationship between salience and time. The lines are relative to only themselves, such that a peak for any particular key word is relative its lowest search frequency. This figure appears to demonstrate that the commonest events were distributed throughout 2010 and not, as feared, clumped towards the end of the year, nearer to stage 1 data collection in January 2011.

Over three dozen other events were cited, those more common being the change in Governor General, the vote to end the Long-Gun Registry, the ongoing debate regarding the treatment of 'Afghan detainees,' and the mayoralty elections in Toronto and Calgary. A few qualifying comments should be made regarding our top five events. Our top event was a bit of a combination as some respondents only cited one of the two summits. The prorogation of Parliament was a bit of a strange but anticipated mention: the prorogation technically began in the dying days of December 2009, but remained in the news throughout early 2010. The extension of Canada's role in Afghanistan seemed to be understood by respondents in different ways, some referring to a 'troop pull-out' or 'withdrawal date' being set, and others referring to an extension of the combat mission. It 
is not this student researcher's aim to uncover exactly what Canada's role in Afghanistan was laid out to be and these answers were both included under the event meta-tag Afghan extension.

The five most common P2 replies were harder to clump, but were essentially as follows: economic growth and stability (16/26 respondents), environment and climate change (14/26), Afghanistan (11/26), health (10/26), and foreign aid (7/26). Due to the variety of specific issues within each of these five groupings a top five issues was constructed but should be considered less useful. Economic growth and stability was the broadest category, with nine respondents referring specifically to "the economy," four respondents citing deficits and debt, and three referring to job creation and unemployment. More than two dozen other general issues were cited, those more common including development and support for Aboriginal and Arctic communities, post-secondary school tuition, government transparency, law \& order issues, and immigration.

\section{Table 2.3.1: Top events for an average respondent}

\begin{tabular}{|l|l|}
\hline Top event (P1) reply & Topic hits $^{*}$ \\
\hline Prorogation (top 5 event) & Political \\
\hline Long Form Census (top 5 event) & Domestic \\
\hline G-20 Spending (top 5 event) & Economic, Foreign \& Domestic \\
\hline Losing the base in UAE & Defense \& Foreign \\
\hline Helena Guergis Debacle & Political \\
\hline
\end{tabular}

*Respondent 13's P1 scores: eco $=.067 ;$ def $=.1$; for $=.167 ;$ dom $=.267 ;$ pol $=.400$.

The mean topic scores for top events were as follows: Economic $=.072$;

Defense $=.162 ;$ Foreign $=.1865 ;$ Domestic $=.251 ;$ and; Political $=.291$. The standard deviation was highest for Political events (.234), considerably above the deviations for the other four topic areas (from .121 for Economic to .170 for Foreign). However, considering the scores range from $0 \rightarrow 1$, and the thus relatively high standard deviations, 
no one subject came exceptionally close to the mean. The 'most average' respondent was respondent 13, a stage 2 control subject and Liberal voter, as displayed in Table 2.3.1.

\section{Table 2.3.2: Top issues for an 'average' respondent}

\begin{tabular}{|l|l|}
\hline Top issue (P2) reply & Topic hits* \\
\hline Pension reform & Economic \& Domestic \\
\hline Daycare & Domestic \\
\hline Mental health issues & Domestic \\
\hline Afghanistan & Defense \\
\hline Foreign aid & Foreign \\
\hline
\end{tabular}

${ }^{*}$ Respondent 25's P2 scores: eco $=.100 ;$ def $=.200$; for $=.200$; domestic $=.500$; and, political $=.000$.

The mean topic scores for top issues were as follows: Economic $=.176$;

Defense $=.102 ;$ Foreign $=.107 ;$ Domestic $=.523 ;$ and, Political $=.0538$. The standard deviation again was highest for the most common topic, in this case Domestic, with a value of .276. Deviations were otherwise relatively similar, ranging from .110 for Political issues to .147 for Economic issues. Finding a 'most average' respondent for issues was more difficult. Respondent 13 leaned heavily on Economic issues (p2_eco=.400). An 'average looking' respondent might be subject 25, a stage 2 treatment subject and also a Liberal voter.

In order to test whether certain topics were more diffuse (i.e. were less likely to be the sole topic hit for an issue or event) a basic topic_overlap variable was computed. Using the Replies dataset, topic scores were added so a reply with an overlap value of 2 indicates it falls into two topic areas (e.g. G8 \& G20 summits, overlap=2 as it tags both Domestic and Foreign). Based on basic bivariate correlations the following was found:

For top events, Foreign was the most overlapping $\left(.772^{* *}\right)$ followed by Domestic $\left(.569^{* *}\right)$. This is likely due to the high frequency of the G8/G20 summits and the 2010 Olympics. Domestic was likely lower due to Long Form Census's popularity (at least 
among Liberals). Economic was less likely to overlap $\left(.274^{* *}\right)$. Defense events had no significant relation to overlap. Political events were significantly unlikely to overlap with other topics $\left(-.332^{* *}\right)$, as these events largely included elections, resignations, and the proroguing of Parliament.

For top issues overlap was less common. Foreign overlapped the most $\left(.443^{* *}\right)$, followed by Economic (.220*). Defense, Domestic, and Political had no significant amount of overlap. Common Foreign issue overlaps were immigration (which also tagged Domestic) and Arctic sovereignty (which tagged with Economic, Defense, and/or Domestic, in various instances). Additionally, Economic overlapped on some environmental issues (primarily tagged Domestic) as some respondents framed 'green' issues as economic ones (e.g. "Giving incentives to small green businesses"). 


\subsection{Top events and pet issues; correlations with demographic and opinion variables, and between issues and events}

In this section we will look chiefly for significant correlations between topic scores and various variables captured in stage 1 using the respondents dataset. This determines what, if any variables, influence personal topic salience. Where merited we will also note correlations between meta-tag dummies and variables in order to flesh out correlations. Additionally, we casually test $\mathrm{Hl}$ by seeing if topic scores for top events and pet issues tended to be the same (i.e. if a high rate of Defense events associates with a high rate of Defense pet issues).

\section{P1 (top five events of 2010) topic correlations}

Economic events were more common among Liberals (.367). Younger respondents were also more likely to cite economic events $(-.376, \mathrm{sig}=.043)$. The only significant association between values and Economic events was a very weak association with more traditional values $v$. age $(-.333$, sig=.097).

Defense events only correlated with values gap, positively albeit weakly $(.365$, $\operatorname{sig}=.067)$.

Foreign events correlated most strongly with gender, with women being more likely to cite events with an international angle $\left(.461^{*}\right.$, sig $\left.=.018\right)$. Foreign also increased with radio $\left(.393^{*}\right.$, sig $\left.=.047\right)$ and crown confidence $(.360$, sig=.071). Though not significant at the 0.1 level, there did appear to be a weak negative correlation with knowledge and Foreign (v. age -.328 , sig= $=.102 ;$ v. all -.290 , sig $=.151)$. 
Knowledge's weak repulsion from Foreign was mirrored by a weak association with Domestic events. Significant at the 0.1 level for all measures, an increase in knowledge increased Domestic events (v. age .351 , sig=.079; v. all .345 , sig=.084).

Due to the overlapping of tags, it is necessary to uncover which events are actually represented by the correlations. Two of the top five events, the G8/G20 summits and the 2010 Olympics, both tagged Domestic and Foreign. As political knowledge correlated in opposite directions for home and away, we know knowledge did not influence citations of these two big events. The Domestic event most associated with knowledge was likely the controversy surrounding the Long Form Census - an event that only made the top five thanks to Liberals, recall a high-knowledge group. Of its eight citers five were Liberals, one a Dipper and two did not provide a vote preference. It is also possible more knowledgeable respondents were able to recall more particular policy events, such as the environment minister's comments on ethical oil (Respondent 20,6/7 for know v. age and $v$, all), and the long-gun registry vote (only cited by those claiming above average knowledge). As for the relation between Foreign and gender, there did not appear to be any particular foreign events responsible for this association.

While Defense scores did not particularly correlate, mentions of the Afghan extension were more common among more knowledgeable respondents (e.g. Afghanistan dummy $\mathrm{x}$ know v. age $.412^{*}$, sig=.036).

The most cited events, Political, did not correlate with any demographic measures. However using the meta-tag system there was a link between knowledge and citing political events and figures. First, there was a weak correlation between knowledge and citing particular figures by proper name (e.g. Proper_drop dummy $\mathrm{x}$ know v. age 
.367 , sig=.065). Second, know. v age had a modest association with citing prorogation (.416*, sig=.034), though this was not true $v$. all. This demonstrates that self-described know-it-alls did indeed show off their political knowledge.

\section{$\underline{\text { P2 (top five issues for 2011) topic correlations }}$}

To start, stage 2 participants were likelier to desire action on Economic issues than their 'drop out' colleagues, though this association was rather weak $(.338$, sig $=.092)$. Unlike events, more predictable or at least comparative patterns were observed among pet issues and various stage 1 variables, though age, gender, academic standing, and values did not correlate with any issue topic scores.

The only values-related measure to associate was values gap which had a modest negative relationship with Political, suggesting that those who do not see a distinct values gap between their generation and those older desire political reform, though on disparate fronts (e.g. constitutional renewal with First Nations, affirmative action programs for Parliament, House of Commons seat redistribution, that Mr. Harper should "stop being a dictator"). Considering the sort of issues that tagged Political it is interesting that a Charter etc. dummy associated with more traditional values (e.g. v. age -.466*, $\operatorname{sig}=.016)$.

Party preference associated in some surprising and unsurprising ways. NDP support had a strong association with Foreign issues $\left(.548^{* *}\right)$; an increase in foreign aid was a common desire. Less expected, Conservatives were particularly disinterested in Economic $\left(-.416^{*}, \mathrm{sig}=.025\right)$ and Defense issues $\left(-.412^{*}\right)$. On the other hand Liberals were particularly interested in Defense issues (.347). These Tory/Grit correlations are 
curious considering national defense and economy are regularly considered 'Conservative-owned' issues (at least by our Tory insider). Moreover, respondents who did not provide a voting intention (recall a largely progressive lot) were slightly likelier to mention Defense $(.367$, sig $=.065)$. This is explained largely by most Defense issues being related to Afghanistan and, moreover, of a prescriptive nature. Four out of five 'undeclared' respondents called for troop withdrawal or better defining Canada's role in the conflict, and three Liberals and a Dipper made similar comments.

Political knowledge strongly associated with Economic issues, particularly so $v$. age $\left(.563^{* *}, \mathrm{sig}=.003\right)$. This was somewhat the result of knowledgeable respondents wanting more focus on job creation (e.g. Jobs dummy * know v. age .358, sig=.072). As knowledge increased though, Domestic issues decreased (e.g. v. age -.365 , sig $=.067$ ). The only issue-specific trend here was a relation between lower knowledge and agriculture and food policy (e.g. Agri/food dummy * know. vage $-.434 *$, sig=.027), with disparate issues such as regulating energy drinks and supporting the local food movement.

Finally media sources played a mostly negative role for particular issue topic areas. Citing any personal sources decreased Political issues $\left(-.430^{*}\right.$, sig=.029) and Economic issues $(-.380$, sig $=.056)$. Reliance on aggregators decreased Defense issues (.352 , sig=.077) and Economic issues $(-.325$, sig=.105), but increased Political issues $(.346, \mathrm{sig}=.083)$. An increase in print reliance weakly increased Defense issues (.343, $\operatorname{sig}=.086)$. 


\section{$\underline{P 1}$ and P2 topic-to-topic correlations}

It was hypothesized that topic areas would carry over from question to question; that someone who thinks Economic events were the tops would also want focus on Economic issues. Ultimately this was not the case. There was only a very weak association for Economic $\mathrm{P} 1$ and $\mathrm{P} 2$ replies (.294, sig=.145) and in fact a weak negative association for Domestic $(-.321, \mathrm{sig}=.110)$. There were also unexpected associations between different topics. Domestic events had a strong association with Economic issues $\left(.467^{*}\right.$, sig=.016). Foreign events strongly associated with Domestic issues $\left(.473^{*}\right.$, sig=.015) and modest-to-weakly repelled Economic issues $(-.343$, sig $=.087)$. 


\subsection{Stage 2 analysis overview}

In the subsequent sections we explore how the experiment turned out and whether or not respondents' causal chronicles were informed by their stage 1 replies. The respondents dataset is used primarily unless otherwise noted.

First (3.1), we will look at how our control and treatment groups differ in terms of stage 1 and stage 2 replies by comparing means. Our control group members considered themselves more knowledgeable than treatment group members which may explain the unanticipated degree of response change post-treatment for both groups.

Second (3.2), we qualitatively analyze our respondents on an individual basis and pick out literal evidence of our three hypotheses. This includes how respondents changed their replies post-treatment and notes the chronicle confidence each respondent expressed. Generally, pet issues appeared more predictive than top events.

Third (3.3), we look for correlations between our meta-tag dummies; whether particular event or issue replies from stage 1 carried over to stage 2 . This produced some evidence supporting $\mathrm{H} 1$ too specific to be captured by looking at topic scores.

Fourth (3.4 through 3.7), we quantitatively analyze the responses for our four 'uptick' demographics (P6.1, P6.2, P6.3, and P6.7); the four populations reported to have increased confidence in the federal government. These case studies are done by, one, looking for dominant narratives using the replies dataset, and by, two, looking for correlations between topic scores and various stage 1 and stage 2 demographic and opinion variables using the respondents dataset. We focus on only the uptick groups as 
no significant narratives or correlations were found for the 'downturn' demographics (P6.4) and the 'stagnant' demographic (P6.8), and only one respondent gave a response for P6.6 (that our downturn demographics later became an uptick group based on events and not the passage of time). We also explore $\mathrm{Hl}$; how identification with demographic groups informs chronicles.

Fifth (3.8), we directly test $\mathrm{H} 1$ by looking at topic-to-topic correlations between stage 1 and stage 2 top-of-mind replies. These are then reviewed in context of other associations in section 3.11 .

Sixth (3.9), we explore $\mathrm{H} 1 \mathrm{c}$ and $\mathrm{H} 2$ by looking at the relationships between chronicle confidence, poll impression, topic scores, and key respondent attributes (knowledge and values). Using both the replies and respondents dataset we gain some understanding of how personal association or disassociation with given poll trends informed chronicle elements. As a precursor to tests in 3.10, we also examine how these relationships were affected by treatment.

Seventh (3.10), we test the effect of spin on our respondents' causal chronicles using independent $\mathrm{T}$-Tests and thus test $\mathrm{H} 2$ and $\mathrm{H} 3$. This was done by creating topic score change variables which measure the change in topic scores from pre- to posttreatment. In spite of significant reply change by control subjects we did find the treatment group to have replied in a significantly distinct manner post-treatment.

Eighth (3.11), to put these findings in perspective, we compare correlations between topics (from 3.8), and between topics and other variables (from the 3.4 to 3.7 case studies). For any particular pair of top-of-mind questions used to test H1 (e.g. P1 and P9.1) there are five opportunities for same topic correlations and 20 for different topic 
correlations. By comparing the relative number of consistent associations (both in terms of significance and direction) between same and different topics, we find support for $\mathrm{Hl}$, as the raw number of positive associations between like and unlike topics is roughly equal. 


\subsection{Stage 1 variable difference between control and treatment groups}

Our control group $(\mathrm{N}=5)$ and treatment group $(\mathrm{N}=5)$ were considerably distinct from one another in a variety of ways. While age, academic standing, and gender were roughly the same for both (though we may not assume random equivalence due to small numbers), opinions and media habits were distinct.

The control group considered itself more knowledgeable regarding Canadian politics; they placed themselves on average 1.4 points higher on a 14-pt combined knowledge scale (11.2 to 9.8). They also considered themselves less progressive (8.6 to 10.6). While equally un-reliant on personal sources (only one such person per group), the control group was much more reliant on radio sources (mean of 0.8 versus 0.2 ) while the treatment group exclusively contained TV-reliant subjects ( 0.6 versus 0 such sources). The treatment group considered polling slightly more vital for democracy (4.4 to 4). Party preference was largely consistent, impressive considering the small sample size: the control group consisted of two Liberals, one Tory, one Dipper, and one Pirate; the treatment group consisted of three Liberals, one Dipper, and one Green. Both groups contained two persons who identified with university graduates and one person who identified with those with a high school diploma or less. The sole Quebecois-identifier was in the treatment group.

In regards to the pre-poll questionnaire, there were more differences between groups. The treatment group appeared to be following Canadian politics more closely, both in the preceding month ( 5 to 4.6 ) and relative to the previous six months (4.4 to 4 ). 
The groups were roughly on par for Canada and crown confidence, despite change in these values for most respondents between stage 1 and stage 2 . When asked about the direction of the federal government in January, both groups had a crown confidence mean of 3.2. When asked the same question in February, most respondents were more optimistic and the respective means for control and treatment were 4 and 3.8. In both groups three respondents felt neutral about the poll trend (poll impression). Two control subjects felt negatively about the poll trend (despite both increasing crown confidence by one point between stage 1 and 2), and the treatment group had one such subject. The sole subject feeling positively about the polls was in the treatment group; curiously a progressive Liberal interested in the environment and social issues. Despite the changes in Canada and crown confidence there was an expectedly positive correlation between crown confidence and poll impression pre-treatment $\left(.655^{*}\right.$, sig=.040). Finally our treatment group members were considerably more confident in their narratives than the control group after giving their pre-treatment causal chronicles (3.8 to 2.2), despite being 'less knowledgeable.' Further exploration of impression and chronicle confidence is included in section 3.9 .

\section{Top events \& pet issues}

At first glance the treatment group appeared to be more 'normal' in terms of their $\mathrm{P} 1$ and $\mathrm{P} 2$ replies. The treatment group cited more top five events (2.8 to 2.2) and more top five issues (2.6 to 1.8). However, the control group contained the unresponsive Respondent 6, who gave no top events, and virtually no replies to the pre- and posttreatment poll questions. Deselecting this respondent, the two groups were actually quite 
similar (see Table 3.1.1, next page). The control group nearly caught up to the treatment group for top five events (now only behind 2.8 to 2.75), as well as for top five issues (up from 1.8 to 2.25 ). Top event topics were roughly the same, with both having very low Economic scores, and Defense and Foreign scores hovering around their respective total means. The only differences were for Domestic and Political top events, with the control group having more of the former (.2917 to .2467$)$ and less of the latter (.3000 to .3600$)$. The greater difference was for pet issues. The control group desired more action on Economic fronts (.3250 to .2150). The treatment group desired more focus on Defense issues, particularly Afghanistan (.1700 to .750$)$. Other issues were largely the same with the plurality of issues classifying as Domestic, one way or another.

Table 3.1.1: Means for topic scores, P6.1: All Canadians, compared for control and treatment subjects

\begin{tabular}{|l|l|l|l|l|l|}
\hline Group & \multicolumn{1}{|c|}{ Economic } & \multicolumn{1}{c|}{ Defense } & \multicolumn{1}{c|}{ Foreign } & \multicolumn{1}{c|}{ Domestic } & \multicolumn{1}{c|}{ Political } \\
\hline Treatment & .2900 & .1300 & .0800 & .0500 & .4500 \\
$(\mathrm{~N}=5)$ & $(.07416)$ & $(.12042)$ & $(.13038)$ & $(.11180)$ & $(.15000)$ \\
\hline Control $(\mathrm{N}=5)$ & .1550 & .0750 & .1850 & .0650 & .5200 \\
& $(.15851)$ & $(.16771)$ & $(.24723)$ & $(.09287)$ & $(.46043)$ \\
\hline Control excl. & .1937 & .0938 & .2313 & .0813 & .4000 \\
Respondent 6 & $(.15326)$ & $(.18750)$ & $(.25931)$ & $(.09869)$ & $(.43205)$ \\
$(\mathrm{N}=4)$ & & & & \\
\hline
\end{tabular}

Despite being more interested in Economic issues, our control group was less likely to initially cite Economic events to explain the overall poll trend. They appeared more interested in Foreign events. Our treatment group, as would be expected, was slightly more inclined to cite the announcement to end Canada's combat role in Afghanistan as an optimism-inspiring event. These averages however did not maintain for demographic subgroups. 
For university graduates (P6.2), our control group was about twice as likely to cite Economic events (mean of .5417 to .2667 ). Our control group also cited Domestic events while our Treatment group did not (.1667 to 0$)$. Alternately, the treatment group chiefly chose Political events to explain graduates' optimism (.4000 to .0833$)$. Foreign scores were roughly the same, comprising between a fifth and a fourth of replies. Defense was a 'non-event' for the control group and an 'also-mention' for the treatment group (.0667).

For P6.3, high school or less, the trend switched back, with our treatment group now citing more Economic events (.4667) than the control group (.2500), though it remained the plurality topic for both. Other topics ranged, without much difference, between $8 \%$ and $20 \%$ of total topic replies.

Finally for explaining what women think (P6.7), topic skews appeared much like those for P6.1. The treatment group was more inclined to choose Economic, Defense, and Political events, while the control group chose more Foreign and Political events. 


\subsection{Qualitative analysis of causal chronicles}

In this section we summarize each respondent's causal chronicle, pre- and posttreatment. Particular replies which have thematic or literal links to stage 1 replies (top events and pet issues) are cited primarily, as are post-treatment replies which link to insiders' spin scripts. Thus this is a casual investigation of all hypotheses as, for examples, we account for events and issues of personal salience being transferred to larger populations (H1), cognitive dissonance manifested in respondents citing nonpolicy or trivial events contributing to poll trends $(\mathrm{H} 2)$, and incorporation of spin posttreatment when spin is in line with a respondent's salient topics or political opinions (H3).

A few qualifications regarding chronicles must be considered. Firstly, most of our poll questions refer to opinion changes during the last three months of 2010. As such, it can be expected that at least one top event per respondent took part during this time period, all things being equal. Second, the responses given to the post-poll questions do not come from a vacuum. There are at any given time a set of events and issues that dominate the headlines, the airwaves, and the conversations of Canadians. If $\mathrm{H} 1$ is true, subjects could at best pick from a selection of 'things in the news' that they consider most important. While some subjects cited obscure policy announcements that did not attract sustained media attention, if a subject desired action on area $\mathrm{X}$, and $\mathrm{X}$ was not in the news whatsoever during our poll period, it would be highly unlikely they would say the government is headed rightly because of $\mathrm{X}$. If the polls had been different and the 
government was down, it may be possible that the subject would cite a lack of action $\mathrm{X}$ as the reason for the downturn. Post-poll question 6.4, the only one to address a downturn, was scrutinized for such occurrences. Third, it is also possible that when crafting their causal chronicles respondents suffered recall bias by thinking back to their stage 1 replies. While recruitment literature did not explicitly refer to $\mathrm{H} 1$ it may be expected that some respondents understood the nature of the experiment and actively responded as was hypothesized.

For whatever reason, our control subjects were almost as likely to change their chronicles 'post-treatment,' despite not receiving any treatment other than being told they could, if they wish, change their answers. It is possible this change was the result of the control group's self-described above-average knowledge of Canadian politics, and that after being given more time to consider the questions they were able to dig into their own personal news archives. Nevertheless, as we will see in section 3.10, treatment subjects did change their replies in a manner significantly distinct from control subjects.

For brevity's sake, we refer to the polled populations by questions numbers used in stage 2 questionnaire. To recall: P6.1/9.1: All Canadians; P6.2/9.2: Canadians who have completed a post-secondary education program; P6.3/9.3: Canadians who have not completed a post-secondary education; P6.4/9.4 and P6.6/9.6: Male Canadians and all Canadians between the ages of 25 and 44; P6.7/9.7: Female Canadians; and P6.8/9.8: Canadians residing in Quebec. 


\section{The Control Group}

Respondent 6 (Pirate Party, male) provided no top events admitting "I do not follow politics at all." His issue replies included "e-government/participatory democracy" and "intellectual property." He provided only two meaningful chronicle replies for the entire stage 2 questionnaire: the Holidays for P6.1 and, for P9.6, "CRTC [Canadian Radio-television and Telecommunications Commission] usage-based billing is opposed by public; Harper orders review." The latter reason was given in error given his reply to P6.5, but it does suggest evidence of H1. In addition to the role of 'the public' in the reply, more importantly much contemporary debate surrounding intellectual property relates to Internet piracy and thus crosscuts with communications policy (particularly Internet bandwidth usage) (Walkin_dead, 2010). It should be noted that Harper did not order this review until 1 February 2011, less than two weeks before the experiment and after all poll periods (Chase and Marlow, 2011). Chronicle confidence improved from 1 to 2 .

Respondent 11 (Liberal, female) cited the Long-form Census debate as a top event, as well as the resignations of Premiers Gordon Campbell and Danny Williams. Her issues included the "Afghan mission" and the "Economy." For P6.1, P6.3, and P6.8, she linked the poll uptick to a "[s]hift in focus to provincial politics" by the media, and did refer to resignations in 2010 and elections expected in fall 2011. The economy was cited for all groups. "War in Afghanistan" was cited for P6.4 and P6.8. For P6.7 she cited the "[p]assage of time since long-form census debacle." She carried over all her replies for her 'post-treatment' questionnaire. Chronicle confidence stagnated at 4. 
Respondent 13 (Liberal, male) called for focus on the deficit, economic growth (coupled with unemployment), and "[k]eeping control of Canadians [sic] natural resources" in stage 1 Economic improvements were cited for P6.2 and P6.7, and falling unemployment for P6.1, P6.2, P6.3, and P6.6. For P6.4 he cited a hypothetical "errant job report claiming Canada was losing jobs?" - the self-doubting question mark his own. For P6.1 he cited the "[d]enial of Potash Corp. sale to BHP Billiton," and though he did not include this among his top five events, this echoes his protectionist attitude towards resources. 'Post-treatment' all these answers remained excluding the 'errant job report' for men and those aged 25-44 (P6.4) and "jobs numbers rebounding" was added for women (P6.7); for both the maternal health initiative was added (though he called it "unpopular" for P6.4 and not P6.7). Chronicle confidence stagnated at 3.

Respondent 22 (Conservative, female) included economic sustainability, the electronic health system and water sustainability among her issues. Economic recovery was cited for all 'uptick' groups. "Environmental initiatives," though unspecified, were cited for P6.3 and P6.7. These replies remained for 'post-treatment' except environmental initiatives for P6.7 was replaced with "[c]hanging health goals to be more realistic"admittedly a stretch to connect to the electronic health system. Chronicle confidence stagnated at 1.

Respondent 27 (NDP, female) gave very specific policy recommendations for her issues, such as "[a]ddressing tax structure/work leave policy so that it is easier for working parents to spend time with their families," and focussing on "Foreign Aid Programs, especially in the Middle East." She provided few answers for section 6, and P6.3 and P6.8 were left blank. 'Post-treatment' Respondent 27 added references to 
economic and/or job recovery to most replies. She did include foreign aid ("especially in the Middle East") among her issues, and section 6 and 9 replies did include support for democracy movements in Egypt and Tunisia and the maternal health initiative, which is essentially a foreign aid program. Chronicle confidence stagnated at 2 .

\section{The Treatment Group}

Respondent 1 (NDP, female) called for "more aid to those in disasters/distress" and to "get rid of the HST." She also dedicated two of her top five events to the office of the Governor General; "M. Jean steps down" and "New G.G. Steps in." Her P6.1 reply lauded the 'new G.G.' for "giving Canada a new feel." She also credited the uptick to passage of time since the initial "shock of the HST." HST rebates were reasoned to make all Canadians, as well as those without a post-secondary education in particular (P6.3), more positive. Respondent 1 said foreign aid to countries in need (particularly Haiti) was relevant for university graduates and women. Interestingly, she identified with 'people from Quebec' (P6.11) but replied that foreign aid was one of the issues not important in Quebec. After treatment however she dropped all references to the G.G., only kept HST rebates for P6.3, and foreign aid for P6.8. Chronicle confidence improved from 3 to 4.

Respondent 16's (Liberal, female) top events included the Potash intervention, Premier Williams' resignation, and the "[d]ecision to extend Afghan mission." All three were cited, though instead of mentioning Williams she cited "unpopular premiers" in British Columbia and Alberta. The extension also appeared for P6.3, and P6.8 included Potash and the premiers. After spin, Respondent 16 included elements of both spin throughout her answers (e.g. for P6.1: "Domestic security in light of unrest in Middle 
East;" "Increased job opportunities and rehiring."). She kept all her previous 'pet' events except Potash. Chronicle confidence improved from 5 to 6.

Respondent 19 (Liberal, female) included the changing role of Canada's troops in Afghanistan in both events and issues. Issues also included "action on the need for affordable housing" and "avoiding another economic downturn." The "troop pull-out" was cited for P6.1. Action regarding affordable housing was cited for P6.1 and P6.3 with references to "low-income families" in both. References to a recovering economy were cited for all groups. After spin, all these elements remained though action on affordable housing was kept only for P6.3. Chronicle confidence stagnated at 4.

Respondent 23 (Green, male) included employment in his issues but made no explicit employment references in section 6. He did refer to a weak opposition for P6.1, P6.2, and P6.7. After spin, weak opposition was appended with notes such as "not providing attractive alternative" (P9.2) and "talking about issues associated with Conservative brand" (P9.3). He added "more grads hired/re-hired" for university graduates but made no other employment references. Confidence stagnated at 3 . In the pre-treatment section he included a note explaining a lack of confidence in his answers citing a poor "memory for time."

Respondent 25 (treatment, Liberal, male) included "fighter jet contracts" among his top events. For P6.3 he included "F-35 purchase - defense talk." His pre-treatment replies also included job gains and "international chaos," and these remained post-spin, perhaps reinforced. For P9.1 he added "discussion of defense issues of little [illegible] (F35s)," and changed his P9.3 answer to "discussion of conservative issues - 
defense/economy." A similar reply was added to P9.7. Chronicle confidence stagnated at 4.

$\underline{\text { Discussion }}$

It does appear that pet issues were incorporated into subjects' causal chronicles, but they were also willing to drop them in exchange for spin elements. A top event seems to be a less useful measure for our purposes. The most common event carryovers were the Potash intervention and the Afghan extension, but as these events both occurred during the poll period and garnered significant media attention it would be imprudent to consider this support of $\mathrm{H} 1$. There were instances of these events appearing in one place but not the other. Respondent 13 did not call the extension a top event but did include it for several groups including all Canadians. Respondent 25 did the same for Potash. It is true though that any mention of these two events did however guarantee their inclusion in, at least, pre-treatment replies. 


\subsection{Quantitative analysis using meta-tag dummies}

In this section we look for correlations between the same keyword meta-tags in stage 1 and stage 2 replies. These correlations are meant to bridge the qualitative analysis in the previous section (2.4) to the topic score analysis in subsequent sections. This is done by testing for carryover of 44 event-, issue-, and policy-specific meta-tags from stage 1 to stage 2 . Many tags only received 'hits' for P1 events or P2 issues exclusively. Event-exclusive tags included Proper drop, G.G., and various event tags such as G8/G20 and Olympics. Issue-exclusive tags included Health, AAND (Aboriginal Affairs and Northern Development), CBSA (Canada Border Services Agency), and Charter of Rights \& Etcetera (which ran the gamut from stopping animal cruelty to the Gaza blockade). Some more general topic tags bridge the gap between issues and events, such as Finance, Foreign Affairs, and Justice.

Proper_drop correlated significantly with its respective P6 tag $\left(.656^{*}\right.$, sig $\left.=.040\right)$. Overlapping somewhat with Proper drop was a G.G. tag which included by-name and by-office references to Governors General of Canada. This tag had the strongest correlation of all tags $\left(.885^{* *}\right.$, sig $\left.=.001\right)$ though this was mostly the result of Respondent 1's multiple G.G. events. A generic All politics tag also proved modestly significant $\left(.656^{*}, \mathrm{sig}=.039\right)$. This tag captured all political events. That there was no significant correlation between Political P1s and P6s using the topic score system likely occurred as this tag did not include reference to 'Holiday cheer' whiles the topic score did. This was troublesome however as some chronicle replies merged the winter recess of Parliament 
with the general Holiday season. Replies had to include explicit reference to a break in Parliament to be coded All politics. A Potash tag was the only significant event-specific tag, linking P1 and P6 with a strength of .620 (sig=.056).

The most significant issue-to-chronicle correlation was for an awkward construct called HRSDC, named for the many-purposed Human Resources and Skills Development Canada. This department and tag includes issues and policies such as skills retraining, pensions, mortgages, housing, and daycare/parental leave. $H R S D C$ issues correlated strongly with instances of $H R S D C$ causal citations $\left(.828^{* *}\right.$, sig=.003). Next most significant were Taxes $\left(.762^{*}\right.$, sig $\left.=.010\right)$ and $\operatorname{Law}\left(.667^{*}\right.$, sig=.035). Law included prostitution, gun control, prisons, sentencing, and generic references to law and order. Law was distinct from a larger Justice tag that subsumed Law, but also included high profile crimes (such as the Col. Williams murder trial) and any reference to violence at the G20 summit. References to Omar Khadr or Afghan detainees in general were coded under a variety of defense-oriented tags. Less significant were a generic Natural resources $\operatorname{tag}(.620, . \mathrm{sig}=.056)$, itself chiefly dependent on Respondent 13, and Foreign aid (excl. maternal health) $(.592$, sig $=.071)$. A maternal health tag did not prove significant due to a lack of citation in stage 1. Other common issue tags such as All things Afghanistan, and its parent tag National Defense, Environment, Justice, and a broad Foreign Affairs tag did not correlate with causal chronicles. 


\subsection{Quantitative analysis of chronicles re: All Canadians more optimistic}

(In sections 3.4 through 3.7 we statistically explore causal chronicles for the four demographic groups that experienced a "positive" poll trend. The replies dataset was used to compare replies to determine particular narratives which associated with particular demographics. The respondents dataset was used to determine how demographic and political opinion variables informed topic scores.)

\section{Correlations with narratives}

Using the replies dataset and a dummy variable for each demographic (e.g. P61, P62, etc.) a modest correlation with Political chronicles emerged for "All Canadians" $\left(.166^{*}, \mathrm{sig}=.038\right)$. To test different narratives, all post-poll, pre-treatment questions were used. The dominant narrative was that Canada is doing 'relatively better' than other countries $\left(.211^{* *}, \mathrm{sig}=.001\right)$. Relatively better tagged topics as disparate as Economic (e.g. "One of the best post-recession economies in the G-8") and Foreign (e.g. "Canada wasn't that impacted by WikiLeaks"). Other key narratives included Big Blue Machine (.178**, sig $=.007)$, the Potash intervention $\left(.138^{*}\right.$, sig $\left.=.036\right)$, and Eyes elsewhere $(.129$, sig=.051). Relative to other demographics, More jobs disassociated with the All Canadians group $(-.112$, sig=.089). 
Table 3.4.1: Means for topic scores, P6.1

\begin{tabular}{|c|c|c|c|c|}
\hline Economic & Defense & Foreign & Domestic & Political \\
\hline .2225 & .1025 & .1325 & .0575 & .4850 \\
\hline
\end{tabular}

Utilizing the respondents dataset, it was observed that almost half of all reasons given for the sustained upswing in public confidence were Political. However this, as well as the other means given, was not without significant variance. Age, gender, and academic standing did not affect how respondents explained a more optimistic public. However values and knowledge did play a significant role.

Table 3.4.2: Correlations between values and Foreign and Political events

\begin{tabular}{|l|c|c|}
\hline & Foreign Events & Political Events \\
\hline Values vs. age & $-.670^{*}(.034)$ & $.802^{* *}(.005)$ \\
\hline Values vs. all & $-.710^{*}(.021)$ & $.754^{*}(.012)$ \\
\hline
\end{tabular}

For values there was a stark divide between more progressive and more traditional respondents. Progressives were likelier to cite Political events, such as Conservative public relations efforts (e.g. a Cabinet shuffle, by-election campaigning, or Stephen Harper doing karaoke - all coded "Big Blue Machine" in the replies dataset). The December Holidays were also coded as Political due to their link to Parliament's winter recess. Progressives also cited a lack of bad news, whether because of the Parliamentary recess or, as Respondent 23, a Green Party supporter wrote, "scandals [are] fading from public memory."

More "traditional" respondents were likelier to cite Foreign events. Our sole stage 2 Conservative voter, Respondent 22 , for instance cited the controversial maternal health initiative, an improvement in foreign relations, and Canada escaping the Wikileaks scandal relatively unscathed. Our more traditional Liberals also cited relative good times 
in Canada while the rest of the world was in chaos, as well as the squashing of the sale of Potash Corp. to an Australian company.

With this values-driven chronicle divide, there emerged some evidence of cognitive dissonance among progressives asked to give credit to a government they do not support. Our traditional respondents were more likely to point to actual policy actions. Despite a positive correlation, however, between crown confidence (Stage 2 measure) and poll impression, there was no correlation, at least for P6.1, between crown confidence and Political. Interestingly our Liberals were more likely to cite Domestic events (-.623) and unlikely to cite Political events $\left(-.633^{*}\right)$. Thus its likely our progressive / Political association is more the result of our two Dippers, one Green and one Pirate (who cited solely the Holidays for P6.1).

Those who voted municipally in 2010 were somewhat more likely to cite Domestic events $(.623, \mathrm{sig}=.054)$. This perhaps supports the notion that knowledge of domestic politics and particular policies manifests itself in voter turnout.

It was hypothesized that an increase in political knowledge would increase Political events in responses overall. It is worth noting that ultimately all replies are 'political' events as they real-world events filtered through the lens of Canadian federal politics. In a sense the Political tag should be understood as events and issues not related to particular or 'hard' policy areas. 
Table 3.4.3: Correlations between knowledge and Foreign and Political Events

\begin{tabular}{|l|c|c|}
\hline & Foreign Events & Political Events \\
\hline Know v. age & $.432(.213)$ & $-.665^{*}(.036)$ \\
\hline Know v. all & $.660^{*}(.038)$ & $-.640^{*}(.046)$ \\
\hline Knowledge gap & $.531(.114)$ & $-.053(.884)$ \\
\hline
\end{tabular}

Political knowledge had a modest, negative association with Political events, and a modest-to-weak, positive association with Foreign events. In a sense we can say that the more knowledgeable subjects were likelier to cite policy actions and issues (particularly in the area of foreign affairs), while the less knowledgeable were likelier to cite matters that make splashy headlines and attract punditry. This is fleshed out by a strong negative correlation between recent attention and Political $\left(-.680^{*}\right.$, sig $\left.=.031\right)$ (recent attention did not correlate with any other P6.1 topic scores and relative attention correlated with none). Against this, however, respondents who considered themselves more knowledgeable $v$. all were still more likely cite particular figures in their P6 chronicles (know v. all * Proper_drop $=.615, \mathrm{sig}=.058)$. 


\subsection{Quantitative analysis for chronicles re: University graduates more optimistic}

\section{Correlations with narratives}

The dominant narrative for university graduates' optimism was More jobs $\left(.171^{* *}\right.$, sig=.010). Relative to other demographics, Defense events were less likely to be associated with graduates $(-.143, \mathrm{sig}=.075)$.

Table 3.5.1: Means for topic scores, P6.2: Graduates, compared for respondents identifying with demographic or not

\begin{tabular}{|l|c|c|c|c|c|}
\hline & Economic & Defense & Foreign & Domestic & Political \\
\hline All $(\mathrm{N}=10)$ & .3500 & .0333 & .2167 & .0667 & .2333 \\
\hline $\begin{array}{l}I D s w / g r a d s \\
(N=4)\end{array}$ & .2500 & .0000 & .2500 & .0833 & .1667 \\
\hline $\begin{array}{l}\text { Doesn't ID } \\
w / g r a d s \\
(N=6)\end{array}$ & .4167 & .0556 & .1944 & .0556 & .2778 \\
\hline
\end{tabular}

Unlike for all Canadians, our respondents were more likely to expect an uptick among graduates due to Economic and Foreign events and issues, largely at the expense of Political events. How does this relate to respondent identity as four of ten subjects identified with 'university graduates' (despite the fact only one actually ${ }^{3}$ has a degree)? While Economic events remain a dominant explanation, there is a considerable difference regarding other reasons. Our graduates thought Foreign events were just as important as Economic ones while our non-graduates thought graduates were nearly as likely inclined

\footnotetext{
${ }^{3}$ The stage 2 group included only one graduate student, who naturally identified themselves with university graduates. The other three 'identifiers' were between the ages of 20 and 22, and had an academic standing of other third or fourth year undergraduate. Due to their age and position in their program it is highly unlikely any of three is actually a university graduate. It is more likely they interpreted university graduates as university students. This is supported by one 20 -year-old third year student who wrote in "uni student" in this section (they were not coded as identifying with any of the three subgroups in question). Based on personal experience however, it is likely that some survey respondents who identify as having a university education are in fact only enrolled in university.
} 
by political events as Economic ones. Further, non-graduates thought this demographic group was more influenced by Political events than self-identified grads claimed. Could this be evidence that those who identify strongly as post-secondary students consider themselves resistant to the 'Big Blue Machine?'

Here gender does play a role as female respondents were somewhat likelier to cite Foreign events $(.600$, sig=.067), though any 'gender relations' should be taken with a measure of skepticism considering only three subjects were male. Interestingly, especially considering the demographic in question, academic standing was weakly significant while age was not. An increase in academic standing decreased Defense scores $(-.614$, sig $=.078)$, which appears to mirror Table 3.5.1.

Traditional values associated with Domestic, with an increase on both values scales driving down Domestic (v. age -.628, sig $=.052 ; v$. all $-.697^{*}$, $\left.\mathrm{sig}=.025\right)$. Domestic events and issues varied, but among our three most traditional subjects (combined values $<9 / 14$ ) their Domestic hits included a focus on law and order and greater investment in health.

Knowledge in itself was not significant for this question, though knowledge gap was. There was a very strong repulsion of perceived gap and Political events $\left(-.820^{* *}\right.$, sig=.004). Thus, for what it is worth, respondents who do not perceive a significant difference between generations were likelier to think university graduates 'susceptible' to events such as cabinet shuffles or more willing to give the government a pass for the holidays.

Nearly as significant and in the other direction, a higher reliance on TV sources for political news increased Political events $\left(.810^{* *}\right.$, sig $\left.=.004\right)$. Our three stage 2 subjects 
who cited a TV source (in all three cases the CBC) all cited at least one purely Political event, and in two cases cited a lack of scandal (though the scandals fading narrative did not correlate significantly with this demographic).

Two of our Liberal respondents seemed to have interpreted the poll question in a uniquely partisan and dissonant manner: that the likelihood of a spring election in which the ruling Conservatives could be defeated was evidence of a federal government 'headed in the right direction.' Respondent 16 cited '[c]onfidence that an election may be pending following the March budget." Respondent 19 cited "[h]ope for a new direction with an election that could come soon." While both replies are up to interpretation, this should be taken as evidence we cannot assume all subjects interpreted even the poll question itself in a uniform manner. 


\subsection{Quantitative analysis of chronicles re: People without post-secondary education more optimistic}

\section{Correlations with narratives}

The dominant narrative for explaining optimism among those without postsecondary education was Social spending $\left(.245^{* *}\right.$, sig=.000). Replies feeding this narrative ranged from the blatant (e.g. "Boosts in funding towards social programs"), to the specific (e.g. "Further action on funding for affordable housing affecting low-income families"), to the specific and perhaps politically blatant (e.g. "Conservatives promise to build [a hockey] Arena in Quebec City"). Unlike for other demographics or Canadians at large, respondents seemed to think less educated Canadians were being 'bought.' While P6.3 replies did not significantly associate with Economic events (relative to other demographics) other dominant narratives were More jobs $\left(.171^{* *}\right.$, sig=.010; same as for graduates) and Economy improving $\left(.118^{*}, \mathrm{sig}=.073\right)$.

Table 3.6.1: Means for topic scores, P6.3: High school diploma or less, compared for respondents identifying with demographic or not

\begin{tabular}{|l|c|c|c|c|c|}
\hline Ell $(\mathrm{N}=10)$ & .3333 & .1000 & .0833 & Domestic & Political \\
\hline $\begin{array}{l}\text { IDs } w / H S \text { or } \\
\text { less }(N=2)\end{array}$ & .6667 & .1667 & .0000 & .167 & .1667 \\
\hline $\begin{array}{l}\text { Does not ID } \\
w / H \text { or or less } \\
(N=8)\end{array}$ & .2500 & .0833 & .1042 & .1042 & .0000 \\
\hline
\end{tabular}

Looking at the means from the respondents dataset, Economic events clearly dominated. For our two respondents who identified with the subgroup, it was overwhelmingly about money. These two people appear largely responsible for pulling the Economic mean up from a quarter of the reason for optimism to a third. The 
importance of Political events was roughly equal to that given for graduates, though our two self-identifiers disagreed.

Again, age and academic standing appear to work independent of each other, each having a modest, negative association with a distinct topic; younger subjects cited more Domestic events $\left(-.689^{*}\right.$, sig $\left.=.027\right)$ while more senior students cited fewer Foreign events $\left(-.679^{*}, \mathrm{sig}=.044\right)$. Gender played no role here.

Table 3.6.2: Correlations between Canada and Crown confidence and Foreign, Domestic, and Political events

\begin{tabular}{|l|c|c|c|}
\hline & Foreign & Domestic & Political \\
\hline Canada confidence (January) & $.724^{*}(.018)$ & $.602(.066)$ & $-.638^{*}(.047)$ \\
\hline Canada confidence (February) & $.243(.498)$ & $.071(.845)$ & $-.585(.076)$ \\
\hline Crown confidence (January) & $.698^{*}(.025)$ & $.830^{* *}(.003)$ & $-.559(.093)$ \\
\hline Crown confidence (February) & $.356(.313)$ & $.573(.083)$ & $-.794^{* *}(.006)$ \\
\hline
\end{tabular}

There was no association between values and this demographic, but personal opinion about the direction of Canada and the federal government was significant. Due to changes in these opinions between the pre-experiment questionnaire and experiment questionnaire, some associations lost their significance but none changed direction. Nor did confidence in Canada contradict confidence in the federal government.

These findings mirror values correlations for P6.1. For the January and February tests, pessimism toward the government increased the rate of Political events to explain popular opinion, perhaps most cynically demonstrated by Respondent 25 whose initial reply to P6.3 was "Harper sang a song." Again, those subjects more approving of Canada and its government's directions were likelier to cite policy achievements, though this association is weaker or even insignificant based on the February numbers. 
For what it is worth, municipal voters were somewhat less likely to cite Foreign events $(-.620$, sig $=.056)$.

Knowledge was only weakly significant and only $v$. all, and associated positively with Domestic (vs. all .608, sig=.062).

Interestingly poll's worth had a strong positive association with Domestic events $\left(.755^{*}, \mathrm{sig}=.019\right)$. This perhaps demonstrates that those who think polls are more important also think that they are more likely to capture public responses to particular policies (also assuming these respondents assume that survey respondents take particular policies into consideration in formulating their general opinion).

Media sources played a more significant role here than with other demographic. Print increased Domestic (.636*, sig $=.048)$ and reduced Political $\left(-.745^{*}\right.$, sig $\left.=.013\right)$. Curiously, radio also increased Domestic at an identical rate but had no effect on Political. $T V$ increased the number of Economic events significantly $\left(.732^{*}\right.$, sig $\left.=.016\right)$, perhaps, as Mr. Mulvihill noted, due to positive economic news coming out of America at the time. 


\subsection{Quantitative analysis of chronicles re: Women more optimistic}

Correlations with narratives

In explaining the opinions of women, our subjects seemed a sexist lot (though that was essentially invited by asking this question). The dominant narrative was Think about the children $\left(.297^{* *}, \mathrm{sig}=.000\right)$, an events set which correlated with no other group. Three subjects, all female, cited events relating to children: policies regarding toy safety and children's health, and "[a]fter a few months, settling into new education pattern for kids." Additionally common was reference to the federal government's maternal health initiative for mothers in developing countries $\left(.138^{*}\right.$, sig=.037). Maternal health was exclusively defined and did not overlap with the "children narrative.

Table 3.7.1: Means for topic scores, P6.7: Women, compared for female and male respondents

\begin{tabular}{|l|c|c|c|c|c|}
\hline & Economic & Defense & Foreign & Domestic & Political \\
\hline All $(\mathrm{N}=10)$ & .2167 & .0833 & .1500 & .1500 & .4000 \\
\hline Women $(N=7)$ & .2381 & .0476 & .2143 & .1429 & .3571 \\
\hline Men $(N=3)$ & .1667 & .1667 & .0000 & .1667 & .5000 \\
\hline
\end{tabular}

Female and male respondents agreed Political events were the most influential on Canadian women polled. Females diverged however in citing Foreign events, which males did not whatsoever. The maternal health initiative was clearly the reason for this which was cited by three females representing the three major federal parties. Our three fellows alternately were more likely to cite Defense events, or lack of events, such as "Less bad news from Afghanistan" (Respondent 23).

The replies for P6.7 most mirrored the trends observed for P61, with a few demographic exceptions; those first: 
Age increased Political $\left(.740^{*}, \mathrm{sig}=.014\right)$ and decreased both Foreign $\left(-.647^{*}\right.$, sig $=.043)$ and Domestic $\left(-.675^{*}\right.$, sig $\left.=.032\right)$. Academic standing also increased Political $(.632$, sig $=.068)$ but decreased Defense $(-.655, \mathrm{sig}=.056)$. All age relationships should probably be tossed as yes, there is a distinct correlation between age and values, but in stage 2 our age range goes only from 20 to 22 . Further there is one missing case for standing which is probably causing trouble.

Again more progressive respondents were likelier to cite Political events (v. age $.714^{*}, \mathrm{sig}=.020 ; v$. all $.591, \mathrm{sig}=.072$ ) than their more traditional counterparts who in this question were likelier to cite Domestic events (v. age $-.727^{*}$, $\mathrm{sig}=.011 ;$ v. all $-.772^{* *}$, sig=.009). Particular Domestic events, cited by the more traditional half of respondents, included "[b]aby steps towards enviro[mental] responsibility by the Conservatives" and the Think about the children elements cited above (though toy safety was cited by a relatively progressive but pro-government direction Liberal). These trends are again supported by crown confidence (stage 2 measure), with confidence in government increasing the rate of Foreign $(.570$, sig=.085) and Domestic events $(.618$, sig=.057), and decreasing Political reasons (-.601, sig=.066). Somewhat bucking this, however, was a positive association between supporting the NDP and Foreign $\left(.704^{*}\right.$, sig $\left.=.023\right)$.

Knowledge decreased Political (v. age $-.692^{*}$, sig $=.027 ;$ v. all $-.688^{*}$, sig $=.028$ ) and increased Domestic (v. age $.611^{*}$, sig $=.061 ;$ v. all .793**, sig $\left.=.006\right)$. This is perhaps best demonstrated by the very specific policy citations made by some of our more knowledgeable subjects (e.g. the regulations on toy safety and focus on children's exercise).

Poll's worth decreased Political (-.607, sig $=.083)$. 
All news sources except TV associated with replies in some way. Foreign was increased by personal $\left(.704^{*}, \mathrm{sig}=.023\right)$ and decreased by websites $\left(-.714^{*}\right.$, sig $\left.=.020\right)$. Domestic was increased by both print and radio, and at the same level (.623, sig=.055) (recall there is a high correlation between print \& radio). Political was increased by aggregator reliance $\left(.647^{*}, \mathrm{sig}=.043\right)$ and decreased by print $\left(-.647^{*}, \mathrm{sig}=.043\right)$. 


\subsection{Correlations between stage 1 and stage 2 topic scores}

Pre-treatment, there was little evidence of correlations between topics of stage 1 event/issue replies and stage 2 causal chronicles. However, post-treatment, correlations did emerge which support $\mathrm{H} 1$ as both control and treatment subjects revised their chronicles. For our four uptick demographics, there were 20 opportunities for same topic correlations and 80 for different topics.

Looking first at pre-treatment replies, there were more correlations between different topics than same topics. The only modest affirmation of our hypothesis here was between Foreign top events and Foreign citations for P6.1 (.617, sig=.057). Otherwise, the only somewhat significant support was found between Defense top events and Defense citations for P6.3 (.533, sig=.113). More significant was the negative association between Political pet issues and Political citations, also for P6.3 (-.570, sig $=.086)$. Between unlike topics there were seven associations at the .05 level; four positive and three negative. Moreover, another twelve associations registered between .05 and .15 significance for unlike topic scores. Comparing positive associations, ultimately, stage 1 replies' topic scores were more likely to predict unlike topics scores for causal chronicles. After treatment, however, things appear to be more in line with predictions. Again there was a significant association between Foreign top events and Foreign citations, though now to a much stronger effect for P9.1 (.731*, sig=.016). This predicted association now extended to three other topics, with Economic pet issues, Defense top events and pet issues, and Political events all behaving as expected at the .1 significance 
level. Again against the grain, however, was a negative association with Political pet issues and Political citations, essentially a mirror correlation of top events (.618 for events and -.619 for issues). In fact for all four uptick demographics Political pet issues had a negative association with Political citations and for P9.7 almost at a significance level on par with our observed Foreign-Foreign association for P9.1. Other positive associations significant at the .05 level included Political events predicting P9.2 Political citations $\left(.768^{* *}\right.$, sig $\left.=.009\right)$, and Economic pet issues associating with P9.7 Economic citations $\left(.673^{*}, \mathrm{sig}=.033\right)$. The only other negative same topic association was observed between Defense pet issues and Defense citations for P9.2 (-.574, sig=.083). Comparing associations up to the .150 significance level, we observe 11 same topic and 13 different topic positive associations, and five same topic and six different topic negative associations. 


\subsection{Respondents attitudes towards poll trends and spin}

Here we explore $\mathrm{H} 3$, cognitive dissonance, to see how respondents' attitudes towards poll trends inform their chronicles, and $\mathrm{Hlc}$, how chronicle confidence is related to chronicle contents. Poll impression was measured by asking respondents how they felt "personally" about the overall positive movement in the polls, with the options positively, negatively, or neutral. Chronicle confidence was measured by asking respondents, using a seven point scale, how confident they were in their replies (ranging from "not at all" to "extremely confident"). For these tests we use the replies dataset and select only replies for our four uptick groups. Significant correlations are cited first using pre-treatment measures then post-treatment measures for which, additionally, treatment respondents' attitudes towards insiders are considered. This way we may test for association between chronicle confidence and poll impression, and reply topics. Doing so, it can be identified if "cognitive dissenters" cite Political events over hard-policy topic events to explain public confidence in a government they oppose. To report treatment and control group means data from the respondents set is used.

Table 3.9.1: Poll impression and chronicle confidence means, pre-treatment*

\begin{tabular}{|l|c|c|}
\hline & Poll impression $(\mathbf{1 \rightarrow 3})$ & Chronicle confidence $(\mathbf{1} \rightarrow \mathbf{7})$ \\
\hline Treatment $(\mathrm{n}=5)$ & 2.0 & 3.8 \\
\hline Control $(\mathrm{n}=5)$ & 1.6 & 2.2 \\
\hline
\end{tabular}

*using respondents dataset

Pre-treatment treatment respondents cited significantly higher levels of chronicle confidence $\left(.632^{* *}, \mathrm{sig}=.000\right)$. This is likely explained by the strong correlation between 
'confidence and poll impression $\left(.395^{* *}, \mathrm{sig}=.000\right)$ as the treatment subjects, on the whole, expressed a more positive poll impression $\left(.333^{* *}\right.$, sig=.000). Poll impression had a strong association with knowledge $\left(.551^{* *}\right.$, sig $\left.=.000\right)$ and a modest association with traditional values $\left(-.169^{*}, \mathrm{sig}=.046\right)$. With topic scores, in a hypothesized manner, a negative poll impression correlated with Political replies $\left(-.209^{*}, \mathrm{sig}=.027\right)$, while a positive impression associated with Defense replies $\left(.231^{*}\right.$, sig $\left.=.014\right)$. These impression correlations are perhaps surprising as our treatment group was, on the whole, less knowledgeable and more progressive. Chronicle confidence did not significantly associate with topic scores, or knowledge or values.

Table 3.9.2: Poll impression and chronicle confidence means, post-treatment*

\begin{tabular}{|l|c|c|}
\hline & Poll impression $(1 \rightarrow 3)$ & Chronicle confidence $(1 \rightarrow 7)$ \\
\hline Treatment $(n=5)$ & 1.8 & 4.2 \\
\hline Control $(n=5)$ & 1.6 & 2.4 \\
\hline
\end{tabular}

*using respondents dataset

Post-treatment, one treatment subject (male, Liberal) changed their poll impression from neutral to negative; no other subject changed their impression. Chronicle confidence increased for two treatment subjects and one control subject, in all three cases by one point. These changes strengthened the association between treatment group membership and confidence but weakened that group's association with impression. The associations between impression and Defense and Political scores remained, albeit slightly weakened. More significant was a negative association between confidence and Domestic events $\left(-.225^{*}\right.$, sig=.016). The associations with knowledge and values strengthened to the 0.01 significance level.

Table 3.9.3: Perception of political insiders' credibility and like-mindedness 


\begin{tabular}{|l|c|c|}
\hline & Credible $(\mathbf{1} \rightarrow \mathbf{7})$ & Politically likeminded $(\mathbf{1} \rightarrow \mathbf{7})$ \\
\hline Mr. Mulvihill (Conservative) & 5.2 & 2.8 \\
\hline Mr. De Sarkar (NDP) & 4 & 3 \\
\hline
\end{tabular}

In the next section we explore the effect treatment had on topic score change. In regards to poll impression and chronicle confidence attitudes towards spin insiders was significant, though these correlations are considering a very small number of respondents. The treatment respondents found the Conservative insider to be more credible. On the whole treatment respondents thought they would "disagree generally" with both insiders, not surprising as both insiders attacked the Liberals. Respective attitudes towards the pro- and anti-government insiders correlated in a largely expected fashion. Poll impression correlated strongly with finding Mr. Mulvihill (Conservatve) credible $\left(.802^{* *}\right.$, sig=.000) and disagreeing with Mr. De Sarkar (NDP) $\left(-.845^{* *}, \mathrm{sig}=.000\right)$. However, agreeing with Mr. Mulvihill correlated negatively with poll impression (-.242*, sig=.044). Associations with chronicle confidence were similar. Perhaps explaining this, higher knowledge values favoured Mr. Mulvihill and disfavoured Mr. De Sarkar. Values associations undermine this however, as while progressives tended to agree with $\mathrm{Mr}$. De Sarkar $\left(.395^{* *}\right.$, sig=.000), they also tended to find Mr. Mulvihill credible $\left(.250^{*}\right.$, sig $=.037)$. These correlations thus are likely more related to personal characteristics of the two insiders. The student researcher would admit Mr. Mulvihill seems dauntingly confident when expressing his views and is about five years older than Mr. De Sarkar. 


\subsection{Correlations between treatment and topic score change}

To statistically test the effect of the spin treatment, bivariate correlations and Independent T-Tests were run using score change measures compared against a treatment dummy. These change measures were created by subtracting pre-treatment topic scores from post-treatment scores for all four uptick demographics. Thus five changes scores were created for each of these four groups (e.g. p61_ECOchange, p61_DEFchange, and etcetera).

While examples of significant relationships were rare, they at least behaved as anticipated. Two significant change correlations emerged. For p61_FORchange (All Canadians), there was a significant difference in the scores for treatment $(\mathrm{M}=0.1100$, $\mathrm{SD}=.11402)$ and control $(\mathrm{M}=0, \mathrm{SD}=0)$ conditions; $\mathrm{t}(8)=-2.157, \mathrm{p}=.063$. In other words, there was a modest correlation between treatment and incorporating Foreign elements into narrative $(p=.606)$. No other topic experienced a relative downturn, the closest possible candidate being Economic (p61_ECOchange $\mathrm{x}$ Spin, $p=-.483$, sig=.157). This in mind, there was a borderline insignificant correlation between perceived agreement with Mr. De Sarkar (our anti-government spokesman) and p61_ECOchange $(-.807$, sig=.099). For p62_ECOchange (University Graduates), there was a significant difference in the scores for treatment $(\mathrm{M}=.3000, \mathrm{SD}=.18257)$ and control $(\mathrm{M}=-.0833, \mathrm{SD}=.11785)$ conditions; $t(8)=-3.944, p=.004$. As a correlation, this was a very strong association between spin and incorporating Economic elements $\left(p=.813^{* *}\right)$. There was however no significant or distinct movement among the other topics relative to this. Again Mr. De 
Sarkar was somewhat statistically relevant as agreeing with his politics increased

Political $(.845$, sig $=.071)$ and decreased Economic $(-.807$, sig=.099).

Table 3.10.1: Frequency of topic score change, compared for treatment and control subjects

\begin{tabular}{|l|c|c|c|c|c|c|c|c|c|c|c|c|c|c|c|}
\hline & \multicolumn{3}{|c|}{ Economic } & \multicolumn{3}{|c|}{ Defense } & \multicolumn{3}{c|}{ Foreign } & \multicolumn{3}{c|}{ Domestic } & \multicolumn{3}{c|}{ Political } \\
\hline Change? & $\downarrow$ & none & $\uparrow$ & $\downarrow$ & none & $\uparrow$ & $\downarrow$ & none & $\uparrow$ & $\downarrow$ & none & $\uparrow$ & $\downarrow$ & none & $\uparrow$ \\
\hline Control & 0 & 3 & 2 & 0 & 4 & 1 & 1 & 3 & 1 & 1 & 2 & 2 & 0 & 4 & 1 \\
\hline Treatment & 1 & 2 & 3 & 1 & 4 & 0 & 2 & 3 & 0 & 1 & 3 & 1 & 0 & 3 & 2 \\
\hline
\end{tabular}

The lack of treatment effects otherwise may be explained by the high rate of narrative change made by control subjects who were equally encouraged by the student researcher to 'copy their answers verbatim' from section six to section nine, or 'think up entirely different answers.' Table 3.10.1 displays whether, and how, topic scores changed for questions P6.3/P9.3 (no post-secondary education) divided by treatment and control groups. Similar trends occurred for the other uptick demographics. It is of course also possible that this demonstrates not unusual behaviour by the Control subjects but a lack of influence by our insiders. 


\subsection{Cumulative analysis: comparing the consistency of associations}

While there were a myriad of associations between various variables with topic scores, and between stage 1 and stage 2 topic scores, many were inconsistent in their direction and at times contradicted one another. However there were still several associations that were demonstrably consistent. For variable to score associations, we consider those consistent in which there was a significant (at the 0.1 level) association between a given variable and both a stage 1 top-of-mind field ( $\mathrm{P} 1$ top events or $\mathrm{P} 2$ pet issues) and at least one stage 2 top-of-mind field ( $\mathrm{P} 6$ or $\mathrm{P} 9$ causal chronicles). For topicto-topic associations, we consider those consistent in which there was a significant association between at least one stage 1 top-of-mind field and at least one stage 2 top-ofmind field. If one particular stage 1 topic score associated with more than one stage 2 topic score, we consider the consistent association to be that which associated in more than one instance. For stage 2 we consider top-of-mind fields for our four uptick groups at either the pre- or post-treatment stage.

\section{Consistent Variable-to-Topic Associations}

For demographic variables, associations for age and gender were consistent. Age associated negatively with Economic, though also had some repeated stage 2 negative associations with Domestic and Foreign. Gender positively associated with Foreign and with no other topic score. Academic standing proved inconsistent, matching age in a 
stage 1 negative association with Economic but in stage 2 negatively associating with Defense on several occasions (P6.2 \& 9.2, and P6.7 \& 9.7).

For political opinion variables there were many associations but only a handful of consistent ones. Values had a consistent negative association with Domestic, meaning more traditional respondents were indeed likelier to cite Domestic issues and policies (P2, P9.2, P9.3, and P6.7 \& 9.7). Otherwise values inconsistently associated, with contradictory stage 1 associations with Economic and in stage 2 negative associations with Foreign and Defense and a positive association with Political. Canada confidence had no association at stage 1 and at stage 2 topic associations were largely only significant using the stage 1 'confidence measure. Crown confidence did prove significant however, using stage 1 and stage 2 measures, and positively associated with Foreign. Though not associated at stage 1 , crown confidence (particularly its stage 2 measure) did have a repeatedly positive association with Domestic elements in causal chronicles (P6.3 \& 9.3, and P6.7 \& 9.7). Due to only one Conservative participating in stage 2 we cannot find any association between voting Conservative and particular topics. Voting Liberal $(\mathrm{n}=5)$ consistently associated with Economic (P1, P9.2, P6.3 \& P9.3) and Defense (P2, P6.7 and 9.7), and voting NDP $(n=2)$ had a consistent association with Foreign, though to a lesser extent (only for P9.3 and P6.7). All stage 2 participants provided a likely vote intention and thus no associations can be found between the 'undecided' and topics. Having voted municipally in 2010 or one's opinion towards opinion polling had no stage 1 or consistent stage 2 topic associations. 


\section{Figure 3.11.1: Consistent* Variable-to-Topic Associations

$\underset{\text { positive association }}{\longrightarrow} \stackrel{\text { negative association }}{\longrightarrow}$

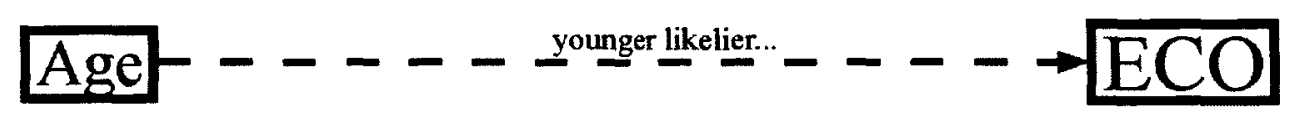

\section{DEF}
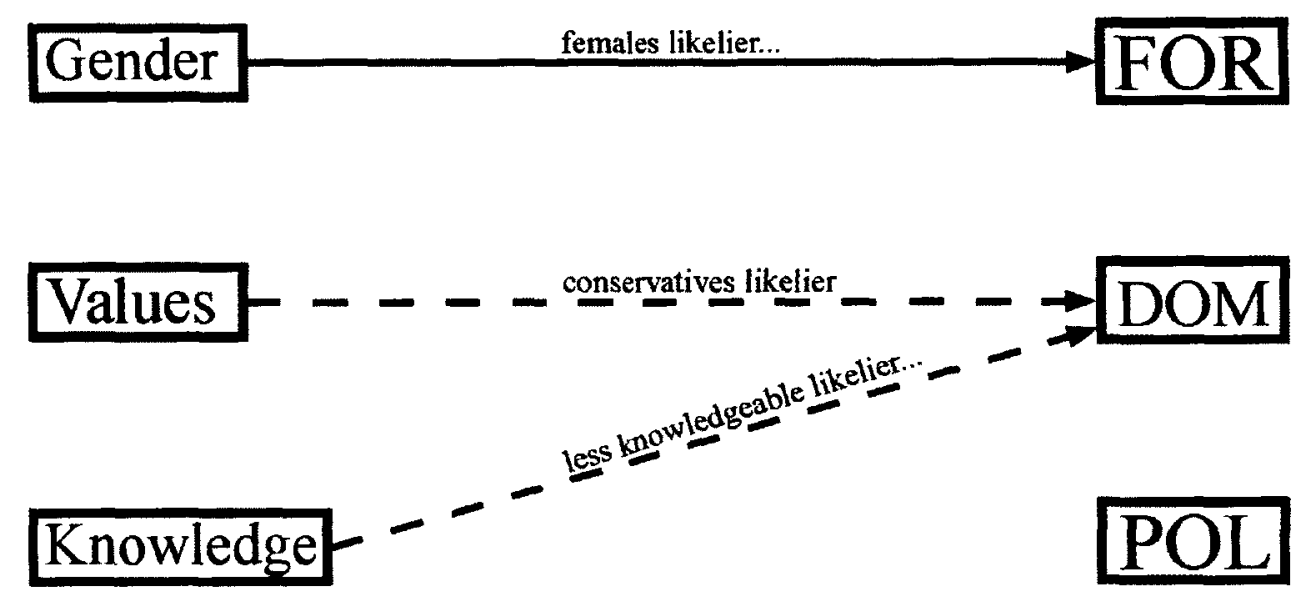

*Consistent associations are those where the variable has a significant association (@ the 0.1 level) in the same direction with both at least one Stage 1 top-of-mind capture (P1 Top Events or P2 Pet Issues) and at least one Stage 2 causal chronicle reply. 


\section{Figure 3.11.2: Consistent* Variable-to-Topic Associations}

$$
\underset{\text { positive association }}{\longrightarrow} \underset{\text { negative association }}{\rightarrow}
$$
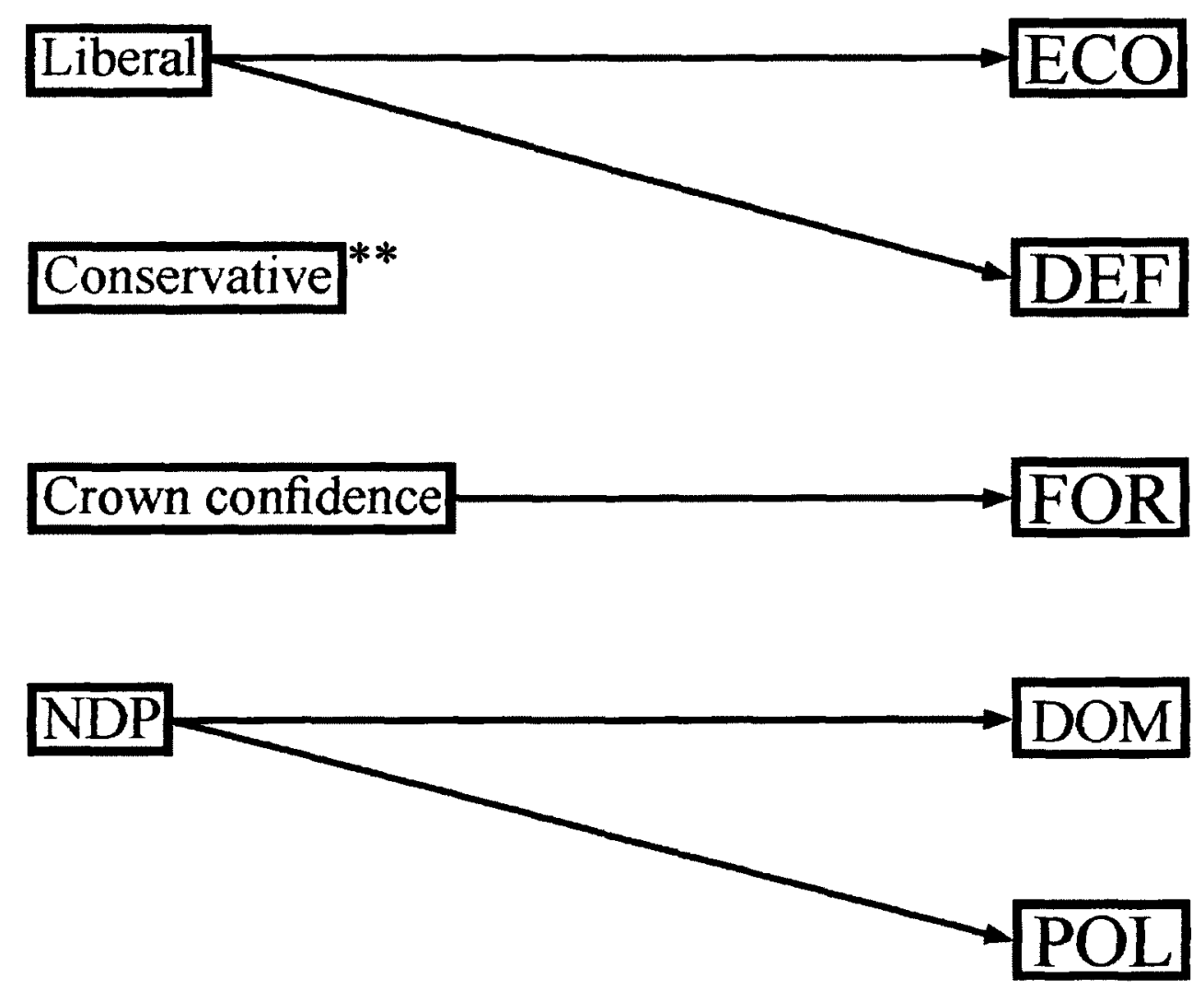

*Consistent associations are those where the variable has a significant association (@ the 0.1 level) in the same direction with both at least one Stage 1 top-of-mind capture (P1 Top Events or P2 Pet Issues) and at least one Stage 2 causal chronicle reply.

**Associations cannot be considered significant as only one likely Conservative voter participated in Stage 2. 
For political knowledge and media variables, there were many correlations but most were inconsistent or contradictory. For knowledge there was a consistent association for Economic. There was some evidence of a positive association for knowledge and Domestic ( $\mathrm{P} 1, \mathrm{P} 9.2, \mathrm{P} 6.3$, and $\mathrm{P} 6.7)$ but this was contradicted with a negative association at stage 1 (P2). Moreover knowledge associated as often with Foreign (positively) and Political (negatively) as it did with Economic in stage 2 . The association between Proper_drop and know v. all was not maintained post-treatment. The only consistent sources association was for aggregators with these news junkies preferring Political issues and eschewing Economic mentions. Personal, print, and radio were inconsistent in their stage 1 and stage 2 associations. Websites only associated in two stage 2 instances, though both negatively with Foreign. $T V$, which did not associate at stage 1 and inconsistently at stage 2 , did have a pair of 'treatment-resistant' associations; positively with both Political (P6.2 \& 9.2) and Economic (P6.3 \& 9.3).

Stage 2 pre-poll variables were largely insignificant. Identifying with Canadians without a post-secondary education had a treatment-resistant positive association with Economic (P6.3 \& 9.3). Other demographic identity captures (graduates and women) did not significantly associate. Chronicle confidence, either pre- or post-treatment was largely insignificant, only associating with Economic for P6.1. 
Figure 3.11.3: Topic-to-Topic Associations

$$
\text { positive association } \quad \text { negative association }
$$
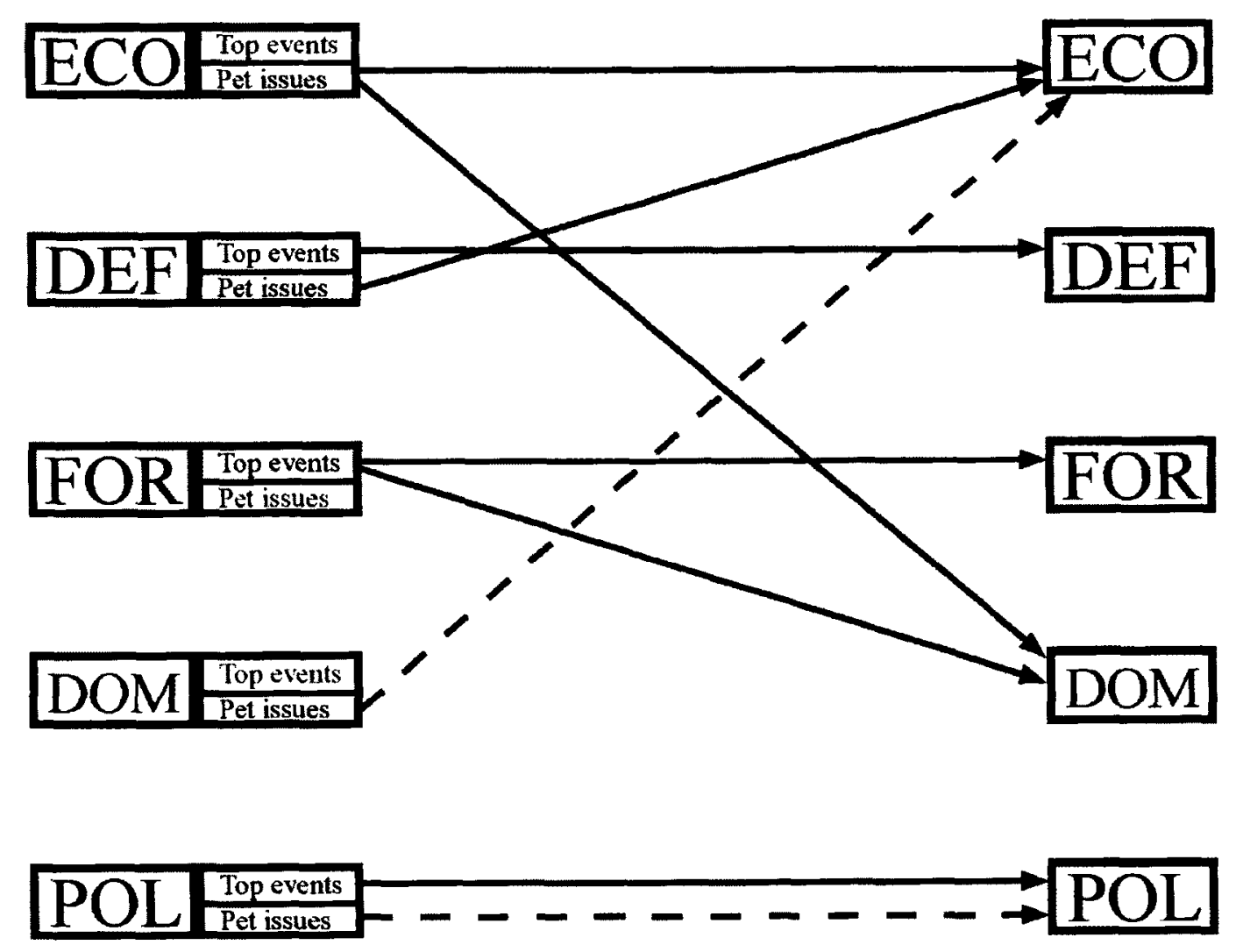

*Topic-to-topic associations are directionally consistent and significant @ the 0.1 level. The left column are Stage 1 captures; the right column are Stage 2 captures (causual chronicles). 


\section{Consistent Topic-to-Topic Associations}

For topic-to-topic correlations, the subject of $\mathrm{H} 1$, hypothesized associations were nearly as consistent as unexpected or contradictory ones. There were nine consistent topic-to-topic correlations: four between same topics positively, one between same topics negatively, and four between different topics. Three stage 1 top-of-mind fields had no consistent associations: Economic top events and Foreign pet issues had no association with any stage 2 topics; Domestic top events associated inconsistently at stage 2 and only pre-treatment.

Supporting H1 were positive associations for Economic pet issues, Defense top events, Foreign top events and Political top events. This contradicts our qualitative observations where $\mathrm{P} 2$ replies appeared more relevant than P1 replies. Against our hypothesis, Political pet issues had a negative association with Political chronicles. Most of these correlations, as discussed in section 3.8 , were only observed with post-treatment replies. For instance, the most consistent and widely observed of our H1-affirming associations was for Economic pet issues which only associated post-treatment (P9.1, P9.3 and P9.7). However, note our one contrary topic-to-topic association emerged similarly (P9.1, P6.3 \& 9.3, and P9.7).

Unexpected associations were stage 2 Economic and Domestic scores. Defense issues positively and Domestic issues negatively associated with Economic stage 2 replies. The Defense-to-Economic association was as consistent as the Economic-toEconomic one, though mostly only pre-treatment. Defense issues inconsistently 
associated with Defense chronicles (positively for P9.1 but negatively for P9.2). The Domestic-to-Economic association was very consistent, largely resisting treatment (negative and significant for P6.1 \& 9.1, P6.2, P9.3, and P6.7 \& 9.7). Economic issues, almost as consistently as they associated with Economic chronicles, associated with Domestic chronicles (P6.1 \& P9.1, and P9.2). Foreign events associated positively with Domestic post-treatment, and with the two uptick demographics for with Foreign-toForeign did not associate (P9.3 and P9.7).

Reviewing our same keyword meta-tag associations, for all P6 and P9 replies, some associations were sustained post-treatment. $H R S D C$ tags remained as consistent post- as pre-treatment. Law became more significant, as all stage 2 respondents with a law hit in their pet issues mentioned legal matters in their chronicles post-treatment. Additionally the Foreign aid (excl. maternal health) tag-to-tag association strengthened. The Natural resources and Taxes associations became insignificant. There were however many other tag-to-tag associations between unlike keywords at all stages and thus these findings should be treated as illustrations of larger topic trends rather than particular support for $\mathrm{H} 1$.

\section{Discussion}

Compared to variable-to-topic correlations, topic-to-topic correlations were more consistent, as even when not associating with the same topic, or associating with the same topic but negatively, there was little variety in the association (e.g. six out of seven Domestic P2 associations were with Economic chronicle elements and all six were negative). This is not an entirely fair conclusion though, as variable-to-topic associations 
were investigated for stage 1 and stage 2 top-of-mind fields, rather than just between stage 1 and 2 fields.

Looking at these topic-to-topic correlations together we do see top events behaving as predicted more than pet issues. Considering our causal chronicles were largely comprised of hard events (rather than ongoing issues or 'developing stories'), it is perhaps not surprising that issues would be less useful as predictive tools. Nevertheless, issues were useful predictors, particularly for Economic chronicles with Economic and Domestic issues neatly informing responses in a largely hypothesized manner. 


\subsection{Questionnaire weaknesses}

The design of the questionnaires was not without error. Some questions were poorly worded. Some potentially important questions were missing and some questions precluded other ones. A preference for simple questions over complicated ones would have produced more useful data. If this project were to be attempted again, it would be wise to note these weaknesses and design questionnaires in a more user-friendly manner.

The poorest designed questions forced respondents to chronicle change among multiple demographics. These were stage 2 questions P6.4/9.4, P6.5/9.5 and P6.6/9.6. P6.4 stated that the government lost confidence with all men and all people aged 25-44 over the month of November 2010. These two demographics were presented in tandem as they demonstrated a similar trend. This question was included in part as well because it was one of the only relatively recent examples of the government losing points among particular demographics. Additionally, while it forced respondents to think quite a ways back (the experiment occurred in mid-February 2011), it was intended to test the effect of temporal distance on motive assignment (e.g. would less knowledgeable respondents prove unable to think back three months rather than one). However the combination of these demographics made it difficult for treatment respondents to incorporate spin, as Mr. Mulvihill spoke particularly about job gains among men. The follow-up questions however likely confounded respondents.

P6.5 reported that confidence in the federal government then rebounded among men and 25-44 year olds over the month of December 2010, and asked respondents 
whether the rebound was due to "the passage of time" (that whatever irked this group in November was forgotten, i.e. issue decay) or the result of 'positive' events. If the latter option was chosen then respondents were instructed to answer P6.6 and provide up to three particular events or issues. These questions were of course then asked again (P9.4, P9.5, and P9.6). No other post-poll questions included such conditional elements.

Only two respondents opted for P6.6, respondents 13 and 19, a control subject and a treatment subject respectively. Both cited an increase in jobs, and Respondent 19 elaborated on greater economic confidence, and also attributed the increase to the winter recess. Mention of the recess illustrates the flaw of the passage of time option as many respondents gave the recess as reason for many sub-groups' increased confidence in government. Unfortunately, the winter recess was not anticipated as a chronicle element, let alone a common one. This awkward combination of the questions may have mitigated the effects of the pro-government spin. While no comment section was included (another flaw, to be addressed below) it may be hypothesized that respondents thought they were expected to change their reply to P6.5 in response to this spin; this was definitely expected by the student researcher. However no respondent switched their reply as such. Respondent 13 (control) maintained the change was due to events and added "Economic growth announcement" to P9.6. Respondent 19 (treatment) on the other hand, switched their P9.5 reply to "passage of time." Respondent 19's P6.4 reply largely attributed the November decline to Defense issues, as well as a lack of action on the economy, and then for 9.4 removed some Defense issues and added the somewhat perplexing reply "Younger people share a different perception of the economy." Regarding these two respondents, both were the only stage 2 participants to identify with "people with a H.S. 
diploma or less." Further, both assigned poll's worth a $5 / 7$, above the stage 2 mean of 4 . This above average faith in polls might explain why these two were inclined to (at least initially) give credence to issues over issue decay.

Other question design errors were less complex, but nonetheless inhibitive. The voter-preference questions sloppily combined undecideds and refusals into one option, something the student researcher ought to have known better after four years as a telephone surveyor: there is a difference between not knowing the answer and refusing to give one. Further, this preference question should have been followed with a commitment question. Much of the polling for the 2011 federal election overestimated NDP and Liberal support and underestimated Conservative support, in part because of a lack of attention to likelihood to vote (admitted for instance by Ekos Research Associates (2011c)). Mercifully, all five respondents who did not provide a voting intention did not participate in stage 2. It may be said, there may be some correlation between indecision and/or refusal to divulge political preference and willingness to participate in an hour long unpaid focus group on a weekend in February in Ottawa, as DK/refuse did have a modest negative correlation with stage 2 participation $(-.386, .052 \mathrm{sig})$. The most significant correlation for $\mathrm{DK} / \mathrm{refuse}$ was with rulebreaker $\left(.472^{*}, .015 \mathrm{sig}\right)$. Weak-tomodest positive correlations (all between $p=.350$ and .399 and sig @ the .1 level) were also observed with these five considering themselves more knowledgeable (particularly $v$. age), more progressive (particularly $v$. all), more likely to rely on television news, score higher for top five issues and desire focus on Defense issues.

The media sources question was largely successful though it may have been designed in a chart-style fashion to reduce 'rule-breaking.' 
The municipal vote question was a poor measure for political activity. While it did correlate in some places, for example suggesting people who have the time to listen to radio news also have the time to care about municipal politics, it offered too many outs, and is not a traditional measure of political participation. This measure runs the risk of committing level error as the experiment is all about federal politics and our participation measure is about municipal elections. Asking whether respondents have volunteered recently for a federal party or candidate, or consider themselves a member of a federal party, would have been more suitable and useful.

The 'identify with' questions in the post-poll questionnaire should not have been so limited. While respondents may have identified with a particular demographic, they may not have identified with the portion of that demographic experiencing a poll trend (i.e. identifying with women in general but not women who are more optimistic). It would have been better to clearly ask if respondents identified with more confident members of group $\mathrm{X}$. The demographic combination discussed above made group identification impossible (as though we could compare men and women, the 25-44 age bracket negates this as no respondent was older than 24). It should not even be assumed females would identify with all women, or that anyone would inherently identify with all Canadians. For instance, our largely unresponsive Respondent 6 replied to 9.1, "people are fickle and foolish, going where the tide pushes them." In an unsolicited note, he added "I do pay attention to the news generally, but I can't think of anything significant enough to influence my opinions" (emphasis his).

This note in mind, it would have been useful to include an open comments section at the end of both stage 1 and stage 2 questionnaires. What unsolicited comments we did 
receive captured respondents wary of how their answers were perceived. While comments could not have been coded quantitatively they would have given our statistical findings greater context.

Less than two months after the experiment the $40^{\text {th }}$ Parliament of Canada fell on a non-confidence motion and an election was called. On Election Day (2 May, 2011), the majority of Liberal MPs were defeated, mostly by Conservative candidates but also many by the NDP. That half of stage 2 participants were expressed Liberal supporters, that our spin doctors were a Conservative and a New Democrat, and that the 2011 election did seem to 'matter' (that campaign effects did contribute to Liberal losses ${ }^{4}$ ), it is fair to say this experiment was timely and potentially relevant to Canadian political history. Unfortunately, in addition to the limited sample, we do not know whether or how our respondents voted. The Carleton Research Ethics Board, at the student researcher's proposal, only approved human interaction until March 12011 , and the informed consent form signed by all respondents did not include the possibility of involvement beyond that date. While it is possible the REB may have approved an extension for human interaction and a two-question survey (did you vote, and if so for which party?) via email, it was not anticipated that the election would matter. As noted, the day after the English-language leaders' debate, Carleton University's Prof. Jonathan Malloy penned an editorial for the Ottawa Citizen with the title, "No one's vote will change." Nevertheless, considering election speculation is always rampant during minority governments, this avenue should have been left open.

\footnotetext{
${ }^{4}$ At the outset of the election the election the Liberals were polling in the mid-20's. They ultimately received only $17 \%$ of the total national vote.
} 


\subsection{Conclusions}

The primary hypotheses $(\mathrm{H} 1)$ was that what respondents considered personal salient (determined by asking for the top political events of 2010 and top issues for federal government focus in 2011) would inform what they considered publically salient (determined by asking what issues and events contributed to shifts in public opinion). Qualitative and quantitative analysis supported this prediction. Qualitatively, salient topics and themes appeared to carry over from stage 1 to stage 2 demonstrating a top-ofmind phenomenon. This may also have been evidence of recall bias. Quantitatively, using meta-tag dummy variables, some same tag-to-tag correlations were sustained but countered by a miscellany of associations between unlike tags. Quantitatively, using bivariate correlations, half of consistent topic-to-topic correlations supported H1. However most of these correlations were only significant post-treatment (for both the control and treatment groups). Discussed below regarding $\mathrm{H} 3$, it is unclear why this occurred. If these correlations existed pre-treatment it could be said we have strong evidence for H1. Considering this peculiar treatment effect, it would be fair to say we have modest support for $\mathrm{H} 1$.

H1 could only be measured in parts (i.e. did a stage 1 topic score correlate to a stage 2 topic score). To directly test $\mathrm{H} 1 \mathrm{~b}$ and $\mathrm{H} 1 \mathrm{c}$ - predictions demographic and confidence variables would contribute to $\mathrm{H} 1$ - would require an individual variable that combines these parts into a standard measure of personal-to-public salience transference. Had the sample been larger, factor analysis could have generated variables to "sum up" 
stage 1 and stage 2 topic scores. Associations between stage 1 and stage 2 factors could have then been controlled for interacting variables. Some conclusions, however, can still be drawn regarding $\mathrm{H} 1 \mathrm{~b}$ and $\mathrm{H} 1 \mathrm{c}$.

$\mathrm{H} 1 \mathrm{~b}$ was that respondents would be more likely to demonstrate $\mathrm{H} 1$ when asked to chronicle a demographic they identify with. Our small sample makes quantitative support or rejection of this hypothesis difficult. It was observed though respondents collectively generated particular narratives with their demographic-centric chronicles (e.g. suggesting Canadians without post-secondary education are more affected by economic events, or women more concerned with policies pertaining to children). For one demographic (no post-secondary education) group-identification correlated positively with narrative.

$\mathrm{H} 1 \mathrm{c}$ was that respondents would express greater confidence in their chronicles when demonstrating H1. Looking at results casually, Chronicle confidence appeared to operate independently from actual chronicle replies. Quantitatively, chronicle confidence related only to media attention. Additionally, though it may have overwhelmed respondents, asking for confidence in each demographic chronicle would have facilitated testing of $\mathrm{H} 1 \mathrm{~b}$.

The second hypothesis $(\mathrm{H} 2)$ was that respondents would engage in cognitive dissonance in chronicling trends they found contrary to their own beliefs. As our stage 2 sample was comprised largely of respondents unlikely to vote for the governing Conservatives, this could not be exhaustively tested for a lack of comparable respondents (i.e. equal numbers pro-government and anti-government respondents). Some evidence supporting $\mathrm{H} 2$ may be found in the correlation between political opinion measures and Political event citations in chronicles. Though not consistent for all demographics, lower 
scores for Canada and Crown confidence and more progressive values associated positively with political events rather than policies. Only for one demographic did a negative poll impression associate with Political events, and more commonly this variable correlated with other topics. While there was a positive correlation between poll impression and chronicle confidence, suggesting respondents with attitudes in line with the poll trend were more confident in their replies, this does not directly demonstrate cognitive dissonance; rather, it could show an inability of respondents to demonstrate this phenomenon. We should not reject the null hypothesis for $\mathrm{H} 2$ as supporting evidence is inconsistent.

$\mathrm{H} 3$ predicted that respondents would incorporate spin from likeminded insiders into their chronicles. $\mathrm{H} 3 \mathrm{~b}$ predicted respondents would also be likelier to incorporate spin associated with their topic scores. Testing $\mathrm{H} 3$ was undermined by control subjects significantly changing their replies when given an opportunity, defying the inherent presumption of a classical experiment. Post-treatment chronicles for both treatment and control groups demonstrated greater support for $\mathrm{H} 1$ than pre-treatment replies. The treatment subjects were distinct in that they increased their topic scores for Foreign events (after receiving anti-government spin referencing instability overseas). As Economic events were added both by control subjects (who considered themselves more knowledgeable) and treatment subjects (who received economy-centric spin from the progovernment insider) we may not discern whether or not treatment subjects sided with the anti-government insider over the pro-government insider. While some correlations were found between attitudes towards the insiders and topic scores, poll impression and chronicle confidence, they were either of low significance or in contradicting directions. 
Considering the small size of each group and the behavior of the control group, it cannot be said that $\mathrm{H} 3$ or $\mathrm{H} 3 \mathrm{~b}$ were thoroughly tested by this experiment.

While evidence to support and test $\mathrm{H} 2$ and $\mathrm{H} 3$, respectively, is lacking, evidence supporting $\mathrm{H} 1$ would suggest that top events and top issues are effective measures of the topics respondents consider personally and publically salient. Future experiments using this method may consider using close-ended lists of events and issues in order to produce more mutually exclusive topic scores and test topic-to-topic associations in a less subjective manner. However, particularly with chronicle questions, it would be difficult to produce lists that may be considered exhaustive. In order to reduce subjectivity, coding of topic scores should in the future be done by multiple researchers simultaneously. 


\section{Works Cited}

Bélanger, É., and Meguid, B.M. (2008), "Issue Salience, Issue Ownership, and IssueBased Vote Choice." Electoral Studies, 27 (3): 477-491.

Boon, A. and Meurs, A. (1991), "Measuring Opinion Distributions: An Instrument for the Measurement of Perceived Opinion Distributions." Quality and Quantity, 25 (4): 359-379.

Bricker, D., and Wright, J. (2011), "Evaluating the Polls: an Open Letter to Ontario's Journalists." Ipsos North America, 14 September, 2011: Online, Available, http:/www.ipsos-na.com/news-polls/pressrelease.aspx?id=5336, accessed 26 November 2011.

Brookes, R., Lewis, J., and Wahl-Jorgenson, K. (2004), "The media representation of public opinion: British television news coverage and the 2001 general election." Media, Culture \& Society, 26 (1): 63-80.

Butler, Peter Marshall (2007), Polling and public opinion: a Canadian perspective, University of Toronto Press.

Chase, S., and Marlow, I. (2011), "Harper steps into Web dispute." Globe and Mail, 1 February, 2011: Online, Available: $\mathrm{http}: / / \mathrm{www}$.theglobeandmail.com/news/technology/tech-news/harper-steps-intoweb-dispute/article1 890567/, accessed 1 December 2011.

Contandriopoulous, D. and Bilodeau H. (2009), "The political use of poll results about public support for a privatized healthcare system in Canada." Health Policy, 90: 104-112.

Ehrat, Johannes (2010), Power of Scandal: Semiotic and Pragmatic in Mass Media, University of Toronto Press.

Ekos Research Associates (2010a), "Race Tights as we Approach the Dog Days of Summer." Ekospolitics, 5 August 2010: PDF, Available, http://www.ekos.com/admin/articles/FG-2010-08-05.pdf, accessed 1 December 2011.

Ekos Research Associates (2010b), "Tories Claw Back Small Lead." Ekospolitics, 19 August 2010: PDF, Available, http://www.ekospolitics.com/wpcontent/uploads/full_report_august_19.pdf, accessed 1 December 2011.

Ekos Research Associates (2010c), "Race Deadlock as Conservatives Falter on Census Decision: Education Emerging as Critical Fault Line in Political Landscape." 
Ekospolitics.com 2 September 2010: PDF, Available,

http://www.ekos.com/admin/articles/FG-2010-09-02.pdf, accessed 1 December 2011.

Ekos Research Associates (2010d), "Voter Intention Stagnant as Tories Eke Out a Bare Lead." Ekospolitics, 16 September 2010: PDF, Available, http://www.ekos.com/admin/articles/FG-2010-09-16.pdf, accessed 1 December 2011.

Ekos Research Associates (2010e), "Lean to Majority Government ... But Only My Majority, Not Yours." Ekospolitics, 30 September 2010: PDF, Available, http://www.ekos.com/admin/articles/FG-2010-10-01.pdf, accessed 1 December 2011.

Ekos Research Associates (2010f), "Conservatives Widen Their Modest Lead in a Placid Political Environment." Ekospolitics, 14 October 2010: PDF, Available, http://www.ekos.com/admin/articles/FG-2010-10-14.pdf, accessed 1 December 2011 .

Ekos Research Associates (2010g), "Conservatives Continue to Enjoy Small Lead." Ekospolitics, 28 October 2010: PDF, Available, http://www.ekos.com/admin/articles/FG-2010-10-28.pdf, accessed 1 December 2011.

Ekos Research Associates (2010h), "Race Deadlock as CPC Sinks and NDP Rises." Ekospolitics, 11 November 2010: PDF, Available, http://www.ekos.com/admin/articles/FG-2010-11-01.pdf, accessed 1 December 2011.

Ekos Research Associates (2010i), "Conservatives pulling away from moribund Liberals." Ekospolitics, 25 November 2010: PDF, Available, http://www.ekos.com/admin/articles/FG-2010-11-25.pdf, accessed 1 December 2011.

Ekos Research Associates (2010j), "Landscape Freezes as Temperature Plummets." Ekospolitics, 9 December 2010: PDF, Available, http:/www.ekospolitics.com/wpcontent/uploads/full_report_december_9.pdf, accessed 1 December 2011.

Ekos Research Associates (2010k), "Moribund landscape: no party shows positive momentum." Ekospolitics, 16 December, 2010: PDF, Available, http://www.ekospolitics.com/wpcontent/uploads/full_report_december_16_2010.pdf, accessed 26 November 2011.

Ekos Research Associates (2011a), "Growing Receptivity to an Election, which Most See Producing a Similar Result." Ekospolitics, 13 January 2011: PDF, Available, 
http://www.ekos.com/admin/articles/FG-2011-01-13.pdf, accessed 1 December 2011

Ekos Research Associates (2011b), "Political Landscape Shows a 7.5 Point Conservative Lead." Ekospolitics, 26 January 2011: PDF, Available, http://www.ekos.com/admin/articles/FG-2011-01-27.pdf, accessed 1 December 2011.

Ekos Research Associates (2011c), "Accurate polling, flawed forecast." Ekospolitics, 17 June, 2011: PDF, Available, http://www.ekospolitics.com/wpcontent/uploads/accurate_polling_flawed_forecast.pdf, accessed 1 December 2011.

Fulton, Helen (2005), "Print news as narrative," in Fulton, H. et al, Narrative and media, Cambridge University Press: 218-244.

Galloway, Gloria (2011), "Liberal health care ads may be working." Globe and Mail, 17 April, 2011: Online, Available:

http://www.theglobeandmail.com/news/politics/liberal-health-care-ads-may-beworking/article1988627, accessed 26 November 2011.

Gardner, Dan (2010), "Sounds plausible - so it must be true." Ottawa Citizen, 26 May, 2010: Online, Available, http://www2.canada.com/ottawacitizen/columnists/story.html?id=0ddea280-0b004b9b- 87cc-8ae3d964c6fc, accessed 26 November, 2011.

Habermas, Jürgen (1989), The structural transformation of the public sphere: an inquiry into a category of bourgeois society. Cambridge, MA: MIT Press.

Johnson-Cartee, Karen S. (2005), News Narratives and News Framing: Constructing Political Reality. Oxford: Rowman \& Littlefield Publishers, Inc..

Kieruj, N. D. and Moors, G. (2010), "Variations in Response Style by Response Scale Format in Attitude Research." International Journal of Public Opinion Research, 22 (3): $320-342$.

kozak, a.m. (2010), "fundamental attribution error." Carousel, 26: p 56.

Labaw, Patricia J. (1980), Advanced questionnaire design, Cambridge, MA: Abt Books [1981].

Lewis, Justin (1999), "The opinion poll as a cultural form." International Journal of Cultural Studies, 2(2): 199-221.

Lindsay, Rogers (1949), The pollsters; public opinion, politics and democratic leadership, New York: A. A. Knopf. 
Lippmann, Walter (1925), The Phantom Public. New York: Harcourt, Brace.

Lule, Jack (2001), Daily news, eternal stories: the mythological role of journalism. New York: Guilford Press.

Marks, G. and Miller, N. (1987), "Ten years of research on the false-consensus effect: An empirical and theoretical review." Psychological Bulletin, 102 (1): 72-90.

Matthes, J. (2008), "Need for Orientation as a Predictor of Agenda-Setting Effects: Causal Evidence from a Two-Wave Panel Study." International Journal of Public Opinion Research, 20 (4): 440-453.

Osborne, T., and Rose, N. (1999), "Do the social sciences create phenomena?: the example of public opinion research." British Journal, 50 (3): 367-396.

Pew Research Centre (2006), "Democrats and Republicans see different realities," pewresearch.org, 6 November, 2006, Online, Available:

http://pewresearch.org/pubs/86/democrats-and-republicans-see-different-realities

Pickup, M., and Johnston, R. (2007), "Campaign trail heats as electoral information: Evidence from the 2004 and 2006 Canadian federal elections." Electoral Studies, 26 (2): $460-476$.

Walkin_dead (2010), "Petition: Stop Internet Usage Based Billing in CA." Supr Bay: 3 November, 2010, Online, Available:

https://forum.suprbay.org/showthread.php?tid=77367, accessed 1 December 2011.

Rotfeld, Herbert Jack (2005), "A snapshot or a painting? Metaphors, myths, misuses and misunderstandings of marketing research information by journalists and other people who should know better." Journal of Consumer Marketing, 22 (1): 4-5.

Ruper, Verica, Ed., (2010), Journalism and meaning-making: reading the newspaper, Cresskill, NJ: Hampton Press.

Scharkow, M., and Vogelgesang, J. (2011), "Measuring the Public Agenda using Search Engine Queries." International Journal of Public Opinion Research, 23 (1): 104113.

Sonck, N. and Loosveldt, G. (2010), "Impact of Poll Results on Personal Opinions and Perceptions of Collective Opinion." International Journal of Public Opinion Research, 22 (2): 230-255.

Wlezien, Christopher (2005), "On the salience of political issues: The problem with 'most important problem'." Electoral Studies, 24: 555-579. 
Wojcieszak, M. and Price, V. (2009), "What Underlies the False Consensus Effect? How Personal Opinion and Disagreement Affect Perception of Public Opinion." International Journal of Public Opinion Research, 21 (1): 25-46.

Wolf, M. R. and Holian, D. B (2006), "Polls, Elite Opinion, and the President: How Information and Issue Saliency Affect Approval." Presidential Studies Quarterly, 36 (4): 584-605. 


\section{Appendix 1: Consent Form}
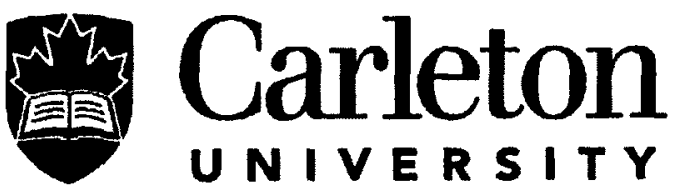

U N IVER S T Y

\section{Canada's Capital University}

Title of research project: A news-quiz with no wrong answers: How do news conscious youth explain public opinion?

Date of ethics clearance: January 10, 2011

Ethics clearance for data collection expires: May 31, 2011

Dear Carleton journalism student,

Thank you considering participating in this research project. You are asked to complete a series of questionnaires and attend a focus-group style session. The purpose of this is to better understand how people explain public opinion and give meaning to those everfluctuating poll numbers than keep politicians and officials on their toes.

If you are reading this, you already have a 'pre-experiment questionnaire.' Before completing it, please read this letter in its entirety. If you choose to consent, include one copy of this letter with your pre-experiment survey in the envelope provided and return them direcly to Elizabeth Dwivedi at the journalism office. You may keep a copy of this letter for your own records. It includes details on who is responsible for this project and who to contact should you have any concerns.

A Carleton student under the supervision of a Carleton faculty member is conducting this research. The student researcher is Jeff Blackman. He is a graduate student in the department of political science. He can answer project-specific questions and may be contacted via email at jblackma@connect.carleton.ca or via telephone at

This research project is a key component of his graduate thesis project. His research supervisor is Professor S.E. Bennett of the department of political science. You may contact Professor Bennett via his department's main office (B640 Loeb Building). This project was reviewed and received ethics clearance by the Carleton University Research Ethics Board. Should you have concerns regarding your involvement in this study, please contact:

Professor Antonio Gualtieri, Chair

Research Ethics Board

Carleton University Research Office

Carleton University

1125 Colonel By Drive

Ottawa, Ontario K1S 5B6

Tel: 613-520-2517 E-mail: ethics@carleton.ca 
Please see the next page for project details.[Page break affected due to formatting] This project's purpose is to investigate how news conscious youth explain public opinion. Journalism students have been selected as they are considered especially news conscious compared to their peers.

By January $31^{\text {st }}, 2011$, you are asked to return this consent form and the enclosed questionnaire. After completion on this first questionnaire, you will be invited to participate in a focus group-style session on either Saturday February $12^{\text {th }}$ or Sunday February $13^{\text {th }}, 2011$. You will be presented with a series of questionnaires dealing with recent change in public opinion and asked to speculate on why changes occurred. Unlike news quizzes you may have completed as part of your journalism program, there are no wrong answers here. You are encouraged to provide whatever you believe to be correct.

In order to investigate how opinions are formed, some experiment participants will be given explanations of the public opinion changes. Political insiders, people who worked on Parliament Hill and in party leadership campaigns, will provide these explanations. You may take notes (paper and pens will be provided). You may then alter your responses accordingly, or not; it is up to you. The insiders had no role in developing this project and will not have access to your responses.

You are asked not to communicate with other participants during these sessions. After the session, a buffet of refreshments (coffee and tea, cake and other snacks) will await you as a token of appreciation for your participation.

Your participation is of course entirely voluntary. All questions are optional. You may choose to withdraw your participation at any point during the project and up to three weeks after the experiment (Withdrawal deadline: Friday March $5^{\text {th }}, 2011$ ). If you choose to withdraw, all your completed questionnaires are destroyed and only a copy of this consent form will be kept with a note specifying that you chose to withdraw and the date of your withdrawal.

Please be assured that your responses will be held in the strictest confidence. While you may know other people in your group, they will not know your answers unless you choose to inform them after the fact. In order to schedule your participation in the experiment, and to connect your responses to the pre-experiment questionnaire with your experiment responses, your name and a method of contact are required. This identifying information will be blacked out after the withdrawal deadline and replaced with an identification number used for statistical analysis. Data will be stored on paper and on a portable hard drive. Data will be kept by the student researcher and may be made available to future students of political science at Carleton.

Your responses will be utilized in Jeff Blackman's graduate thesis. No individuals will be identifiable and the thesis will discuss group trends rather than individual replies. If you would like a copy of Mr. Blackman's thesis, contact him personally; it will be available summer 2011. 
Please see the next page to sign this informed consent form. . [Page break affected due to formatting]

\section{Consent:}

I have read the above letter and voluntarily consent to participate in the study as described above.

Specify method of contact (telephone number or @connect email address):

Signature of participant

Date

Signature of student researcher

Date 


\title{
Appendix 2: Recruitment Poster
}
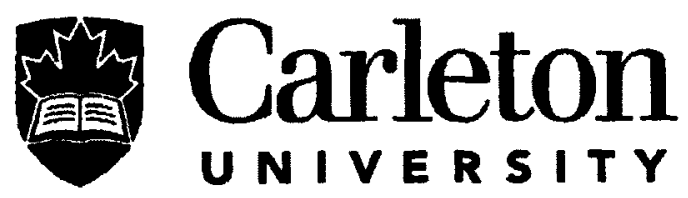

U N I VERS I T Y

Canada's Capital University

\author{
Carleton journalism students \\ (Second year standing or higher) \\ are invited to participate in:
}

\section{A News-Quiz with No Wrong Answers: How do news conscious youth explain public opinion?}

Step One: Pick up a 'quiz' and consent form at the journalism office ( 346 St. Pat's) and return it there by Monday January $31^{\text {st }}$.

Please return materials directly to Elizabeth Dwivedi.

Step Two: Keep yourself available for one afternoon during the weekend of February $12^{\text {th }}$ and $13^{\text {th }}$. You'll be asked to respond to some new public opinion information and maybe get 'spun' by political insiders who have worked on Parliament Hill. The session will be held in St. Pat's and a free buffet will be provided.

For more information, contact student researcher Jeff Blackman Telephone:

/ Email: jblackma@connect.carleton.ca

This project has been reviewed and cleared by

The Carleton University Research Ethics Board Telephone: (613) 520-2517 / Email: ethics@carleton.ca 


\section{Appendix 3: Recruitment Script}

Hello, my name is Jeff Blackman. I'm a graduate student in political science here at Carleton and I'm looking for journalism students like you to help me pursue my thesis. I'm investigating how we explain public opinion and give meaning to those everfluctuating poll numbers that keep politicians and officials on their toes. Towards this research, I ask you to complete a pair of news quizzes with no wrong answers.

The first quiz is about looking back on 2010 and forward through 2011. It's available at the journalism departmental office - 346 St. Patrick's Building - and may be dropped off there as well as late as Monday January $31^{\text {st }}$. It comes in a pre-addressed envelope and with two consent forms: one for you to keep and one for you to submit. You'll need to include your name and a method of contact - email or phone will do - so you may participate in the second stage of the research.

The second quiz will be held in a focus group-style setting, but you are only expected to write down your opinions, not to voice them. You'll be given some new, real information about Canadian public opinion and asked to speculate what the new numbers mean. You'll be divided into four groups. Some of you will be given 'official explanations' from political insiders; individuals who have worked on Parliament Hill and party leadership campaigns. You can take their word or not, remember: there are no wrong answers. The groups will be held in the afternoons of Saturday February $12^{\text {th }}$ and Sunday February $13^{\text {th }}$. You'll need to be available for no more than 90 minutes on one of those two days. There will be free coffee, cake and other refreshments served as a thank you for your participation.

Your participation in all stages of this study is entirely voluntary. You can withdraw at any time if you change your mind. Your responses will be held in the strictest confidence and your fellow participants will not know any of your answers.

This research project has been reviewed and received ethics clearance by the Carleton University Research Ethics Board. You may contact the REB Chair, Antonio Gualtieri, with any concerns via ethics@carleton.ca. This project has been developed in consultation with my thesis supervisor, Prof. Scott Bennett of the political science department, and Prof. Klaus Pohle of the journalism department. The final report, my thesis, will not identify individuals and will be available for viewing summer of 2011 .

Again, my name is Jeff Blackman. I'm happy to answer some questions now but you may email me at jblackma@connect.carleton.ca. That's J-B-L-A-C-K-M-A at connect dot Carleton dot ca. You may also call me at

Thank you for your time. 


\section{Appendix 4: Stage 1 (time 1) or pre-experiment questionnaire}

\section{Pre-experiment questionnaire}

You must be enrolled in journalism to participate in this study. The information collected in this survey will be used in conjunction with your responses to an experiment to be held in February, should you choose to participate further. Final analysis, in the form of a graduate thesis, will in no way identify individuals and rather focus on aggregate, or group, trends. Please keep a copy of the consent form packaged with this questionnaire and refer to it for further details.

Your participation is greatly appreciated. Please print clearly and feel free to take your time responding to each question. Remember, this is a news quiz with no wrong answers. 
1. In your opinion, what were the biggest Canadian political events in 2010 ? List up to five in no particular order. You do not need to include dates.

i.

ii.

iii.

iv.

v. 
2. What issues do you think the federal government should focus on in 2011? List up to five in no particular order. Please refer to general policy areas or pressing issues rather than propose specific legislation or decisions.

i.

ii.

iii.

iv.

V. 
Please circle one number for the scale questions. If you make a mistake, write out the number.

3. Relative to people your age, how knowledgeable of Canadians politics do you consider yourself to be?

$$
\begin{array}{lllllll}
1 & 2 & 3 & 4 & 5 & 6 & 7
\end{array}
$$

$1=I$ know a lot less than people my age

$4=I$ know about the same as people my age

$7=I$ know a lot more than people my age

4. Relative to all adult Canadians, how knowledgeable of Canadian politics do you consider yourself to be?

$$
\begin{array}{lllllll}
1 & 2 & 3 & 4 & 5 & 6 & 7
\end{array}
$$

$1=I$ know a lot less than most people $4=I$ know about the same as all adult Canadians

$7=I$ know a lot more than most people

5. What are your top three sources for Canadian political news? Specify the medium if necessary (e.g., the print or online edition of a newspaper). You may include private or informal sources such as family and friends. If you list individuals please specify your relation, not their name (e.g., sibling, partner, professor, etc).

1.

2.

3. 
6. All things considered, do you think that Canada is headed in the right direction?

$$
\begin{array}{lllllll}
1 & 2 & 3 & 4 & 5 & 6 & 7
\end{array}
$$

$1=$ Strongly disagree

4=Neutral

$7=$ Strongly agree

7. All things considered, do you think that the federal government of Canada is headed in the right direction?

$$
\begin{array}{lllllll}
1 & 2 & 3 & 4 & 5 & 6 & 7
\end{array}
$$

$1=$ Strongly disagree

$4=$ Neutral

$7=$ Strongly agree

8. Relative to people your age, do you feel your values are more traditional or progressive?

$$
\begin{array}{lllllll}
1 & 2 & 3 & 4 & 5 & 6 & 7
\end{array}
$$

$1=$ Much more traditional than most people my age

4=I consider my values average

$7=$ Much more progressive than most people my age

9. Relative to all adult Canadians, do you feel your values are more traditional or progressive?

$$
\begin{array}{lllllll}
1 & 2 & 3 & 4 & 5 & 6 & 7
\end{array}
$$

$1=$ Much more traditional than the average Canadian

$4=I$ consider my values average

$7=$ Much more progressive than the average Canadian 
10. If a federal election were held tomorrow, what party would you vote for?

Conservative Party of Canada

_ Liberal Party of Canada

_ New Democratic Party

Bloc Quebecois

_ Green Party of Canada

Other (Please specify):

Don't Know / Refuse to Answer

— Would not vote

11. Did you vote in the 2010 Ottawa municipal elections? Please choose the answer that best fits your experience.

- Yes

_ No, but I voted in another municipality

- No, I was ineligible due to age / citizenship

- No, extenuating circumstances prevented it

- No, for whatever other reason

- Refuse to Answer

12. All things considered, how vital do you consider public opinion polls for ensuring our government behaves in a democratic fashion?

\section{$\begin{array}{lllllll}1 & 2 & 3 & 4 & 5 & 6 & 7\end{array}$}

$1=$ Not at all vital

4=Relatively vital

$7=$ Extremely vital 
Demographic data for statistical analysis:

13. Age:

15. Academic Standing:
14. Gender: Male Female

$1^{\text {st }}$ Year Undergraduate $2^{\text {nd }}$ Year Undergraduate $3^{\text {rd }}$ Year Undergraduate

$4^{\text {th }}$ Year Undergraduate $1^{\text {st }}$ Year Graduate / Master's $2^{\text {nd }}$ Year Graduate / Master's Post-graduate / Doctoral

Please print your first and last name. Your name will be used solely to connect your responses from this survey to your responses to the experiment to be held in February, should you choose to participate. After the experiment's completion, all names will be replaced with ID numbers. ID numbers are used to sort responses and conduct analysis of group trends.

First name: Last name: 


\section{Appendix 5: Stage 2 (time 2a) or pre-poll questionnaire}

\section{Pre-poll questionnaire}

You must be enrolled in journalism to participate in this study. The information collected in this survey will be used in conjunction with your responses to the survey you completed in January. Final analysis, in the form of a thesis, will in no way identify individuals and rather focus on aggregate, or group, trends.

Your participation is greatly appreciated. Please print clearly and feel free to take your time responding to each question. Remember, this is a news quiz with no wrong answers. 
5.1 How attentively have you been following Canadian political news for the past month?

$$
\begin{array}{lllllll}
1 & 2 & 3 & 4 & 5 & 6 & 7
\end{array}
$$

$1=$ Not at all attentive

$4=$ Somewhat attentive

$7=$ Extremely attentive

5.2 How does this compare to your attention to Canadian political news over the past six months?

$$
\begin{array}{lllllll}
1 & 2 & 3 & 4 & 5 & 6 & 7
\end{array}
$$

$1=$ Much less attention than usual

$4=\mathrm{My}$ usual degree of attention

$7=$ Much more attention than usual 
5.3 All things considered, do you think that Canada is headed in the right direction?

$$
\begin{array}{lllllll}
1 & 2 & 3 & 4 & 5 & 6 & 7
\end{array}
$$

$1=$ Strongly disagree

4=Neutral

$7=$ Strongly agree

5.4 All things considered, do you think that the federal government of Canada is headed in the right direction?

$$
\begin{array}{lllllll}
1 & 2 & 3 & 4 & 5 & 6 & 7
\end{array}
$$

$1=$ Strongly disagree

$4=$ Neutral

$7=$ Strongly agree

5.5 If a federal election were held tomorrow, what party would you vote for?

Conservative Party of Canada

_ Liberal Party of Canada

_ New Democratic Party

_ Bloc Quebecois

_ Green Party of Canada Other (Please specify):

- Don't Know / Refuse to Answer

_ Would not vote 


\section{Appendix 6: Stage 2 (time 2b) or post-poll questionnaire}

\section{About the data}

The polls cited in this questionnaire were conducted by EKOS Research Associates Inc., a Canadian polling company with over three decades of research experience. These national polls surveyed on average 1500-3000 adult Canadians. All the data have been statistically weighted to ensure the samples' composition reflects that of the actual population of Canada according to Census data. All cited data has an average margin of error of $+/$ $5 \%$ or lower.

\section{Survey Notes}

Please print all answers.

The questions in this section will ask you to hypothesize causes for changes in public opinion. All questions relate to confidence in the Government of Canada and the survey question studied is, "All things considered, would you say the Government of Canada is headed in the right direction or the wrong direction?" The terms Government of Canada and federal government will be used interchangeably. They should not be understood as an approval rating of the Prime Minister and his party, or as an expression of voting intentions, but as a measure of public confidence in the overall direction of the federal government.

Short descriptions and charts will illustrate changes which have occurred between bi-weekly polling periods over the past six months. You do not need to include specific dates in your answers or provide reasons for choosing particular causes. Causes can include issues and events beyond Canadian political news. 
Some questions will ask about polling trends for specific groups. You may 'recycle' answers from previous questions. For example, you may say the same event caused an overall change in public opinion and was especially important among a particular group. 
Figure 6.1

All things considered, would say the Government of Canada is headed in the right direction or the wrong direction?

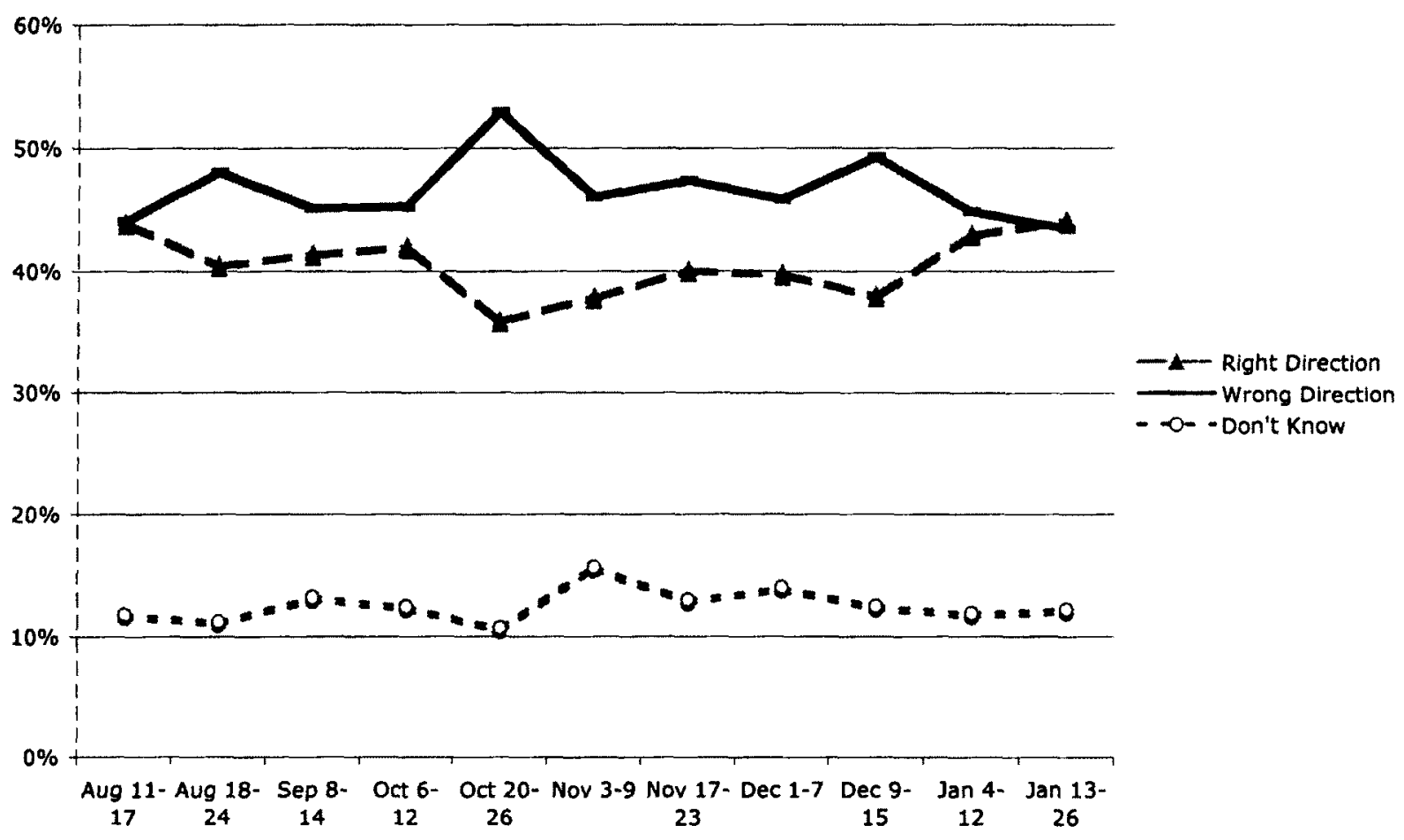

In late October 2010, a majority of Canadians polled said the Government of Canada was headed in the wrong direction $(53.1 \%$ versus $36.1 \%$ in the right direction). Since this peak in pessimism, however, the federal government has been steadily righting itself among the public.

By the latter half of January, a slim plurality of Canadians considered their government headed in the right direction ( $44.2 \%$ over $43.6 \%)$. While within the average margin of error for EKOS' national polls $(+/-3 \%)$, no EKOS poll has shown Canadians to be so closely divided on this question since the summer.

See next page for question. 
6.1 What happened in the past three months (November through January) to improve opinions of the federal government? In no particular order, please list up to five issues or events potentially responsible for Canadians' growing optimism.

1.

2.

3.

4.

5. 


\section{Figure 6.2}

University graduates: All things considered, would you say the Government of Canada is headed in the right direction or the wrong direction?

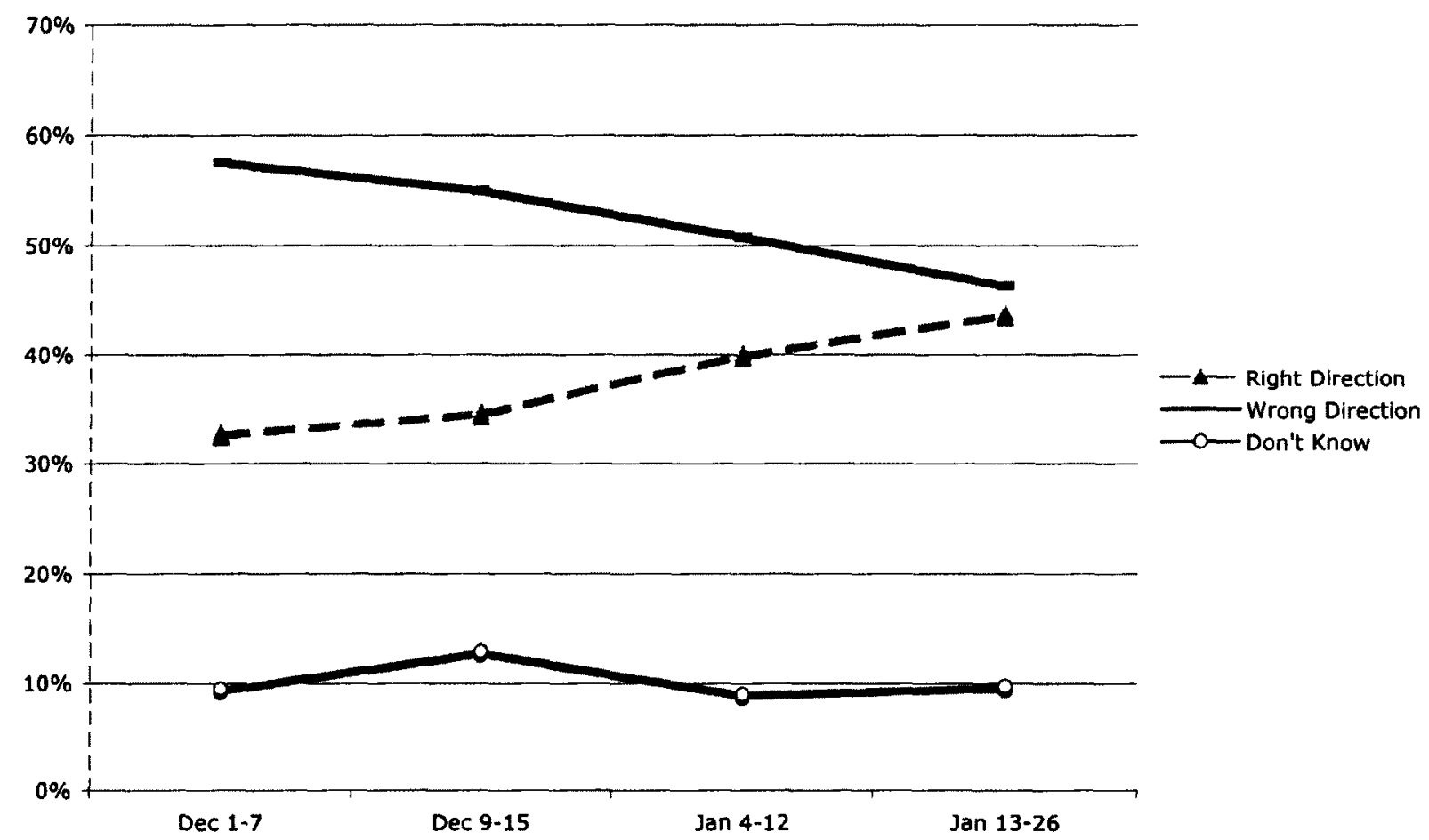

In the past two months a regularly disapproving demographic has expressed greater confidence in the Government of Canada. Canadians with a bachelor's degree or greater have gone from disapproving of the government's direction by a difference of $15.6 \%$ to only $2.7 \%$.

See next page for question. 
6.2 What happened in the past two months (December and January) to change university graduate's minds? List up to three events or issues that may have contributed to this 'positive' change.

1.

2.

3. 


\section{Figure 6.3}

High school diploma or less: All things considered, would you say the Government of Canada is headed in the right direction or the wrong direction?

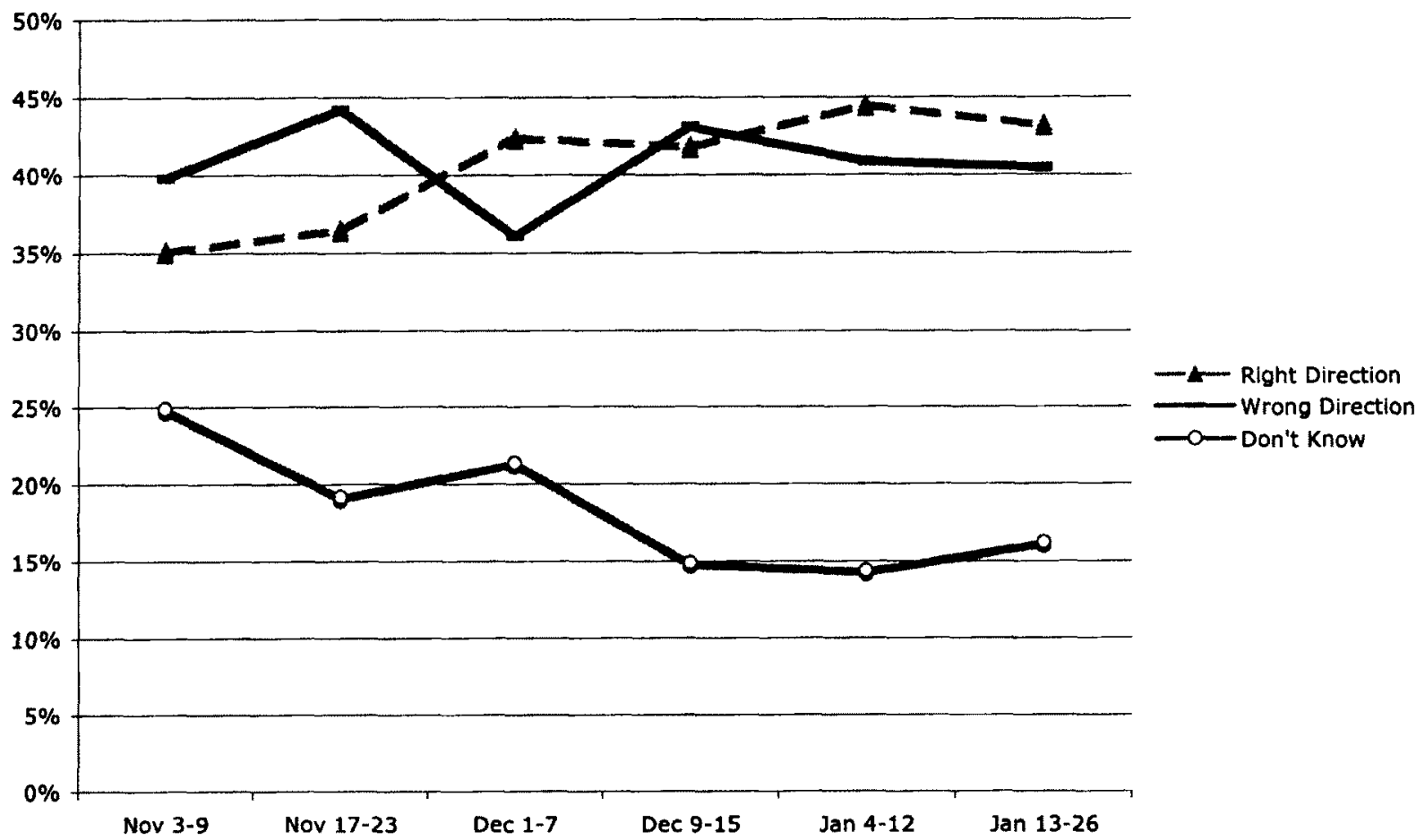

Since early November, Canadians with a high school education or less have increasingly considered the Government of Canada "headed in the right direction." While their negative ratings have fluctuated, Canadians without post-secondary education seem to be making up their minds about the federal government, and positively so.

In early November, this demographic split $39.9 \%$ wrong direction versus $35.2 \%$ right direction, with an above-average "don't know" response rate of $24.9 \%$. By late January, the breakdown had improved for the federal government: $43.3 \%$ right, $40.6 \%$ wrong and $16.2 \%$ don't know. This brings the high school or less group roughly in line with Canadians with a college or CEGEP diploma $(+45.3 \%,-41.9 \%$, DK $12.8 \%)$, whose numbers held relatively steady during the same time frame.

\section{See next page for question.}


6.3 What may have contributed to Government of Canada gains among Canadians yet to complete post-secondary program? In no particular order, list up to three events or issues from the past three months (November through January) which may be responsible for this development.

1.

2.

3. 
Figure 6.4

Response rate: The Government of Canada is headed in the right direction.

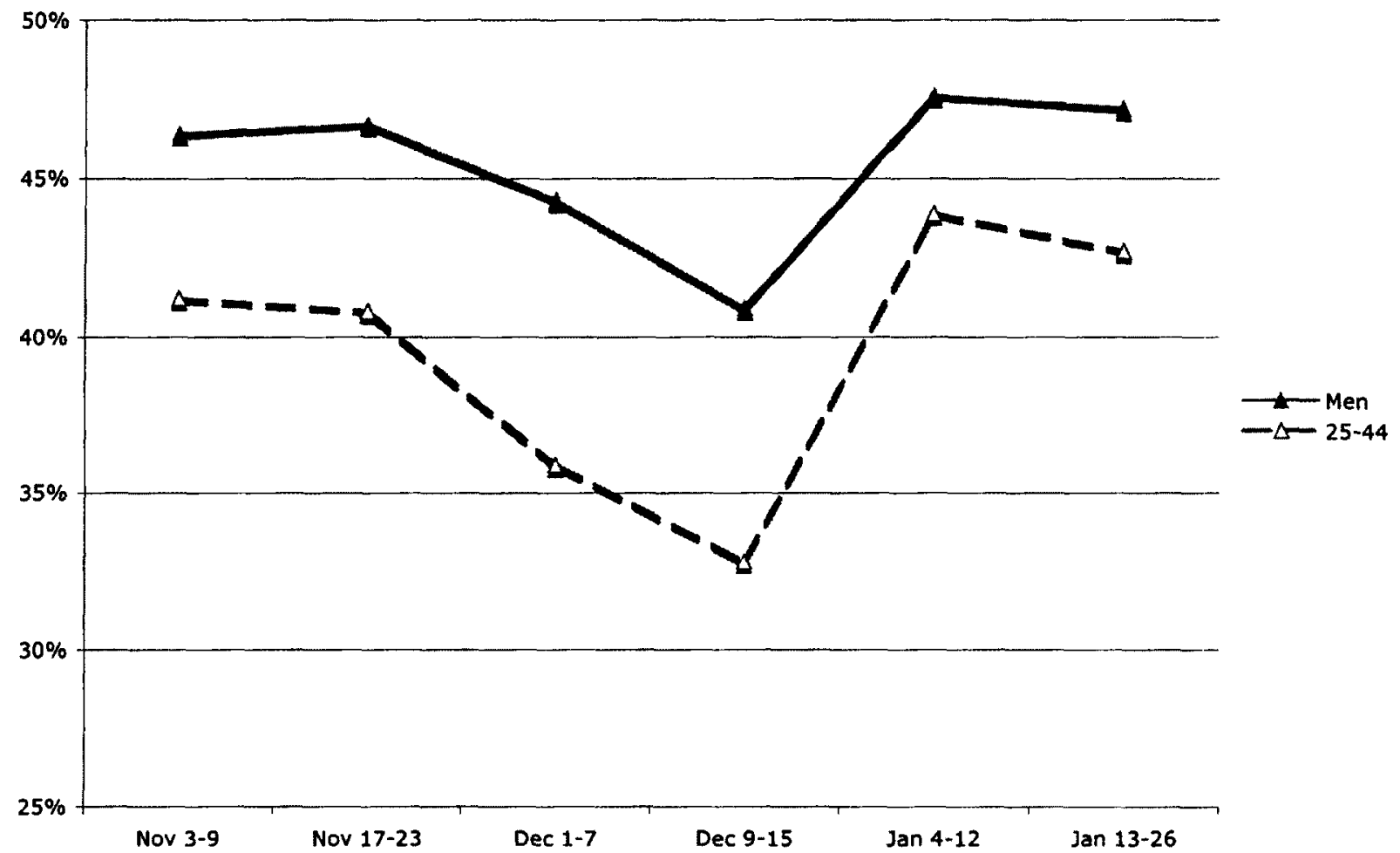

Figure 6.4 shows a similar poll trend among two overlapping demographic groups. Men of all ages, and Canadians between the ages of 25 to 44 both showed a marked decrease in government confidence after Remembrance Day, then perked up sometime between mid-December at the early January. While men have on average been $5 \%$ more likely to consider the Government headed in the right direction than 25-to-44-years-olds, the trend lines for both samples appears to be synchronized. No similar pattern is found in the data for women, other age groups, or education background.

\section{See next page for questions.}


6.4 What issues or events may have caused men and 25-44-year-olds to simultaneously lose confidence in the federal government during November and December? List up to three in no particular order.

1.

2.

3.

6.5 Presuming a shared set of issues or events caused men and 25-to-44year-olds to express less confidence in the Government's direction, which of the following two statements would you agree with more:

[ ] a) Approval ratings among men and 25-to-44 year olds rebounded because of the passage of time; or

[ ] b) Approval ratings among men and 25-to-44-year-olds rebounded because of important issues or events between mid-December and early January. 
If you answered a) to question 6.5, skip ahead to question 6.7. If you answered b) to question 6.5, proceed to question 6.6.

6.6 What issues or events may have caused men and 25-44-year-olds to simultaneously express greater confidence in the federal government between mid-December and early January? List up to three in no particular order.

1.

2.

3. 


\section{Figure 6.7}

Women: All things considered, would you say the Government of Canada is headed in the right direction or the wrong direction?

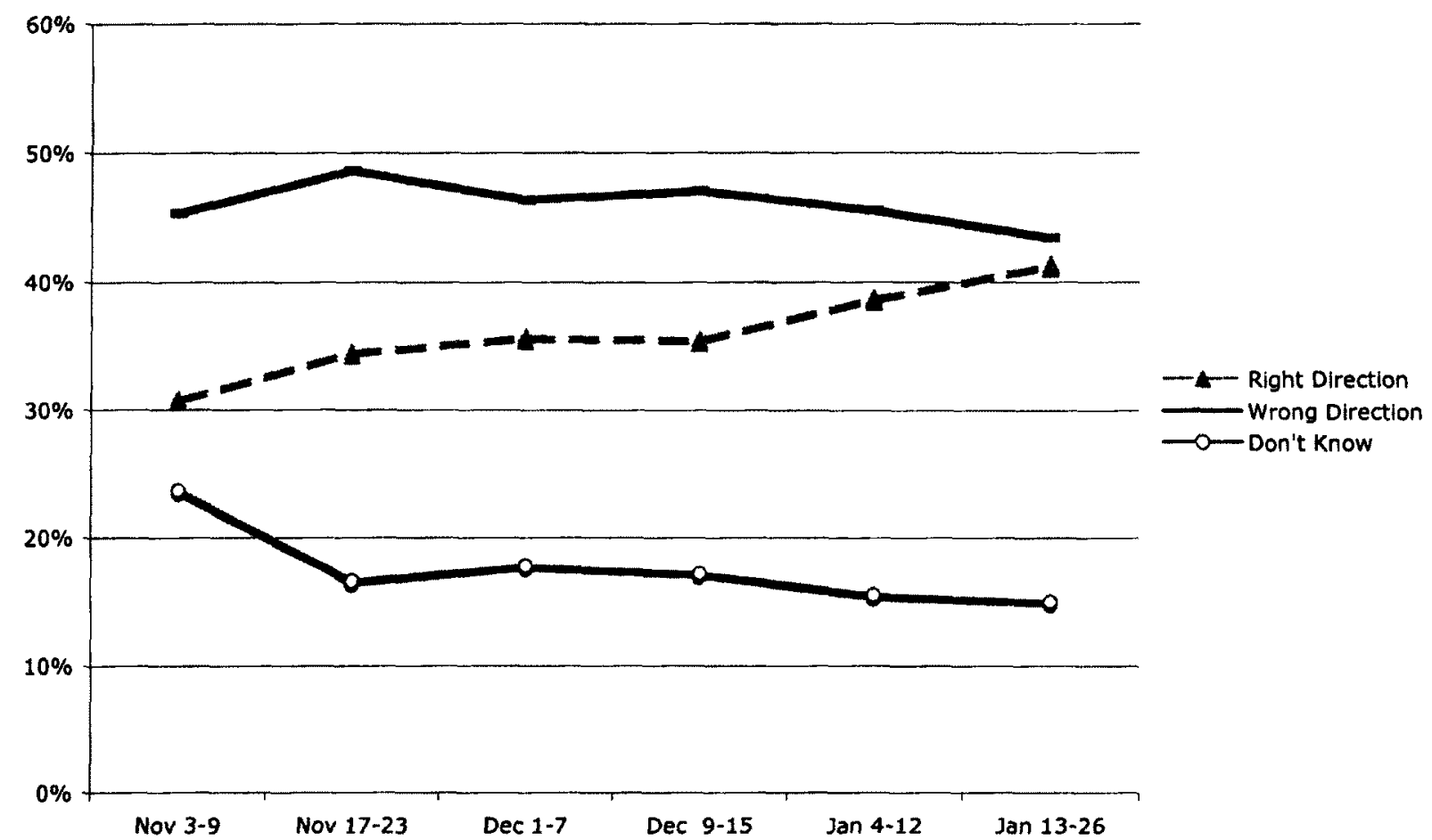

While a consistent plurality of women have disapproved of the federal government's direction since at least summer 2010 , more recently a growing number of Canadian women polled have felt positively. Since hitting a seasonal low of only $30.9 \%$ right direction, the Government has gained about ten percentage points with women ( $41.4 \%$ right direction in mid-tolate January).

See next page for question. 
6.7 What happened in the past three months (November and January) to cause a change among women polled? List up to three events or issues that may have contributed to this 'positive' change?

1.

2.

3. 


\section{Figure 6.8}

Response rate: The Government of Canada is headed in the right direction?

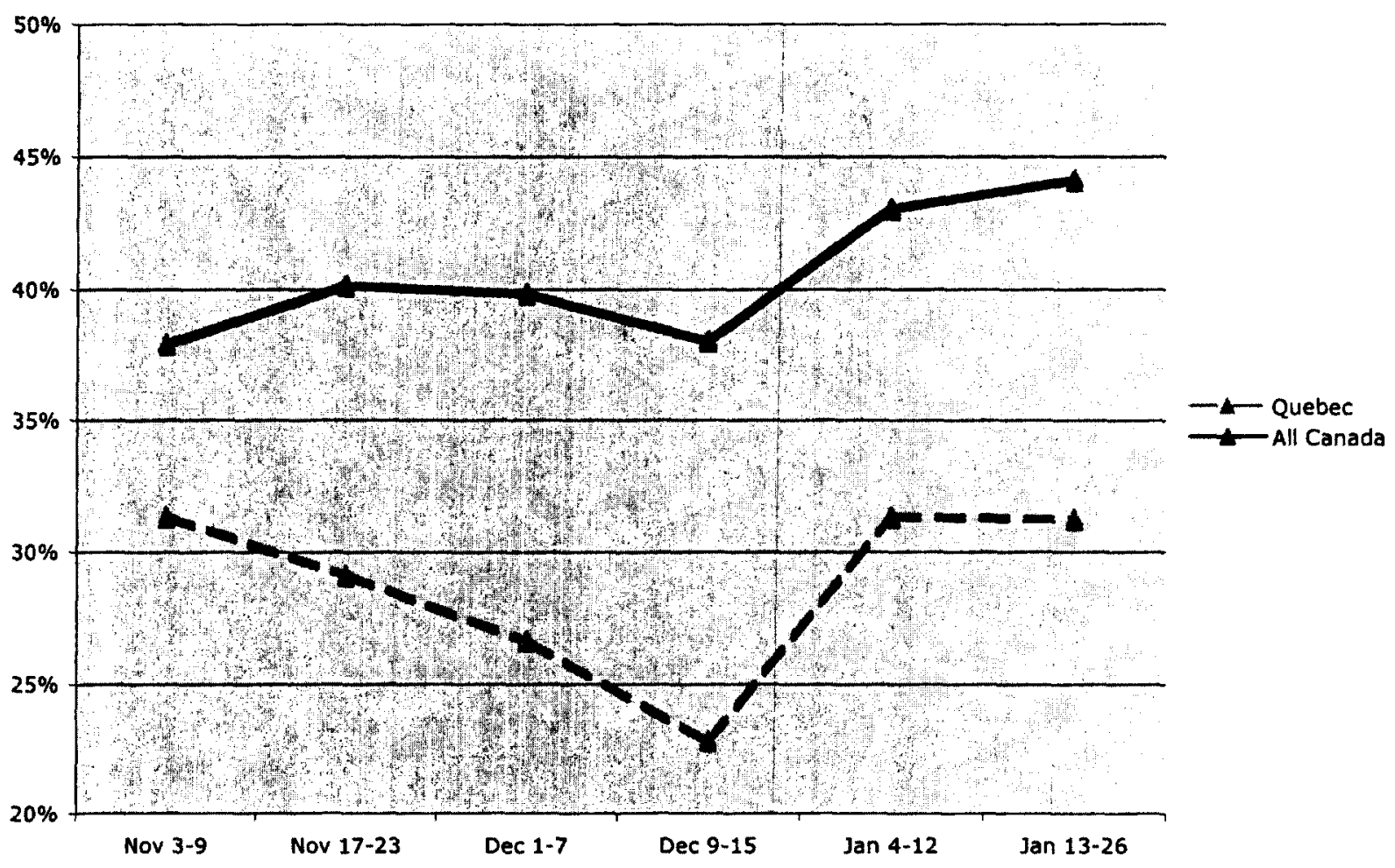

Polling all Canadians, the Government of Canada has picked up about five percentage points worth of approval in the past three months. In Quebec, however, public confidence appears stuck beneath a glass ceiling in the low thirties. Going back to mid-August, approval in Quebec did not deviate from the mid-to-high twenties. The disapproval rate in Quebec has fluctuated between $58 \%$ and $66 \%$ since mid-August.

See next page for question. 
6.8 What issues or events may have had no significant effect in Quebec but had a positive effect in the rest of Canada? List up to three in no particular order.

1.

2.

3. 
6.9 Overall, how confident do you feel in your explanations for changes in public opinion?

$$
\begin{array}{lllllll}
1 & 2 & 3 & 4 & 5 & 6 & 7
\end{array}
$$

$1=$ Not at all confident

$4=$ Somewhat confident

$7=$ Extremely confident

6.10 How do you personally feel about these 'positive' changes in Canadians' opinions?

Positively, as it reflects my own opinion.

_ Negatively, as it does not reflect my own opinion.

_ Neutral

_ Unsure / Don't Know

6.11 Do you identify with any of the particular population segments addressed in this questionnaire? Select all that apply.

University graduates

__ People with a high school diploma or less

_ People from Quebec 


\section{Appendix 7: Insiders biographies and spin scripts}

\section{Pro-government insider's biography and spin script}

Brendan Mulvihill has been working for a Conservative MP since the 2008 election as a legislative and communications assistant. Prior to working on the Hill, Brendan was a franchise owner and General Manager of BeaverTails Ottawa. Brendan has worked on election campaigns for the last 15 years across eastern and northern Ontario. He has been seen walking the halls of Carleton since 1997 in pursuit of a degree.

My Spin

Three broad factors have contributed to the rise in support for the government over the past three months.

Jobs, Jobs, Jobs - stronger than expected job growth has seen the unemployment rate declining and new entrants are joining the workforce. HS educated males were disproportionately affected by the recession and the returning jobs boost and already favourable demographics' support.

Uncle Sam Got His Groove - while job numbers have improved only modestly they are no longer losing jobs. The return of the stock market has renewed the American medias confidence in the economy. As Canadians consume more US news than Canadian news, positivity and confidence in the US culture has a impact on Canadian confidence irrespective of our already stronger economic position.

Iggy MIA - while the official opposition has taken bus tours, speaking tours and only stopped short of lighting his hair on fire, they continue to miss the alternative narrative Canadians are seeking. They are focused on esoteric issues or debating issues on the Conservative turf. Talking about fighter jets that won't even be purchased until 2016 means talking about security and defence issues, themes favourable to the Conservative brand. 


\section{Anti-government insider's biography and spin script}

Hijal De Sarkar has been a Parliamentary Assistant to a New Democrat MP since October of 2010. Before working on the Hill, he was an NDP candidate in Ottawa South in the 2008 election and an executive on the Ottawa South NDP Electoral District Association. His career prior to getting into politics was in sales. Hijal has been involved in every federal election since 1997.

My spin:

The media's election fixation - The media is obsessed with the "will they or won't they" question of an election. As a result, they're focused on the horse-race aspect of politics, and not on the bread and butter issues we've been championing since the last election.

The media as Liberal sycophants - The NDP has been talking about delaying corporate tax cuts and using the money on more urgent priorities since the 2008 election. Only now that the Liberals have picked up our tune is the media paying it any attention. It is like this with most issues. The NDP has been on the forefront on big issues like the environment, but it gets no traction until the Liberals steal our playbook.

Canada's stability relative to the rest of the world - As Canadians look to the Middle East and see tumult and regime change, it makes them realize how peaceful and stable things are in Canada, making them less inclined to change the government.

Holiday boost - This poll was conducted shortly after the holidays, when Canadians were in a festive mood with friends and family, and were paying less attention to politics. 


\section{Appendix 8: Insider evaluation questionnaires}

\section{Insider Evaluation: Brendan Mulvihill}

You must be enrolled in journalism to participate in this study. The information collected in this survey will be used in conjunction with your responses to the survey you completed in January. Final analysis, in the form of a thesis, will in no way identify individuals and rather focus on aggregate, or group, trends.

Your participation is greatly appreciated. Please print clearly and feel free to take your time responding to each question. Remember, this is a news quiz with no wrong answers.

You have received some explanation from a political insider regarding Canadians' changing levels of confidence in the federal government.

8.a.1 How credible do you consider this source?

$$
\begin{array}{lllllll}
1 & 2 & 3 & 4 & 5 & 6 & 7
\end{array}
$$

$1=$ Not at all credible

4= Somewhat credible

$7=$ Extremely credible

8.a.2 Considering their explanation, do you think you and this source would generally agree on political matters?

$$
\begin{array}{lllllll}
1 & 2 & 3 & 4 & 5 & 6 & 7
\end{array}
$$

$1=$ Disagree generally

4=Sometimes agree, sometimes disagree

$7=\underline{\text { Agree }}$ generally 


\section{Insider Evaluation: Hijal De Sarkar}

You must be enrolled in journalism to participate in this study. The information collected in this survey will be used in conjunction with your responses to the survey you completed in January. Final analysis, in the form of a thesis, will in no way identify individuals and rather focus on aggregate, or group, trends.

Your participation is greatly appreciated. Please print clearly and feel free to take your time responding to each question. Remember, this is a news quiz with no wrong answers.

You have received some explanation from a political insider regarding Canadians' changing levels of confidence in the federal government.

8.b.1 How credible do you consider this source?

$$
\begin{array}{lllllll}
1 & 2 & 3 & 4 & 5 & 6 & 7
\end{array}
$$

$1=$ Not at all credible

4=Somewhat credible

$7=$ Extremely credible

8.b.2 Considering their explanation, do you think you and this source would generally agree on political matters?

$$
\begin{array}{lllllll}
1 & 2 & 3 & 4 & 5 & 6 & 7
\end{array}
$$

$1=$ Disagree generally

4=Sometimes agree, sometimes disagree

$7=$ Agree generally 


\section{Appendix 9: Stage 2 (time 3) or post-treatment questionnaire}

The Stage 2 (time 3) or post-treatment questionnaire is identical to the Stage 2 (time $2 \mathrm{~b}$ ) or pre-treatment questionnaire, the only exception being that questions are numbered 9.1, 9.2, etc., rather than 6.1, 6.2, etc. 


\section{Appendix 10: Debriefing Script}

Thank you for participating in this study. It is greatly appreciated and your answers will contribute to a greater understanding of the role public opinion plays in our democratic society.

It is requested that you refrain from discussing the proceedings of this session until all sessions are complete, so no earlier than Monday February $14^{\text {th }}, 2010$.

If you should decide you do not want your responses used for any research purposes, please contact the student researcher, me, Jeff Blackman. My contact information is available in the spare consent form you received when you began your participation. You may ask for my contact information now should you require it. If you choose to withdraw all your responses will be destroyed, without protest, and only a record of your withdrawal will be kept. The record will consist of your consent form, with a note affixed stating that you chose to withdraw and the date of withdrawal. The deadline to withdraw is Friday March $5^{\text {th }}, 2010$. If you're interested in seeing the final report, my graduate thesis, please contact me and I will ensure you receive a copy once it is complete and passed by my department.

If you have any other questions, I would be happy to answer them now, and in private if you so choose.

Now, all of you are welcome to enjoy the complimentary refreshments buffet set up in Room (to be determined). 


\section{Appendix 11: Telephone scheduling script}

Hello, this is Jeff Blackman. I am a Carleton University, political science student and I am researcher responsible for the 'News-quiz with no wrong answers', which you recently completed. I am calling to schedule and confirm your participation in a focusgroup style session on [NSERT DATE \& TIME].

This second part of the study is an important component of my research and will build upon your answers in the news quiz. It is of course voluntary and all your responses will be kept confidential. You will not be identified in any reports stemming from these sessions.

Is now a good time to schedule your availability? If not, when should I call back?

The session on [INSERT DATE \& TIME] will take approximately [DEPENDS ON SESSION]. You are not expected to bring anything with you. Pens and paper will be provided. You may bring a copy of your consent form with you should you want to refer to it during the session.

There may be peers of yours in the session. However, there is to be no verbal or written communication between participants during the session. Your fellow participants will not be privy to your thoughts and opinions. Please recall this project has been reviewed and cleared by the Carleton University Research Ethics Board and all efforts will be made to ensure the security of your responses.

After the session, there will be a complimentary refreshment buffet. It is requested however that you do not bring food or drinks into the session itself.

There will be no audio or video recording of the session. Myself, the student researcher, may take notes in order to document proceedings.

If at any time you wish to withdraw from the session, feel free to make your wishes known. Your documents will be destroyed without protest, and only a record of your withdrawal will be kept. The record will consist of your consent form, with a note affixed stating that you chose to withdraw and the date of that withdrawal. You may withdraw at this time if you so choose.

Do you have any questions regarding this session, other than the location, which I will provide in a moment?

Would you be available to attend a session at [LOCATION TO BE DETERMINED], on [INSERT DATE \& TIME], for [LENGTH OF SESSION]? Confirm or ...

If not, would you be available for [CYCLE THROUGH ALTERNATE DATES \& TIMES]? Confirm or ... 
If none of these times are suitable, then you unfortunately cannot participate in the next stage of this study. I thank you for your participation. You will be withdrawn from this study. You may still request to see the final report if you so choose.

If confirmed...

I may call you back to remind you of this upcoming session 48 hours before it occurs and confirm your attendance.

Thank you for your time and have a good day.

Answering machine message:

Hello, this is Jeff Blackman. I am a Carleton University, political science student and I am researcher responsible for the 'News-quiz with no wrong answers', which you recently completed. I am calling to schedule and confirm your participation in a focusgroup style session during the weekend of February $12^{\text {th }}$ and $13^{\text {th }}$. Please call me back to confirm your availability. My phone number is . Please call between the hours of $9 \mathrm{am}$ and $9 \mathrm{pm}$, any day of the week. Thank you for your participation thus far. I look forward to speaking to you.

Research notes:

Participants will not be called more than once every 72 hours and will only be called between the dates of February $1^{\text {st }}$ and February $11^{\text {th }}$, ensuring they are called no more than three times, not including a confirmation call.

Confirmation call:

Hello. It's Jeff Blackman, the Carleton student researcher responsible for the 'News-quiz with no wrong answers', which you recently completed. You are scheduled to attend a focus group-style session at [LOCATION TO BE DETERMINED], on [INSERT DATE \& TIME], for [LENGTH OF SESSION]; are you still able to attend? Confirm or ...

If not, would you be available for [CYCLE THROUGH ALTERNATE DATES \& TIMES]? Confirm or ...

If none of these times are suitable, then you unfortunately cannot participate in the next stage of this study. I thank you for your participation. You will be withdrawn from this study. You may still request to see the final report if you so choose.

Thank you for your time and have a good day. 


\section{Appendix 12: Email scheduling script}

Hello,

This is Jeff Blackman. I am graduate student researcher responsible for the 'News-quiz with no wrong answers', which you recently completed. The purpose of this message is to schedule and confirm your participation in a focus-group style session on [INSERT DATE \& TIME]. Please read this entire letter before responding.

This second stage of the study is an important component of my research and will build upon your previous answers. It is of course voluntary and all your responses will be kept confidential. You will not be identified in any reports stemming from these sessions.

The session on [INSERT DATE \& TIME] will take approximately [DEPENDS ON SESSION]. You are not expected to bring anything with you. Pens and paper will be provided. You may bring a copy of your consent form with you should you want to refer to it during the session.

There may be peers of yours in the session. However, there is to be no verbal or written communication between participants during the session. Your fellow participants will not be privy to your thoughts and opinions. Please recall this project has been reviewed and cleared by the Carleton University Research Ethics Board and all efforts will be made to ensure the security of your responses.

After the session, there will be a complimentary late-lunch buffet. It is requested however that you do not bring food or drinks into the session itself.

There will be no audio or video recording of the session. Myself, the student researcher may take notes in order to document proceedings.

If at any time you wish to withdraw from the session, feel free to make your wishes known. Your documents will be destroyed without protest, and only a record of your withdrawal will be kept. The record will consist of your consent form, with a note affixed stating that you chose to withdraw and the date of that withdrawal. You may withdraw at this time if you so choose.

If you have any questions regarding this project before you choose to participate or withdraw, please feel free to send them to me via email or call me at may be reached from $9 \mathrm{am}$ to $9 \mathrm{pm}$, any day of the week.

Would you be available to attend a session at [LOCATION TO BE DETERMINED], on [INSERT DATE \& TIME], for [LENGTH OF SESSION]? If you are unavailable, please let me know and I will attempt to schedule you for another session. If you are unavailable for any of the four possible sessions then you unfortunately cannot participate in the next stage of this study. I thank you for 
your participation. You will be withdrawn from this study. You may still request to see the final report if you so choose.

Thank you for your time and have a good day.

Sincerely,

Jeff Blackman

MA Candidate

Carleton University

Department of Political Science

iblackma@connect.carleton.ca

Research note: If no response is received from the participant within four days, the email will be sent only once more. 